\title{
The influence of coping on social support and quality of life of people with rheumatic diseases
}

Citation for published version (APA):

Savelkoul, M. (2002). The influence of coping on social support and quality of life of people with rheumatic diseases. [Doctoral Thesis, Maastricht University]. Universiteit Maastricht. https://doi.org/10.26481/dis.20020125ms

Document status and date:

Published: 01/01/2002

DOI:

10.26481/dis.20020125ms

Document Version:

Publisher's PDF, also known as Version of record

\section{Please check the document version of this publication:}

- A submitted manuscript is the version of the article upon submission and before peer-review. There can be important differences between the submitted version and the official published version of record. People interested in the research are advised to contact the author for the final version of the publication, or visit the DOI to the publisher's website.

- The final author version and the galley proof are versions of the publication after peer review.

- The final published version features the final layout of the paper including the volume, issue and page numbers.

Link to publication

\footnotetext{
General rights rights.

- You may freely distribute the URL identifying the publication in the public portal. please follow below link for the End User Agreement:

www.umlib.nl/taverne-license

Take down policy

If you believe that this document breaches copyright please contact us at:

repository@maastrichtuniversity.nl

providing details and we will investigate your claim.
}

Copyright and moral rights for the publications made accessible in the public portal are retained by the authors and/or other copyright owners and it is a condition of accessing publications that users recognise and abide by the legal requirements associated with these

- Users may download and print one copy of any publication from the public portal for the purpose of private study or research.

- You may not further distribute the material or use it for any profit-making activity or commercial gain

If the publication is distributed under the terms of Article $25 \mathrm{fa}$ of the Dutch Copyright Act, indicated by the "Taverne" license above, 
The influence of coping

on social support and quality of life of people with rheumatic diseases

Manon Savelkoul 
The influence of coping on social support and quality of life of people with rheumatic diseases / Manon Savelkoul

- Maastricht University, thesis - With references With summary in Dutch

ISBN 90-9015439-6

Design: de Koning Harder ontwerpers, Utrecht

Printing: Datawyse, Maastricht 


\section{The influence of coping on social support and quality of life of people with rheumatic diseases}

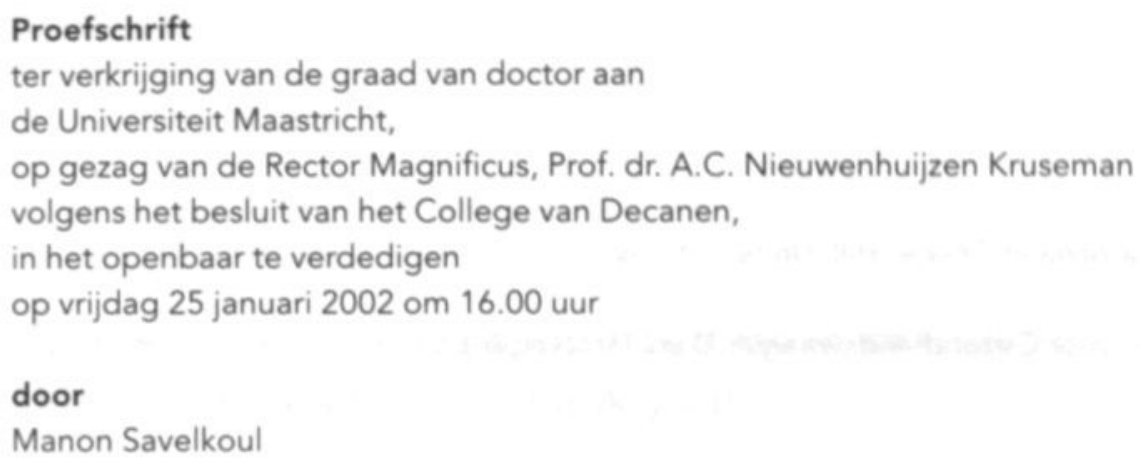


Promotores:

Prof. dr. G.J. Kok

Prof. dr. H.W. van den Borne

\section{Co-promotor:}

Dr. L.P. de Witte

\section{Beoordelingscommissie:}

Prof. dr. W.J.A. van den Heuvel (voorzitter)

Prof. dr. R.F. DeVellis (University of North Carolina at Chapel Hill, United States)

Prof. dr. J.M.J.P. van der Linden

Dr. F.L.P. van Sonderen (Noordelijk Centrum voor Gezondheidsvraagstukken, Groningen)

Dr. J.W.S. Vlaeyen

The printing of this thesis is financially supported by the Dutch Arthritis Association, the Institute for Rehabilitation Research (iRv), and the Rehabilitation Foundation Limburg (SRL). 
To everyone who has supported me in completing this thesis: thank you, thank you! 
and

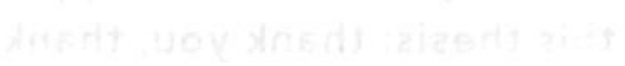




\section{Contents}

1 Introduction 8

2 Stimulating active coping in patients with rheumatic diseases: A systematic review of controlled intervention studies

3 Social support, coping and subjective well-being in patients with rheumatic diseases

4 Development, content, and process evaluation of a coping intervention for patients with rheumatic diseases

5 Effects of a coping intervention on patients with rheumatic diseases: Results of a randomized controlled trial

6 Social support as a mediator between active coping and quality of life in patients with rheumatic diseases: Results of a longitudinal study

7 Discussion

Summary

Samenvatting 
1

Introduction 


\section{Abstract}

The prevalence of rheumatic diseases is growing worldwide. While this is important in itself, rheumatic diseases have affective, behavioral, and social consequences too for many patients and consequently may decrease the patients' quality of life. As there is no cure for rheumatic diseases and, besides, in many patients reduced quality of life persists in spite of treatment, improving the rheumatic patients' quality of life seems to be very useful. Increasing social support in patients with rheumatic diseases may be a helpful way to do so because there are indications that social support has a positive influence on quality of life. Social support, in turn, may be increased by active coping by the rheumatic patients.

This thesis describes the influence of coping on social support and quality of life of patients with rheumatic diseases. The focus is on patients with chronic rheumatic diseases affecting the joints (rheumatoid arthritis, osteoarthritis, ankylosing spondylitis and less common diagnoses like psoriatic arthritis and juvenile chronic arthritis).

In this introductory chapter, explanations are given successively of rheumatic diseases, the prevalence of rheumatic diseases, the impact of rheumatic diseases on quality of life, the variables quality of life, social support and coping, and finally the research questions themselves.

\section{Rheumatic diseases}

Rheumatic diseases comprise more than 100 conditions. These can be divided into three categories: inflammatory joint diseases (e.g. rheumatoid arthritis, juvenile arthritis, psoriatic arthropathy, ankylosing spondylitis), connective tissue diseases (e.g. systemic lupus erythematosus, scleroderma, polymyositis/dermatomyositis, polymyalgia rheumatica and giant cell arteritis), and noninflammatory and miscellaneous musculoskeletal diseases (e.g. osteoarthritis, gout, back pain, soft tissue rheumatism, and osteoporosis) [1]. Three of the most prevalent rheumatic conditions are osteoarthritis (OA), rheumatoid arthritis (RA), and ankylosing spondylitis (AS). OA can cause disabling destruction of joints. The principal joints affected are those of the spine, the knee, and the hip, and certain joints in the hand. The course of the disorder is different according to which site is involved. Women are affected about twice as often as men by OA of the knee; OA of the hip is equally common among older men and women. Only a minority of joints affected by OA become symptomatic and the severity of symptoms and disability vary for unknown reasons. The cause of OA is unknown [2]. Moreover, it is not easily treated; the medications most often used are frequently ineffective [3] and although surgical treatment of affected joints offers great relief to selected patients, it is expensive and generally reserved for those in a restricted age range who are most severely affected [4]. RA is a disorder resulting in musculoskeletal deformities due to destruction of articular tissues and erosions of bone, and in severe mechanical abnormalities of the joints. Women are more likely to develop RA than men; the ratio is 2 (or 3):1 [5-7]. The cause of RA is also unknown [2]. Problems related to the treatment of RA in the form of drug side effects are common [8]. AS is characterized by back pain, generalized stiffness and reduced movement due to involvement of the sacroiliac joints [9]. AS has the following additional features: insidious onset under the age of 40 years and higher incidence in males (the male to female ratio is about 2:1 to $3: 1$ [10]); it lasts longer than three months, is associated with morning stiffness, and improves with exercise [2]. The cause of AS too is unknown [10]. There is no specific cure for AS. Treatment in the form of medication may sometimes arrest the inflammatory process. Besides, nonsteroidal antiinflammatory drugs are useful for reducing pain and improving mobility [2]. 


\section{Prevalence of rheumatic diseases}

The prevalence of self-reported rheumatic diseases in the Netherlands measured in 1996/1997 was $10.7 \%$ [11]. Moreover, the prevalence of rheumatic diseases in the Netherlands is expected to increase between 1994 and 2015 by $25 \%$ to $45 \%$ [12]. The age-dependent expression of rheumatic diseases implies that it is also a growing problem in other populations with increasing numbers of the elderly. In fact, a growing prevalence of rheumatic diseases is reported in Australia [13], the United States [14,15], Canada [16], the United Kingdom [17], Sweden, and France [18]. In the United States, for example, the prevalence rate of self-reported arthritis is projected to increase from 15\% (37.9 million persons) in 1990 to $18.2 \%$ (59.4 million persons) in 2020 [14].

\section{Impact of rheumatic diseases on quality of life}

In addition to the physiological and clinical effects, rheumatic diseases appear to have affective, behavioral, and social consequences for many patients. The WHO Scientific Group on Rheumatic Diseases reports that rheumatic diseases have a major impact on the work and personal lives of individuals in that pain and disability, often accompanied by fatigue, depression and loss of employment, are associated with the major groups of rheumatic conditions [2]. Functional impairment in activities of daily living is a consequence of rheumatic diseases that is mentioned frequently $[19,20]$. Besides, many patients report dysfunction in emotional behavior, social interaction and communication as well as separation or divorce and a lower rate of remarriage after divorce [19]. Compared to healthy people, people with rheumatic diseases go out (e.g. shopping, visiting people, going for a walk, going to work) less often. In addition, more patients with rheumatic diseases than healthy people express a wish to meet friends and relatives more frequently [21]. It can be a mental strain to people with rheumatic diseases not to be able to do the things they were accustomed to doing and to feel prevented from performing activities they want to perform. It can also be dissatisfying to the patients to have to decline to take part in various activities together with relatives and friends. In addition, patients may fear the progression of the disease and becoming dependent on others. Besides, patients can become frustrated by the fact that their outward appearance is healthy and that they therefore are looked upon by other people as such, whereas they themselves do not feel well at all. Also, resentment at having to be exposed to other people's lack of understanding of the functional impairment caused by the disease is not uncommon [22].

\section{Quality of life, social support and coping}

From the description above, it is obvious that rheumatic diseases may have a negative influence on the quality of life of the patients. More specifically, rheumatic diseases may impair the physical status (autonomy, mobility), psychological status (emotional stability), and social status (social activity, role performance) of the patients [23], representing the health-related quality of life [24], as well as decrease the more subjective quality of life represented by patients' evaluations of happiness in life and satisfaction with life [21], which can also be labeled "subjective well-being" [25]. This conceptualization of quality of life is subject-bound, meaning that the individual's perceptions lie at its core.

Until now there is no cure for rheumatic diseases. Consequently there is clearly room for new approaches to enhance the rheumatic patients' quality of life. Moreover, for many patients with rheumatic diseases, reduced quality of life persists in spite of treatment. One way to improve the rheumatic patient's quality of life may be by in- 
creasing the support the patient receives from the social environment as the findings from several studies suggest that this social support has a positive influence on quality of life $[26,27]$. Social support is the degree to which a person's basic social needs (affection, esteem or approval, belonging, identity, and security) are gratified through interaction with others by the provision of socioemotional aid (e.g. affection, sympathy and understanding, acceptance, and esteem from significant others) or the provision of instrumental aid (e.g. advice, information, help with family or work responsibilities, financial aid) [28]. Improving social support for people with rheumatic diseases is even more important if indications that social support may decrease as a consequence of having a rheumatic disease [19-21,29-31] are taken into consideration; loss of social interactions was a recurring theme in interviews with rheumatic patients and a large number of patients reported altered relationships with family, friends, and spouses, suggesting isolation and conflict [20]. Obviously, increasing social support in patients suffering from rheumatic diseases can be an important issue in helping these patients gain a higher quality of life. One way to reach this goal may be through influencing the way rheumatic patients cope [30,32,33]. According to Lazarus and Folkman [34], coping consists of constantly changing cognitive and behavioral efforts to manage specific external and/or internal demands that are appraised as taxing or exceeding the resources of the person. The way people cope with illness differs and depends on their character structure, experience, and the nature of their illness. Cultural, social, and economic factors all play a part in this process. An array of coping strategies is available to individual patients and may be employed in a major illness [35]. The process is complex, and coping is often not consistent across situations. There are indications, however, that persons tend to develop a personal style of adaptation to se- vere stress [36]. Coping can be classified according to two dimensions: Managing a stressful situation (active coping) versus avoidance (passive coping), and emotionfocused coping (aimed at restraining emotions caused by a stressful situation) versus problem-focused coping (aimed at changing the cause of the stressful situation) $[37,38]$. Active coping can be emotion-focused (directed at changing the meaning of the stressor, e.g. positive reappraisal, cognitive restructuring, reassuring thoughts), as well as problem-focused (aimed at changing the situation which is creating the stress, for example action-directed coping, seeking social support). Passive coping is always emotion-focused; examples are wishful thinking and palliative coping $[37,38]$. There are indications that active coping increases social support whereas passive coping discourages the social environment from supporting the patient $[30,32,33]$. However, in the literature there are two other ways mentioned in which coping and social support are related and influence quality of life. Some studies postulate that social support may be a source for effective coping and in this way improve quality of life $[33,39,40]$. In other studies indications have been found for a reciprocal relationship between coping and social support with both variables influencing quality of life $[41,42]$.

\section{Research questions}

A review of the literature, as described above, indicates that coping, social support and quality of life are key variables in the rheumatic diseases. The way coping and social support in rheumatic patients work in influencing the patients' quality of life should be considered as contributing to theory as well as to the quality of the patient's life. In this thesis, the effects of stimulating active coping in people with rheumatic diseases on these patients' coping, social support and quality of life are investigated. Also, 
the relationship between coping and social support in influencing quality of life of people with rheumatic diseases is investigated and more specifically, the hypothesis that active coping improves quality of life by increasing social support is tested. The focus is on coping with problems in general. Coping in the present study is not restricted to dealing with the rheumatic disease as people with rheumatic diseases can be expected to encounter problems in all kinds of life domains (e.g. work, family life, partnership relations, contacts with friends and acquaintances). The research questions are: (1) What effects does stimulating active coping in people with rheumatic diseases have on coping, social support and quality of life? and (2) Is there support for a hypothesized sequence between active coping, social support, and quality of life? To reach a homogeneous study population, the focus is on patients with rheumatic diseases affecting the joints: rheumatoid arthritis (RA); osteoarthritis (OA); ankylosing spondylitis (AS); a combination of RA, OA, AS, possibly with another rheumatic disease (no fibromyalgia); and less common diagnoses like psoriatic arthritis, juvenile chronic arthritis, adult onset M.Still, spondylarthrosis, spondylarthropathy (associated with M. Crohn), and diffuse idiopathic skeletal hyperostosis (DISH).

Chapter 2 describes a systematic review on controlled intervention studies aimed at stimulating active coping in people with rheumatic diseases. A cross-sectional study on the relationship between coping and social support in influencing the subjective well-being of people with rheumatic diseases is presented in chapter 3. Chapter 4 deals with the development, content and process evaluation of a coping intervention we implemented to increase active coping, and thereby improve social support and quality of life in patients with rheumatic diseases. Chapters 5 and 6 both describe results of a randomized controlled trial of this intervention. The effects on coping, social support and quality of life are reported in chapter 5 and the testing of a subsequent relationship between active coping, social support and quality of life is described in chapter 6. Chapter 7 closes the thesis by discussing the main findings, methodological reflections, recommendations for future research and practice implications.

\section{References}

[1] Silman AJ, Hochberg MC. Epidemiology of the rheumatic diseases. New York: Oxford University Press, 1993.

[2] WHO Scientific Group on Rheumatic Diseases. Rheumatic diseases: Report of a WHO Scientific Group (WHO Technical Report Series; 816). Geneva: WHO, 1992.

[3] Bradley JD, Brandt KD, Katz BP, Kalasinski LA, Ryan SI. Comparison of an antiinflammatory dose of ibuprofen, an analgesic dose of ibuprofen, and acetaminophen in the treatment of patients with osteoarthritis of the knee. N Engl J Med 1991;325:87-91.

[4] Felson DT. The course of osteoarthritis and factors that affect it. Rheum Dis Clin North Am 1993;19:607-15.

[5] Hochberg MC, Spector TD. Epidemiology of rheumatoid arthritis: Update. Epidemiol Rev 1990;12:247-52.

[6] Markenson JA. Worldwide trends in the socioeconomic impact and long-term prognosis of rheumatoid arthritis. Semin Arthritis Rheum 1991;21:4-12. 
[7] Spector TD. Rheumatoid arthritis. Rheum Dis Clin North Am 1990;16:513-37.

[8] Alarcón GS. Epidemiology of rheumatoid arthritis. Rheum Dis Clin North Am 1995;21:589-604.

[9] Rigby AS. Ankylosing spondylitis. In: Silman AJ, Hochberg MC, editors. Epidemiology of the rheumatic diseases. New York: Oxford University Press, 1993: 105-47.

[10] van der Linden S, van der Heijde D. Ankylosing spondylitis: Clinical features. Rheum Dis Clin North Am 1998;24:663-76.

[11] Statistics Netherlands, Ministry of Health, Welfare and Sports. Vademecum of health statistics of the Netherlands 1998. The Hague: Sdu uitgeverij, 1998.

[12] Maas IAM, Gijsen R, Lobbezoo IE, Poos MJJC, editors. Volksgezondheid Toekomst Verkenning 1997. I De gezondheidstoestand: Een actualisering. [Future scenarios for public health 1997. I Update on the state of public health] Maarssen: Elsevier / De Tijdstroom, 1997.

[13] Glover J, Woollacott T. A social health atlas of Australia. Adelaide: South Australian Health Commission, 1992.

[14] CDC. Arthritis prevalence and activity limitations United States, 1990. MMWR 1994;43:433-8.

[15] Lawrence RC, Helmick CG, Arnett FC, Deyo RA, Felson DT, Giannini EH, Heyse SP, Hirsch R, Hochberg MC, Hunder GG, Liang MH, Pillemer SR,
Steen VD, Wolfe F. Estimates of the prevalence of arthritis and selected musculoskeletal disorders in the United States. Arthritis Rheum 1998;41:778-99.

[16] Badley EM, Wang PP. Arthritis and the aging population: Projections of arthritis prevalence in Canada 1991 to 2031 . J Rheumatol 1998;25:138-44.

[17] Parker CJ, Morgan K, Dewey ME. Physical illness and disability among elderly people in England and Wales: The Medical Research Council Cognitive Function and Ageing Study. The Analysis Group. J Epidemiol Community Health 1997;51:494-501.

[18] Badley EM, Crotty M. An international comparison of the estimated effect of the ageing of the population on the major cause of disablement, musculoskeletal disorders. J Rheumatol 1995;22:1934-40.

[19] Anderson KO, Bradley LA, Young LD, McDaniel LK, Wise CM. Rheumatoid Arthritis: Review of psychological factors related to etiology, effects, and treatment. Psychol Bull 1985;98:358-87.

[20] Liang MH, Rogers M, Larson M, Eaton HM, Murawski BJ, Taylor JE, Swafford J, Schur PH. The psychosocial impact of systemic lupus erythematosus and rheumatoid arthritis. Arthritis Rheum 1984;27:13-9.

[21] Cornelissen PGJ, Rasker JJ, Valkenburg HA. The arthritis sufferer and the community: A comparison of arthritis sufferers in rural and urban areas. Ann Rheum Dis 1988;47:150-6. 
[22] Samuelsson A, Ahlmén M, Sullivan M. The rheumatic patient's early needs and expectations. Patient Educ Couns 1993;20:77-91.

[23] Jacobs JWG, van der Heide A, Rasker JJ, Bijlsma JWJ. Measurement of functional ability and health status in the arthritic patient. Patient Educ Couns 1993;20:121-32.

[24] World Health Organization Quality of Life assessment - group (WHOQOL). Position paper from the World Health Organization. Soc Sci Med $1995 ; 41: 1403-9$.

[25] Fuhrer MJ. Subjective well-being: Implications for medical rehabilitation outcomes and models of disablement. Am J Phys Med Rehabil 1994;73:358-64.

[26] Krol B, Sanderman R, Suurmeijer TPBM. Social support, rheumatoid arthritis and quality of life: Concepts, measurement and research. Patient Educ Couns 1993;20:101-20.

[27] Doeglas DM. Functional ability, social support and quality of life: A longitudinal study in patients with early rheumatoid arthritis. Groningen:

Rijksuniversiteit Groningen, 2000.

[28] Thoits PA. Conceptual, methodological and theoretical problems in studying social support as a buffer against life stress. J Health Soc Behav 1982;23:145-59.

[29] Fitzpatrick R, Newman S, Lamb R, Shipley M. Social relationships and psychological well-being in rheumatoid arthritis. Soc Sci Med 1988;27:399-403.
[30] Smith CA, Wallston KA. Adaptation in patients with chronic rheumatoid arthritis: Application of a general model. Health Psychol 1992;11:151-62.

[31] Kutner NG. Social ties, social support, and perceived health status among chronically disabled people. Soc Sci Med 1987;25:29-34.

[32] Dunkel-Schetter C, Folkman S, Lazarus RS. Correlates of social support receipt. J Pers Soc Psychol 1987; 53:71-80.

[33] Ros WJG. Social support in cancer patients. Utrecht, The Netherlands: Utrecht University, 1989.

[34] Lazarus RS, Folkman S. Stress, appraisal and coping. New York: Springer, 1984.

[35] Folkman S, Lazarus RS. An analysis of coping in a middle-aged community sample. J Health Soc Behav 1980;21:219-39.

[36] Vaillant GE. Health consequences of adaptation to life. Am J Med 1979;67:732-4.

[37] Parker JDA, Endler NS. Coping with coping assessment: A critical review. Eur J Personality 1992;6:321-44.

[38] de Ridder DTD, Schreurs K. Coping en sociale steun van chronisch zieken. [Coping and social support in chronic diseases] Zoetermeer: Nationale Commissie Chronisch Zieken, 1994. 
[39] Manne SL, Zautra AJ. Spouse criticism and support: Their association with coping and psychological adjustment among women with rheumatoid arthritis. J Pers Soc Psychol 1989;56:608-17.

[40] Holohan CJ, Moos RH, Holohan CK, Brennan PL. Social support, coping and depressive symptoms in a late-middle aged sample of patients reporting cardiac illness. Health Psychol 1995;14:152-63.

[41] Billings AG, Moos RH. The role of coping responses and social resources in attenuating the stress of life events. J Behav Med 1981;4:139-57.

[42] Schreurs KMG, de Ridder DTD. Integration of coping and social support perspectives:

Implications for the study of adaptation to chronic diseases. Clin Psychol Rev 1997;17:89-112. 
2

Stimulating active coping in patients with rheumatic diseases: A systematic review of controlled intervention studies

Manon Savelkoul', Luc de Witte ${ }^{2}$, and Marcel Post ${ }^{2}$

Submitted for publication

'Department of Health Education and Promotion, Maastricht University, Maastricht, The Netherlands ${ }^{2}$ Institute for Rehabilitation Research, Hoensbroek, The Netherlands 


\section{Abstract}

Teaching patients with rheumatic diseases to cope actively with their problems may increase the social support they receive and, consequently, the quality of their lives. In this paper a systematic review of coping interventions for people with rheumatic diseases is described.

Fourteen controlled trials were selected. Effects on quality of life have been measured in 13 studies of which 6 found positive effects. Effects on social support have been found in one of four studies investigating this variable. Coping has been measured in three studies with effects found on active coping in one study. No study explicitly examined the sequential relationship between active coping, social support, and quality of life.

There is a need for well-designed research on the relationship between active coping, social support and quality of life in patients with rheumatic diseases, as this may open new perspectives in patient education.

\section{Introduction}

Most educational interventions for people with rheumatic diseases are hybrids. It is possible, however, to identify key components. Seemingly dissimilar programs may actually achieve their effects because of a certain element they share. Identifying this element and its effects may facilitate the construction of new interventions that make maximal use of effective intervention components to reach desired outcomes. There are many group interventions for people with rheumatic diseases which in some way stimulate participants to cope actively. There are suggestions from the literature that active coping has a positive effect on social support, and via social support on quality of life [1-9]. A review of the literature performed in 1997 suggested that there is still little support for this sequence from controlled studies [10]. The importance of finding evidence for a sequential relationship between active coping, social support, and quality of life, lies in possible new perspectives in patient education; if active coping actually leads to a higher degree of support from people in the environment and this improves the patients' quality of life, teaching patients to cope actively becomes a very useful component in patient education. The methodology of the systematic review has been applied to find out if group interventions in which patients with rheumatic diseases are stimulated to cope actively, increase active coping, social support received, and/or quality of life. A secondary objective was to investigate whether there is support for active coping increasing social support, which, in turn, improves the quality of life in patients with rheumatic diseases. The purpose of the review is to provide practitioner and research readers with information about effects on coping, social support and quality of life of coping interventions for people with rheumatic diseases, to consider the practice implications of the effects found, and to make recommendations for future research.

\section{Methods}

The review followed the procedures outlined for systematic reviews [11-13].

\section{Search Strategy}

The sources that were used to locate studies were: electronic databases (the Cochrane Controlled Trial Register, MEDLINE, EMBASE, PsycINFO, Social Sciences Citation Index, and Current Contents); reference lists of all relevant, not necessarily selected, articles (also reviews), and reference lists of articles which were found in this way; personal communication; bibliographic databases (psychosocial care interventions for people with chronic diseases listed for another study, effect evaluations of interventions for the chronically ill collected for another study, 
and trial registries from grant funds in rheumatology); and not formally published literature like research reports, conference proceedings, and dissertations.

In deciding which electronic databases and what search terms to use in each database, we have worked closely with a librarian. In all search strategies, the design was defined first; randomized controlled trial (RCT) or controlled clinical trial (CCT), because these are superior to other designs when answering the questions under study. If possible, the Cochrane optimally sensitive search strategy for randomized controlled trials [14] was used. The definition of design was combined with several terms for rheumatic diseases (e.g. arthritis, rheumatic diseases, ankylosing spondylitis) and finally with varying descriptions of the intervention under study (e.g. coping, problem solving, stress management). No outcome variables were incorporated in the search strategies as some outcomes evaluated in the studies may be relevant, but were not considered in the indexing of the article [13]. Determined by local availability, MEDLINE was screened for publication years 1966 (January) to 2000 (August), EMBASE for 1984 (January) to 2000 (August), PsycINFO for 1967 (January) to 2000 (August), Social Sciences Citation Index for 1995 (January) to 2000 (June), Current Contents for 1998 (January) to 2000 (August), and finally The Cochrane Controlled Trials Register issue 4 (1999) has been searched. No language restrictions were included in the search strategy.

\section{Selection Criteria}

Selection criteria are described in figure 1. To make sure that the studies were all on a homogeneous patient population, selection was restricted to interventions in patients of whom the majority suffer from chronic rheumatic diseases affecting the joints (e.g. rheumatoid arthritis, osteoarthritis, ankylosing spondylitis). Only randomized controlled trials and nonrandomized controlled trials (controlled clinical trials) were included in the review and the control group should receive standard medical care or a placebo intervention. Also for inclusion, the intervention under study had to refer to teaching patients active coping with problems in general. Many interventions in patients with rheumatic diseases have concerned themselves primarily or exclusively with pain management. Because the focus of the present review is on the effects of active coping with problems in general (stresses of daily life), and because there are indications that coping with pain is different from coping with these stresses of daily life $[15,16]$, intervention studies on coping with pain have been excluded. Selection also was restricted to interventions in groups of patients. In addition, studies have been selected with coping, social support (social support and/or loneliness), and quality of life (life satisfaction and/or functional health status) as one of the dependent variables. Life satisfaction should be operationalized as satisfaction with self-care ability, leisure situation, vocational situation, financial situation, sexual life, partnership relations, family life, contacts with friends and acquaintances, or with life in general. Functional health status as a dependent variable should encompass sickness impact on, or health-related behavioral problems with regard to physical, psychological, and social functioning. Physical functioning may be indicated by somatic autonomy and mobility control, psychological functioning by emotional stability and psychological autonomy and communication, and social functioning by mobility range and social behavior.

Selection was performed by two investigators (MP and MS). Both individually applied the selection criteria (figure 1) to each article identified. For this purpose, the articles were blinded for title, authors' names and institutional affiliations, abstract, journal name and date of publication, 
results, discussion, acknowledgements, sources of financial support, and references. In one case, missing information was necessary for selection of the article and was received on request with the corresponding author. No response was given to requests for information that was necessary for the selection of two other possibly relevant interventions. Results of the application of the selection criteria were discussed. Disagreement was handled subsequently by letting a third, blinded investigator (LW) decide.

\section{Methodological assessment}

All studies meeting the selection criteria were rated for methodological strength. Criteria used for the methodological assessment are described in figure 2. The criteria are based on generally accepted principles [17], and checklists developed by experts in the field [18-20]. All criteria measure the internal validity of the trials. A total score for methodological quality was obtained by adding scores on all items; all items had the same weight. If information on an item was lacking, score " 0 " was assigned. Methodological assessment of the selected trials was performed by two investigators (MP and MS) separately. To prevent bias, the title, authors' names and institutional affiliations, abstract, journal name and date of publication, acknowledgements, sources of financial support, and references were deleted from the articles. The results of the methodological assessment were discussed in order to reach agreement. Subsequently, disagreement was handled by letting another, blinded investigator (LW) decide.

If information for the methodological assessment was lacking, efforts were made to obtain this information from the corresponding authors for the articles.
1. Study population:

2. Study design:

3. Control group:

4. Intervention:

5. Dependent variables:
- Majority of patients having one or more chronic rheumatic disease(s) affecting the joints

- Randomized controlled trial or controlled clinical trial

- Standard medical care or a placebo intervention

- In some way teaching patients to cope actively with various problems they may encounter in daily life

- In groups of patients

- Coping / Social support / Loneliness / Life satisfaction / Functional health status

Figure 1. Criteria for inclusion of articles in the systematic review. 


\section{Criteria": \\ Patient assignment}

1. Was there a homogeneous study population with respect to diagnosis?

2. Was a method of randomization performed? ${ }^{1}$

3. Was the procedure for randomization adequate? ${ }^{1}$

- adequate: generation of random number list (each study participant has the same chance of receiving each intervention)

- not adequate: patients were allocated alternately, or according to date of birth, date of admission, hospital number, et cetera

4. Was the randomization concealed (concealed allocation of study conditions)? ${ }^{1}$

5. Were the study groups similar at baseline for potential prognostic confounders like age, gender, disease duration? ${ }^{1,2}$

6. Was the number of patients in the smallest study group higher than 25 ? ${ }^{1}$

\section{Masking}

7. Was outcome assessment blinded to group assignment?

8. Were patients naive to allocated intervention(s)?

9. Were providers of the intervention(s) naive to allocated intervention(s)?

\section{Patient follow-up}

10. Were outcome variables relevant?

- relevant: useful/meaningful operationalizations of coping, social support and/or quality of life

11. Were reliable and valid instruments used to measure the outcomes?

\section{Results}

\section{Results of the search strategy}

The search for studies resulted in more than 500 unduplicated titles of which 30 were possibly relevant. Of these 30 studies, 16 [21-36] met the inclusion criteria listed in figure1. In two cases, two studies were on the same trial: A cost analysis of an intervention [36] of which an evalua- tion for other outcome variables was described in another article [33], and a five-year follow-up of a trial [32] of which a short-term evaluation was reported in an article published some years before [27]. Consequently, the final outcome of the selection was 14 studies. Of one selected study described in Dutch [28], the corresponding author sent us an article on the same trial in English [37] in response to our request for methodological information. 
12. Was the number of dropouts and missing values acceptable?

- acceptable: number of randomized patients minus number of reported patients at main moment(s) of effect measurement for outcome measure divided by all randomized patients $x 100$ was $<10$ in each group

- partly acceptable: number of randomized patients minus number of reported patients at main moment(s) of effect measurement for outcome measure divided by all randomized patients $\times 100$ was $<20$ in each group

13. Was the dropout a-select?

14. Was the number of withdrawals from treatment acceptable $(<10 \%)$ ?

15. Was the withdrawal from treatment a-select?

16. Was there a good compliance in the intervention group(s): mean attendance at least $80 \%$ of all sessions?

17. Were there standardized co-interventions or no co-interventions?

18. Was there a measurement at post-intervention in all study groups?

19. Was there a measurement at follow-up in all study groups?

20. Were the outcome measures collected at equal points in time in all study groups?

\section{Statistical analysis}

21. Were the findings corrected for possible confounders?

22. Did the analysis include an intention-to-treat analysis?

\footnotetext{
'Score: yes $=1$, partly $=0.5, \mathrm{no} / ? / \mathrm{nr}$ (not relevant) $=0$

1 Score "partly" (0.5) impossible

2 If no full similarity at baseline, score "no" $(0)$ is assigned and the missed score ( 1 or 0.5$)$

can be gained at criterion 21; if full similarity (score "yes" = 1), then the score on criterion 21 is " $n r$ " (not relevant $=0$ )
}

Figure 2. Criteria for methodological assessment.

Ten studies were randomized controlled trials [22-26, $28 / 37,31,33 / 36,34,35]$. All other four studies were nonrandomized controlled trials $[21,27 / 32,29,30]$. Eight trials $[21,23,28 / 37,29,30,31,34,35]$ involved patients with rheumatoid arthritis; in four trials [22,24-26] patients with rheumatoid arthritis, osteoarthritis and a minority with other types of arthritis participated; one trial [33/36] included patients with osteoarthritis exclusively; and in one trial [27/32] all participants were diagnosed with rheumatoid arthritis or osteoarthritis. All studies were published between 1983 and 1999.

\section{Methodological score}

Of all 308 methodological criteria that had to be scored (22 criteria applied to 14 trials), initially 44 criteria were scored differently by the reviewers. Consequently, the ini- 
tial disagreement on the methodological score was $14 \%$. Table 1 shows that the total methodological scores range from 5.5 to 12 . The maximum attainable methodological score is 22 . Obviously the range of the scores is restricted and the methodological quality of the selected trials, as was measured with our criteria, is not very high. In general, information on many aspects of methodological quality is lacking (table 1). Particularly the procedure for randomization (criteria 3 and 4) and outcome assessment (criterion 7), assuring patients and providers remain blind to expected outcomes (criteria 8 and 9), withdrawal from treatment (criteria 14 and 15), compliance (criterion 16), and co-interventions (criterion 17), are not sufficiently described in the selected articles. Based on the information available (table 1), however, it can be concluded that quality in statistical analysis (corrections for possible confounders and inclusion of an intention-to-treat analysis) in particular was relatively poor. This indicates room for improvement in study methods in this area or, if the study methods were correct but not described, in study descriptions. Table 1 shows that scores related to patient assignment and patient follow-up were relatively high. For patient assignment, high scores were caused by homogeneity of the study population (criterion 1), inclusion of randomization (criterion 2), and adequate size of the smallest study group (criterion 6). Patient follow-up was scored relatively high because of measurements taking place at post-intervention (criterion 18) and follow-up (criterion 19), and outcome assessments taking place at equal points in time in all study groups (criterion 20).

After including the missing methodological information that was received on request with some corresponding authors, scores improved on patient follow-up (criterion 11,14,15,16), patient assignment (criterion 3,5), and masking (criterion $7,8,9$ ). The scores based on the information that we received from the corresponding authors are indicated in brackets in table 1; the total scores after inclusion of previously missing methodological information are indicated after the total scores assigned originally. In interpreting these scores it is important to know that some of the information requested was not provided by the authors and that not all authors responded to our request for information.

\section{Intervention characteristics}

Of studies in which more than one intervention was tested $[23-26,28 / 37,33 / 36]$, only interventions that in some way stimulate active coping are included in this review, as the aim of the review is to investigate effects of active coping. In most of these studies [23,26,28/37,33/36], active coping was encouraged in only one of the interventions tested, but in one study [24], two interventions encompassing the stimulation of active coping were tested. Consequently these are both incorporated in this review. In another study [25] also two interventions with a focus on active coping were tested. Because these interventions both have the exact same content and only differ in background of persons leading the intervention, only the intervention as it was planned originally ("the lay-taught intervention") will be discussed.

The available characteristics of the interventions are described in figure 3. No intervention was described as being specifically aimed at stimulating patients to cope actively with problems they encountered in their daily lives. In general, three types of interventions can be identified from the descriptions in the selected articles (figure 3): self-management in which illness self-management skills are taught $[22,24-26,27 / 32,30,31,34,35]$, education-support groups which include teaching self-management skills in an atmosphere of emotional support [21,33/36], and cognitive-behavioral therapy which is aimed at improving the patients' way of dealing with pain and stress 


\title{
Table 1
}

\section{Methodological quality of the studies}

\author{
Methodological criteria
}

Total score

\begin{tabular}{|c|c|c|c|c|c|c|c|c|c|c|c|c|c|c|c|c|c|c|c|c|c|c|c|c|}
\hline Study & $n(E / C)$ & 1 & 2 & 3 & 4 & 5 & 6 & 7 & 8 & 9 & 10 & 11 & 12 & 13 & 14 & 15 & 16 & 17 & 18 & 19 & 20 & 21 & 22 & \\
\hline [21] & $38(19 / 19)$ & 1 & 0 & $\mathrm{nr}$ & $\mathrm{nr}$ & 1 & 0 & $?$ & 0 & 0 & 1 & 0.5 & 1 & $?$ & $?$ & $?$ & $?$ & $?$ & 1 & 1 & 1 & nr & 0 & 7.5 \\
\hline 22) & $286^{\prime}(134 / 65)$ & 0.5 & 1 & $?(1)$ & $?$ & 0 & 1 & $?$ & $7(0)$ & $7(0.5)$ & 0.5 & 1 & 1 & $?$ & ?(1) & $?$ & $7(1)$ & $7(0)$ & 1 & 0 & 1 & 1 & 0 & $8.0(11.5)^{2}$ \\
\hline 23] & $105^{3}(35 / 35)$ & 1 & 1 & $?$ & $?$ & $?$ & 1 & $?$ & $?$ & $?$ & 1 & 0.5 & 0 & 0.5 & $?$ & $?$ & 0 & $?$ & 1 & 1 & 1 & 1 & 0 & 90 \\
\hline 24) & $96(32 / 28 / 36)$ & 0.5 & 1 & $?$ & $?$ & 0 & 1 & $?$ & $?$ & $?$ & 0.5 & 0.5 & 1 & 0.5 & $?$ & $?$ & 1 & $?$ & 0 & 1 & 1 & 1 & 0 & 9.0 \\
\hline (25) & $100^{3}(34 / 32)$ & 0.5 & 1 & $?(1)$ & $?$ & 0 & 1 & $?$ & 0.5 & $?(0.5)$ & 0.5 & 1 & 0.5 & 1 & $?$ & $?$ & 1 & $P(0)$ & 1 & 0 & 1 & 1 & 0 & $10.0(11.5)^{2}$ \\
\hline (26) & $459^{3}\left(153 / 153^{4}\right)$ & 0.5 & 1 & $?$ & $?$ & 1 & 1 & $?$ & $?$ & $?$ & 0.5 & 1 & 0.5 & $?$ & $?$ & $?$ & $?$ & $?$ & 1 & 0 & 1 & nr & 0 & 7.5 \\
\hline$[27 / 32$ & $200(100 / 100)$ & 0.5 & 0 & $\mathrm{nr}$ & $\mathrm{nr}$ & 0 & 1 & $?$ & $7(0.5)$ & $7(0)$ & 0.5 & 0.5 & 0 & 0.5 & ?(1) & $?$ & $7(1)$ & 1 & 1 & 1 & 1 & 1 & 0 & $8.0(10.5)^{2}$ \\
\hline$[28 / 37]$ & $105^{1}(27 / 23)$ & 1 & 1 & $?(1)$ & $?(1)$ & 1 & 0 & $?$ & 0.5 & 0.5 & 0.5 & 1 & 0.5 & 0 & ?(1) & $7(0)$ & $?(1)$ & 1 & 1 & 1 & 0 & $n$ & 0 & $9.0(13)^{2}$ \\
\hline [29) & $10(5 / 5)$ & 1 & 0 & nr & $\mathrm{nr}$ & $?$ & 0 & $?$ & $?$ & $?$ & 0.5 & $?$ & $?$ & $?$ & $?$ & $?$ & $?$ & 1 & 1 & 1 & 1 & $?$ & $?$ & 5.5 \\
\hline [30] & $68(31 / 37)$ & 1 & 0 & $\mathrm{nr}$ & $\mathrm{nr}$ & 0 & 1 & $?$ & $?$ & $?$ & 0.5 & $?$ & 1 & 1 & $?$ & $?$ & $?$ & $?$ & 1 & 1 & 1 & 0 & 1 & 8.5 \\
\hline [31] & $75(38 / 37)$ & 1 & 1 & $?$ & $?$ & 0 & 1 & $?$ & $?$ & $?$ & 1 & 1 & 0.5 & 0.5 & $?$ & $?$ & 1 & 1 & 1 & 1 & 1 & 1 & 0 & 12.0 \\
\hline$[33 / 36]$ & $363^{1}\left(91 / 91^{4}\right)$ & 1 & 1 & $?$ & $?$ & 1 & 1 & $?$ & 0 & $?$ & 0.5 & 1 & 0 & 0.5 & $?$ & 0.5 & $?$ & $?$ & 1 & 1 & 1 & nr & 0 & 9.5 \\
\hline [34] & $100\left(50 / 50^{4}\right)$ & 1 & 1 & $?(1)$ & $?(1)$ & 1 & 1 & $?$ & $?(0.5)$ & $P(0)$ & 0.5 & $?(1)$ & 1 & $?$ & 1 & ne & $?(1)$ & $?(0)$ & 1 & 1 & 1 & 0 & 0 & $9.5(14)^{2}$ \\
\hline [35] & $68(38 / 30)$ & 1 & 1 & $?(0)$ & $?(0)$ & $?(1)$ & 1 & $?(1)$ & $?(0)$ & $?(0)$ & 0.5 & 0.5 & 1 & 1 & $?(1)$ & $?(1)$ & $?(1)$ & $?$ & 1 & 1 & 1 & 0 & 1 & $10.0(15)^{2}$ \\
\hline
\end{tabular}

$\begin{array}{lcccccccccccccccccccccccc}\text { Total score } & 11.5 & 10 & & & 5 & 11 & & 1 & 0.5 & 8.5 & 8.5 & 8 & 5.5 & 1 & 0.5 & 3 & 4 & 13 & 11 & 13 & 6 & 2 \\ ? & - & - & 10 & 10 & 3 & - & 14 & 10 & 12 & - & 3 & 1 & 5 & 13 & 12 & 10 & 10 & . & . & . & 1 & 1\end{array}$

$n=$ number of patients randomly assigned to intervention group (E) and control group (C);

methodological criteria 1-22: see figure 2 , score 1 = yes, score $0.5=$ partly and score $0=$ no/unknown;

$\mathrm{nr}=$ not relevant (score 0 )

' Four study groups in original study

${ }^{2}$ Score after inclusion of missing methodological information provided by corresponding authors

${ }^{3}$ Three study groups in original study

${ }^{4}$ Estimated number; information not available 
$[23,28 / 37,29]$. Illness self-management skills are basic skills (e.g. the use of heat and massage as pain management tools, protection of joints through improved body mechanics, conservation of energy through pacing activities, and the prudent practice of exercise and rest), traditionally taught by nurses, occupational and physical therapists. Additional self-management skills taught in educational programs include knowing how to solve arthritis-related problems and how to adapt and combine various techniques to achieve maximal benefit [38]. Cognitive behavioral techniques are associated with behavior therapy or cognitive-behavior therapy and intended to increase such skills as voluntary relaxation of the skeletal muscles, diverting attention away from pain, re-interpreting pain by challenging irrational pain-related cognitions, solving everyday problems more effectively through the use of learned and practiced cognitive procedures, selfreinforcement of adaptive behavior, increasing assertiveness, and developing a view of oneself that emphasizes a sense of mastery or control [38].

The studies on the effects of the Arthritis Self Management Program [22,25] investigated a nonrevised [22] and a revised [25] version. The latter was designed specifically to enhance self-efficacy by using self-efficacy-enhancing strategies based on skills mastery, modeling, reinterpreting symptoms, and persuasion. Four other studies $[24,26$, $31,35]$ reported evaluations of interventions which were in some way based on this Arthritis Self-Management Program. 
Participants

Arthritis Self-Management Program

Structure: Six sessions, spread over four months

Rheumatoid arthritis

Osteoarthritis

Aims: Not described

Content: Teaches patients the general principles of managing arthritis, emphasizes the nature of arthritis, the appropriate use of medication. range of motion and isometric exercises, relaxation techniques, joint protection, nutrition, interaction of patients with physicians, and evaluation of nontraditional treatments.

- Family members can participate if they wish.

Includes group discussion, practice, use of contracts and diaries to improve compliance and weekly feedback.

Arthritis Self-Management Course

Structure: Six weekly sessions (two hours)

Aims: Not described

Content: Basic anatomy and physiology of a joint, principles of arthritis self-help, preparing for exercise (use of heat, massage, and relaxation), isometric exercise, exercise diaries, arthritis medications, solving social and/or functional problems resulting from arthritis, depression, nutrition, nontraditional treatments, joint protection, work simplification, physician and allied health professionals-patient communications.

- Self-help type of instruction and small-group dynamics are emphasized.

Community Education Program

Structure: Six weekly sessions (two hours)

Aims: Not described

Content: Basic anatomy and physiology of a joint, description of rheumatoid arthritis and osteoarthritis (rheumatologist); preparing for exercise, range of motion exercises, isometric/ isotonic exercise (physical therapist); nutrition (registered dietitian); arthritis medications, avoiding quackery (rheumatologist); joint protection, avoiding and coping with functional problems, work simplification (occupational therapist); working with your doctor, solving problems created by arthritis (social worker).

- Lecture-oriented classes; no explicit emphasis on group process.
Rheumatoid arthritis

Osteoarthritis

Gout or pseudogout

Figure 3. Intervention characteristics. (to be continued on the next pages) 
Figure 3. (continued)

Study Intervention: Self-management

Participants

Arthritis Self-Management Course

Structure: Six weekly sessions (two hours)

Aims: Not described

Content: Overview of types of arthritis, range of motion and isometric exercises, relaxation techniques, use of medications, nutrition, methods of solving problems encountered in daily living, joint protection, evaluation of nontraditional therapies, and techniques of patient-physician communication.

\section{Arthritis Self-Care Education Program}

Structure: Six sessions (two hours)

Aims: Enhancing self-care capabilities.

Content: Encouragement of active practice of self-care (contracts), problem identification and problem solving.

- Family members and friends can participate if they wish.

\section{7/32 Arthritis Education Program}

Structure: Six weekly sessions (150 minutes)

Aims: Teaching factual knowledge, develop skills and help in coping with chronic disease.

Content: Medical aspects, pain management, available treatments, stress management, self-awareness and communication skills, exercise; work simplification and joint protection; nutrition and leisure; availability of community resources.
Rheumatoid arthritis

Osteoarthritis

Other types of arthritis

Rheumatoid arthritis

Osteoarthritis

Other chronic

musculoskeletal diseases

Rheumatoid arthritis

Osteoarthritis

Rheumatoid arthritis

Structure: Six weekly sessions with one double session (two sessions in one) within this period

Aims: Information on rheumatoid arthritis and treatment possibilities (lectures and group discussions); coping with daily problems (practicing); exchanging feelings and emotions with other patients.

Content: Rheumatoid arthritis and development of the disease (rheumatologist); diagnostic procedure and observation of development (rheumatologist); changes 
in joints and functional constraints (occupational therapist); treatment with medicines and surgery (rheumatologist, practice nurse); pain and coping with pain (psychologist); physical exercise (physiotherapist); joint protection (occupational therapist); social legal problems; self-help (social worker, practice nurse).

- Short lectures, group discussions, and practicing recommended behaviors are components of every session.

Groups led by psychologist and lecturer.

Structure: Five weekly sessions (two hours)

Aims: Strengthening of self-efficacy and self-management behaviors.

Content: Contracting, goal setting and feedback to stimulate physical exercises at home; self-management and problem solving; information on the disease and treatment; pain management and relaxation; physical exercises; communication skills; coping with depression (methods are discussed and maintenance of social contacts and daily activities are emphasized).

- Partners can participate if they wish.

\section{Problem-Based Interactive Education Program}

Structure: Eight weekly sessions (150 minutes)

Aims: Not described

Content: Establishing contact within the group and discussion of each individual's main problem with the disease and suggestions how to overcome this problem (active participation of group members); focus on capability to pursue preferred priorities rather than feel discouraged by limitations; understanding disease process (led by a professional doctor); medication, surgery, alternative treatments (nurse); diet, fasting, and basic nutrition (dietitian); pain management by rest, exercise and relaxation (physiotherapist); hand function, hand program, technical aids (occupational therapist); how to live with rheumatoid arthritis (social worker); practical session: training kitchen (occupational therapist); review of earlier sessions followed by free discussions.

- Content of each session is based on discussions of how to solve the problems of the patients. Patients allowed to bring one relative or friend in the last session. Informal extra meeting after one year. 
Figure 3. (continued)

Study Intervention: Self-management

Structure: Nine daily sessions (afternoons) within two weeks

Aims: To encourage patients to assume management of the disease, improve patient-relevant disease-related disorders (disability, depression, social issues). Content: Pathogenesis, drug therapy (benefits and limitations), impact of physicotherapy, practical exercise in remedial gymnastics, use of joint protection devices, orthopedic perspectives, psychological counseling emphasizing sense of control and skill in coping with the disease, stress management and relaxation exercise, dietetics, information about unproven cures and social assistance to improve utilization of public social resources.

- Interactive discussion, problem solving, goalsetting, diaries and feedback to stimulate techniques patients were taught.

Cooperation between rheumatologists, physicotherapists, psychologists, and social workers.

Family members and friends can participate if they wish.

Completed by means of a supervised monthly meeting structured during one year to establish patients' mutually interactive help and to consolidate achievements.

\section{Study Intervention: Education-support groups}

\section{Participants}

Structure: Four weekly meetings (90 minutes)

Aims: Educational forum regarding rheumatoid arthritis and its treatment and provide a climate of emotional support.

Content: Patients introduce themselves and any attending family members, and briefly discuss their physical and social situations; rheumatologist, rheumatology nurse specialist, and physical or occupational therapist attend at least one session to answer questions; groups led by facilitator of discussion, allowing topics to arise spontaneously; patients are individually instructed to perform joint exercises four times daily and to apply moist heat to affected joints immediately before each exercise session. 


\section{Participants}

33/36 Education Groups

Osteoarthritis

Structure: 10 weekly two-hour meetings followed by 10 monthly two-hour meetings

Aims: Not described

Content: Information about osteoarthritis, recommendations on coping or self-treatments, and when to use the health care system with active involvement of the participants.

\section{Study Intervention: Cognitive-behavioral therapy}

23

\section{Stress Management}

Structure: 10 weekly sessions ( 90 minutes)

Aims: Not described

Content: Help the patient identify sources of stress and learn relaxation techniques and strategies for coping.

- A psychologist structures (determines the content) and directs all activities.

\section{Cognitive-Behavioral Therapy}

Structure: 10 weekly sessions (two hours)

Aims: To improve coping with pain and disease-related stress

(e.g. physical impairment).

Content: Biomedical information provided by a rheumatologist, assessment of the patients' coping repertoire and self-management of active coping behavior (clinical psychologists). Special attention is given to the differential effects of behavioral coping with regard to pain, mobility, and self-care. The following coping strategies are trained: progressive relaxation, rational thinking, active coping behaviors (distraction by pleasant activities, continuation of activities by reducing demands) and goalsetting with emphasis on adjustment of demands to the current physical condition. Homework assignments are given at the end of every session and evaluated in the next session.

\section{Participants}

Rheumatoid arthritis

Rheumatoid arthritis 
Figure 3. (continued)

Study Intervention: Cognitive-behavioral therapy

\section{Participants}

Structure: Six sessions ( 90 - 120 minutes) during two weeks

Aims: To deliver opportunities to improve skills in cognitive, emotional, and behavioral dealing with the disease; giving as many as possible ways of dealing with the disease in response to the following problems presented by the patients: pain, depression, decreasing functional abilities, fear for unpleasant side effects of medicines, insecurity about possible future developments of the disease, and communication problems with friends and acquaintances.

Content: The transactional stress-coping model proposed by Lazarus and Folkman (introduction); distraction, relaxation, objectifying pain (coping with pain); visualization (reducing helplessness, fear for unpleasant side effects of medicines); training in getting pleasure out of life (changing depression, development of stress buffering techniques); role plays (increasing social skills); topic of conversation: "loss and grief" (different ways of coping). 


\section{Effects on coping, social support, and quality of life} Post-intervention observation time is not provided in one study [26]. From descriptions of almost all other studies, it is clear that the effects of the interventions were first measured within four weeks after the end of the intervention. In one study [27/32], however, measurements analyzed to detect any effects of the intervention did not take place until approximately 10 months after the end of the intervention. In four studies [22,24-26], no follow-up assessments were made. Final follow-up assessments in the other studies varied from three months $[29,30]$ to almost five years [32] after the end of the intervention.

In general, outcome measures to investigate the effects of the interventions in selected trials included knowledge, physical status, psychological status, health-related behaviors, and health service utilization. As far as outcome variables which are relevant for this systematic review are concerned, table 2 shows that only three $[28 / 37,29,35]$ of all selected studies investigated the effects of the interventions on coping specifically. The results indicated that in only one [35] of these trials, did the intervention increase active coping but not until the first follow-up. With regard to social support, improvements were found in only one [35] of the four studies $[21,24,28 / 37,35]$ investigating the effects on this variable. In this study, contacts with relatives and friends were reported by the patients as being improved right after the end of the intervention and this effect was sustained until the second follow-up. In another study [33/36] the number of people listed as a source for social support was used as an outcome measure; no effects have been found on this variable. Effects on quality of life were measured in two studies by measuring life satisfaction $[23,31]$ and in 13 studies by means of asking the patients about their functional health status [22-26,27/32,28/37,29-31,33/36,34,35]. In both studies measuring life satisfaction, no improvements have been found on this variable. Positive effects of the intervention on functional health status were seen in 6 of the 13 studies measuring this variable. More specifically, results showed a decrease in anxiety detectable at second follow-up [33/36], an increase in psychological autonomy at post-intervention not sustained until follow-up [29], a decrease in perceived disability at post-intervention not sustained until follow-up, as well as an increase in selfconfidence and relations to friends, both sustained until follow-up [34], less problems caused by the rheumatic diseases at post-intervention and follow-up [27/32], an increase in disability at post-intervention and first followup which did not sustain until the second follow-up measurement [31], and a decrease in disability and depression both sustained until the second follow-up measurement [35]. No effects on functional health status were found in all other studies measuring this variable [22-26,28/37,30]. 
2 Stimulating active coping in patients with rheumatic diseases:

A systematic review of controlled intervention studies

\section{Table 2}

Results of individual studies

\section{Social support}

Study

Coping

Social support

Loneliness

\section{Quality of life}

\section{Self-management}

22 (RCT)

24 (RCT)

$0^{2} 0^{3}$

25 (RCT)

26 (RCT)

$27 / 32$ (CCT)

30 (CCT)

31 (RCT)

34 (RCT)

35 (RCT)

$0++9+++10$

Cognitive-behavioral therapy

$\begin{array}{lll}21 & (\mathrm{CCT}) & 0 \\ 33 / 36 & (\mathrm{RCT}) & 0\end{array}$

Education-support groups

23 (RCT)

28/37 (RCT)

29 (CCT)
$0^{16} \quad 00^{17}$

$00^{18} 0+19$
$0^{1}$

$0^{1}$

$0^{4}$

$0^{1}$

$0^{1} \quad 0^{4}$

$00^{1} \quad+t^{5,6}$

$00^{4} \quad 00^{7}$

$000^{8}$

$++0^{1} \quad 000^{7}$

$+0^{1} \quad++^{5} \quad 00^{6}$

$+++1+++4$

$000^{4} \quad 000^{13} \quad 00+{ }^{14}$ 


\section{Notes table 2}

$0=$ no significant effect, $+=$ significant positive effect:

RCT = randomized controlled trial; CCT = controlled clinical trial;

First sign means effect assessed first time after the intervention, second sign means effect assessed second time after the intervention, third sign means effect assessed third time after the intervention

\section{${ }^{1}$ Disability}

2 Perceived instrumental support

${ }^{3}$ Perceived affective support

${ }^{4}$ Depression

${ }^{5}$ Problems with arthritis: self-confidence, relations to relatives and friends

${ }^{6}$ Problems with arthritis: depressed feelings, difficulties working, fear of the future

${ }^{7}$ Functional health status (six subscales measuring physical, psychological, and social aspects)

${ }^{8}$ Well-being

${ }^{9}$ Active problem-oriented coping

10 Improved contacts with relatives and friends

${ }^{11}$ Adequacy of families' attitudes and behavior

${ }^{12}$ Number of people listed as a source of social support (social support measured indirectly)

${ }^{13}$ Health status (one scale integrating mobility, physical activity, and social activity)

${ }^{14}$ Anxiety

${ }^{15}$ Life satisfaction

${ }^{16}$ Coping with stress (palliative reaction pattern, active problem solving, seeking social support, disclosure of emotions, comforting cognition, awaiting / avoidance)

${ }^{17}$ Social support (potential emotional support, actual emotional support, mutual visits)

${ }^{18}$ Coping with stress (active coping, trivialize)

${ }^{19}$ Coping with stress (distraction)

${ }^{20}$ Negative affect

21 Positive affect 


\section{Sequential relation between coping, social support, and quality of life}

Synthesizing the results of the individual studies does not lead to indications that active coping leads to an increase in social support which, in turn, improves quality of life. Table 2 shows that only two studies investigated the effects on all three variables coping, social support, and quality of life $[28 / 37,35]$. In one of these trials active coping actually increased [35], but this effect was not detected until six weeks after the end of the intervention. As improved social support and quality of life were reported directly after the end of the intervention as well as six weeks and almost one year after the intervention, these findings do not indicate a sequential relationship between active coping, social support and quality of life.

Besides, a variable related to coping as well as social support were both measured in another selected study [21]. Results of this trial showed that patients with higher ratings on perceptions of abilities to cope with rheumatoid arthritis (e.g. ability to ask for help in completing household tasks, explain the disease to others, verbalize feelings of depression or frustration, and engage in customary degree of sexual activity), tended to perceive their family relationships with respect to the disease as being more adequate than those with lower ratings. This indicates a relationship between social support and self-efficacy in dealing with the disease ("perceptions of selfcoping") which, although probably strongly related to coping, is not the same as coping.

\section{Discussion}

The heterogeneity of the interventions (figure 3) and of operationalizations of outcome measures (table 2) in the trials included in this systematic review makes a mathematical synthesis of intervention effects inappropriate. Consequently, the results from the trials have been dis- cussed in narrative form.

The results of the individual studies (table 2 ) illustrate that in general, coping and social support were seldom outcome variables in the studies under review. Indicators of quality of life, on the other hand, were measured in almost all trials as an outcome variable. The results of the studies reviewed are consistent in that many provide evidence for improvement in functional health status as an indication of quality of life, which can be attributed to the interventions (table 2). However, in 7 of the 13 studies investigating effects on quality of life, no effects could be found. In general, the 6 studies in which effects on quality of life are found are similar in methodological quality to the 7 studies in which no effects are detected. In the few studies in which coping or social support was measured, significant effects on these variables could be found in only one study [35] (table 2). The methodological quality of this study (table 1) is higher than the methodological quality of the studies in which no effects could be found on coping $[28,29]$ or social support $[21,24,28]$. Whether active coping leads to more social support for the patient which, in turn, improves the quality of life, cannot be determined in the present review. An explanation can be found in the focus of the studies under review; none was specifically aimed at investigating the effects of active coping with daily problems on social support, nor with the effects of this social support, triggered by active coping, on quality of life.

Post-intervention observation time is not provided in one study [26]. From descriptions of the other studies it is clear that in all of these studies except one, the effects of the interventions have been first measured within four weeks after the end of the intervention; in one study [27/32], measurements analyzed for detecting any effects of the intervention did not take place until almost one year after the end of the intervention. In this study some 
short-term effects may not have been assessed. Intervention effects may decay or increase with time and consequently follow-up assessments are important. In four studies $[22,24-26]$ no follow-up assessments were made. In these studies no effects were found at post-intervention. The absence of follow-up assessments may have masked effects that increase over time. Final follow-up assessments in the other studies varied from three months $[29,30]$ to almost five years [32] after the end of the intervention. In intervention studies a longer followup than three months may be desirable to detect effects that increase with time and also to gain an insight into decreasing effects.

In many cases, information for the methodological assessment was lacking. Although efforts were made to obtain this information from the articles' corresponding authors, we only succeeded in 6 of 14 cases and in some of these 6 cases we were not provided with all the information we requested. Consequently, it may be the case that the methodological quality of the studies was actually higher than the scores based on the information we got from the published articles and corresponding authors.

Additional remarks can be made on the scores attainable for some of the criteria used for methodological assessment. Criterion 8 "Were patients naive to allocated intervention(s)" (figure 2) is undoubtedly relevant for methodological quality (internal validity). Score "yes" on this criterion, however, is only possible in trials with some kind of placebo intervention as a control condition. In trials with a (waiting list) control group it is impossible to keep all patients naive to allocated interventions as patients in the control group know that they receive no intervention; "partly" naive, however, is possible in these trials if patients in the intervention group(s) are not told the expected effects of the intervention(s). Keeping providers of the intervention(s) naive to allocated interventions (criterion
9) is also important for the methodological quality or, more specifically, the internal validity of a trial. In the trials under review, however, it is not possible to keep providers completely naive as providing a group intervention in patients with rheumatic diseases implies knowing what it is about. Partly naive, however, is possible if providers are not told the expectations on results.

It has been suggested that the quality of clinical trials should be assessed by blinded raters to limit the risk of introducing selection bias into systematic reviews [13]. For this review, the methodological quality was not assessed blindly of the outcome as the results sections of the articles most probably would contain important information on the methodological quality (figure 2). However, methodological quality assessment was explicitly performed independently of the outcome. Besides, blinding for author's names and affiliation, names of the journals, date of publication, sources of financial support, and acknowledgements, as we did, is sufficient to produce significantly lower and more consistent scores than open assessments [18].

Besides all this, there is a possible limitation to systematically reviewing the literature which is known as "publication bias", implying that studies with results that are significant, interesting, from large well-funded projects or of higher quality, are more likely to be submitted, published, or published more rapidly than studies without such characteristics. Publication bias may lead to an overestimation of the effects of the interventions under review [13]. In a meta-analysis among 19 published education trials in osteoarthritis and rheumatoid arthritis, however, trials demonstrating little or negative effect and trials demonstrating positive effect were equally represented [39]. Besides, to reduce publication bias, in the present systematic review efforts have been made to find unpublished studies. Despite these efforts, there remains a 
possibility of bias because it might be difficult to get information on unpublished studies that are relatively unknown, of poorer quality and/or with nonsignificant, not interesting or negative results. Consequently, the number of coping interventions showing negative or no effects may be larger than the studies discussed in this review. This bias may be limited by the fact that in patient education as a relatively new discipline, dissemination of information about methods that are not efficacious may be treated as equally important as information about methods that are effective.

The results of the review have several implications. Welldesigned research addressing questions on the way coping by rheumatic patients works is required, as it may lead to increasing the patient's well-being by improving educational interventions accordingly. Many claims about the effectiveness of interventions are based on variables other than coping and therefore do not contribute to theory on coping and at the same time neglect the fact that there are many indications that coping is a key variable in chronic diseases. It is important that any trial of a coping intervention in patients with rheumatic diseases should measure the relevant theoretical correlates (coping, social support, and quality of life), generate comparable intervention and control groups, correct for possible confounders, perform an intention-to-treat analysis, ensure minimal loss to follow-up and adequate length of follow-up. Also important is that all information necessary for methodological assessment is provided in sufficient detail.

Selection in this review was restricted to controlled trials in patients with rheumatic diseases, because in questions of effectiveness, a control group is essential. Not many of the selected studies, however, investigated coping and social support and none of the selected studies focussed on the subsequent relationship between coping, social support, and quality of life. Selecting other prospective study designs with follow-up measurements, besides controlled trials, as well as extending selection to studies into other chronic diseases might be a convenient addition to find indications for the effects of active coping as well as for the hypothesized sequence between active coping, social support, and quality of life. Nevertheless, more robust designs are needed for evidence-based implications.

One of the criteria used for the methodological assessments of the trials concerned the homogeneity of diagnosis of the study population (criterion 1 in figure 2), because it was expected that diagnosis may influence susceptibility to the intervention. In two of the trials $[22,26]$ incorporated in the present review, however, it was found that persons with osteoarthritis and rheumatoid arthritis benefited similarly from the intervention under study. In addition, important information for future assessments is that disease duration and formal education made no differences in susceptibility to the intervention [26].

The positive effects of group interventions in which people with rheumatic diseases are stimulated to cope actively by teaching them self-management skills or skills in dealing with pain and stress, should be considered by health educators. Identifying patients with a decreased quality of life and helping them in dealing with their daily problems is recommended.

\section{References}

[1] Dunkel-Schetter C, Folkman S, Lazarus RS. Correlates of social support receipt. J Pers Soc Psychol 1987;53:71-80.

[2] Smith CA, Wallston KA. Adaptation in patients with chronic rheumatoid arthritis: Application of a general model. Health Psychol 1992;11:151-62. 
[3] Ros WJG. Social support in cancer patients. Utrecht: Utrecht University, 1989.

[4] Savelkoul M, Post M, de Witte L, van den Borne B. Social support, coping and subjective well-being in patients with rheumatic diseases. Patient Educ Couns 2000;39:205-18.

[5] Doeglas D, Suurmeijer T, Krol B, Sanderman R, van Rijswijk M, van Leeuwen M. Social support, social disability, and psychological well-being in rheumatoid arthritis. Arthritis Care Res 1994;7:10-5.

[6] Penninx BWJH, van Tilburg T, Deeg DJH, Kriegsman DMW, Boeke AJP, van Eijk JTM. Direct and buffer effects of social support and personal coping resources in individuals with arthritis. Soc Sci Med 1997;44:393-402.

[7] McColl MA, Lei H, Skinner H. Structural relationships between social support and coping.

Soc Sci Med 1995;41:395-407.

[8] Manne SL, Zautra AJ. Spouse criticism and support: Their association with coping and psychological adjustment among women with rheumatoid arthritis. J Pers Soc Psychol 1989;56:608-17.

[9] Lazarus RS, Folkman S. Stress, appraisal, and coping. New York: Springer, 1984.

[10] Schreurs KMG, de Ridder DTD. Integration of coping and social support perspectives: Implications for the study of adaptation to chronic diseases. Clin Psychol Rev 1997;17:89-112.
[11] Crombie IK. The pocket guide to critical appraisal: A handbook for health care professionals. London: BMJ, 1996.

[12] Chalmers I, Altman DG, editors. Systematic reviews. London: BMJ, 1995.

[13] Mulrow CD, Oxman AD, editors. Cochrane collaboration handbook (updated September 1997). In: The Cochrane Library (database on disk and CDROM). Oxford: The Cochrane Collaboration, Update Software 1994, issue 4.

[14] Dickersin K, Scherer R, Lefebre C. Identifying relevant studies for systematic reviews. BMJ 1994;309:1286-91.

[15] Gijs L, Huiskes CJAE, Kraaimaat FW. Rheumatoide Arthritis: Psychologische Aspekte und verhaltenstherapeutische Interventionen. [Rheumatoid arthritis: Psychological aspects and behavioral therapy] In: Meerman R, Vandereycken W, editors. Verhaltenstherapeutische Psychosomatik in Klinik und Praxis. Stuttgart/New York: Schattauer, 1991: 275-313.

[16] Parker J, McRae C, Smarr K, Beck N, Frank R, Anderson S, Walker S. Coping strategies in rheumatoid arthritis. J Rheumatol 1988;15:1376-83.

[17] Moher D, Jadad AR, Nichol G, Penman M, Tugwell $P$, Walsh S. Assessing the quality of randomized controlled trials: An annotated bibliography of scales and checklists. Control Clin Trials 1995;16:62-73. 
[18] Jadad AR, Moore RA, Carroll D, Jenkinson C, Reynolds DJM, Gavaghan DJ, McQuay HJ. Assessing the quality of reports of randomized clinical trials: Is blinding necessary? Control Clin Trials 1994;17:1-12.

[19] Verhagen AP, de Vet HCW, de Bie RA, Kessels AGH, Boers M, Bouter LM, Knipschild PG. The Delphi List: A criteria list for quality assessment of randomized clinical trials for conducting systematic reviews developed by Delphi consensus. J Clin Epidemiol 1998;51:1235-41.

[20] van der Heijden GJMG, van der Windt DAWM, de Winter AF. Physiotherapy for patients with soft tissue shoulder disorders: A systematic review of randomized clinical trials. BMJ 1997;315:25-30.

[21] Potts M, Brandt KD. Analysis of education-support groups for patients with rheumatoid arthritis. Patient Couns Health Educ 1983;4:161-6.

[22] Lorig K, Lubeck D, Kraines RG, Seleznick M, Holman HR. Outcomes of self-help education for patients with arthritis. Arthritis Rheum 1985;28:680-5.

[23] Shearn MA, Fireman BH. Stress management and mutual support groups in rheumatoid arthritis. Am J Med 1985;78:771-5.

[24] Cohen JL, van Houten Sauter S, DeVellis RF, McEvoy DeVellis B. Evaluation of arthritis self-management courses led by laypersons and by professionals. Arthritis Rheum 1986;29:388-93.

[25] Lorig K, Feigenbaum P, Regan C, Ung E, Chastain RL, Holman HR. A comparison of lay-taught and professional-taught arthritis self-management courses. J Rheumatol 1986;13:763-7.

[26] Goeppinger J, Arthur MW, Baglioni AJ, Brunk SE, Brunner CM. A reexamination of the effectiveness of self-care education for persons with arthritis. Arthritis Rheum 1989;32:706-16.

[27] Lindroth Y, Bauman A, Barnes C, McCredie M, Brooks PM. A controlled evaluation of arthritis education. Br J Rheumatol 1989;28:7-12.

[28] Huiskes CJAE, Kraaimaat FW, Brons MR, Bijlsma JWJ. Het effect van gedragstherapie en ergotherapie bij patiënten met reumatoide artritis. [The effects of behavioral therapy and ergotherapy on patients with rheumatoid arthritis] Gedragstherapie 1991;24:253-68.

[29] von Jungnitsch G, Langhof S. Ein Krankheitsbewältigungstraining für Patienten mit chronischer Polyarthritis: Trends und erste Ergebnisse. [Effects of a cognitive-behavioral group therapy for patients with rheumatoid arthritis] Z Klin Psychol Psychopathol Psychother 1991;39:283-99.

[30] Mattussek S. Die "cP-Schule Hannover": Entwicklung eines Curriculums und Durchführing einer kontrollierten Studie zur Schulung von Patienten mit einer chronischen Polyarthritis. [A controlled prospective study of an educational intervention ("CP-Schule Hannover") for patients with rheumatoid arthritis] Z Rheumatol 1992; 51(Suppl 1):41-50. 
[31] Taal E, Riemsma RP, Brus HLM, Seydel ER, Rasker JJ, Wiegman O. Group education for patients with rheumatoid arthritis. Patient Educ Couns 1993;20:177-87.

[32] Lindroth Y, Bauman A, Brooks PM, Priestley D. A 5year follow-up of a controlled trial of an arthritis education programme. Br J Rheumatol 1995;34:647-52.

[33] Gallagher RA, Miller C, Cronan TA, Groessl E. Gender differences in participation and responsiveness to a health intervention for older Americans. Women Health 1997;25:63-81.

[34] Lindroth Y, Brattstrom M, Bellman I, Ekestaf G, Olofsson Y, Strombeck B, Stenshed B, Wikstrom I, Nilsson JA, Wollheim FA. A problem-based education program for patients with rheumatoid arthritis: Evaluation after three and twelve months. Arthritis Care Res 1997; 10:325-32.

[35] Scholten C, Brodowicz T, Graninger W, Gardavsky I, Pils K, Pesau B, Eggl-Tyl E, Wanivenhaus A, Zielinski CC. Persistent functional and social benefit 5 years after a multidisciplinary arthritis training program. Arch Phys Med Rehabil 1999;80:1282-7.

[36] GroessI EJ, Cronan TA. A cost analysis of self-management programs for people with chronic illness. Am J Community Psychol 2000;28:455-80.

[37] Kraaimaat FW, Brons MR, Geenen R, Bijlsma JWJ. The effect of cognitive behavior therapy in patients with rheumatoid arthritis. Behav Res Ther 1995;33:487-95.
[38] DeVellis RF, Blalock SJ. Psychological and educational interventions to reduce arthritis disability. Baillieres Clin Rheumatol 1993;7:397-416.

[39] Superio-Cabuslay E, Ward MM, Lorig KR. Patient education interventions in osteoarthritis and rheumatoid arthritis: A meta-analytic comparison with nonsteroidal antiinflammatory drug treatment. Arthritis Care Res 1996;9:292-301. 
3

Social support, coping and subjective well-being in patients with rheumatic diseases

Manon Savelkoul', Marcel Post ${ }^{2}$, Luc de Witte ${ }^{2}$, and Bart van den Borne'

Patient Education and Counseling 2000;39:205-18

'Department of Health Education and Promotion, Maastricht University, Maastricht, The Netherlands ${ }^{2}$ Institute for Rehabilitation Research, Hoensbroek, The Netherlands 


\section{Abstract}

The purpose of this cross-sectional study is to examine the relationship between social support, coping, and subjective well-being by testing three hypotheses: (1) social support influences subjective well-being via coping; (2) coping influences subjective well-being via social support; (3) there is a reciprocal relationship between social support and coping, and both concepts influence subjective well-being.

Data were analyzed from 628 patients with one or more chronic rheumatic disorder(s) affecting the joints, in some patients combined with another rheumatic disease (no fibromyalgia).

Although causal inferences are not possible, the results present a plausible causal sequence in supporting the second hypothesis. This is only true, however, for coping by awaiting / avoidance: Coping by awaiting / avoidance led to less social support and this decrease in social support influenced subjective well-being negatively.

\section{Introduction}

People with rheumatic diseases may suffer from pain, limited functional ability and everyday activities may be affected $[1,2]$. Consequently, they can experience a decline in well-being [3]. There is some evidence from previous research that social support plays a role in the rheumatic patients' well-being [4-11]. Other studies have shown that coping can influence the well-being of a person [12-17]. So far, only a few studies have been done on the combined effects of coping and social support on well-being [18]. The subjects of these studies were patients with rheumatic and other chronic diseases and also members of the general public [19-23]. From these studies, it can be concluded that the relationship between coping and social support and their relationship with well-being is still not clear. For this study, three hypotheses concerning possible relationships between social support, coping, and well-being in rheumatic patients have been postulated and tested (figure 1).
A

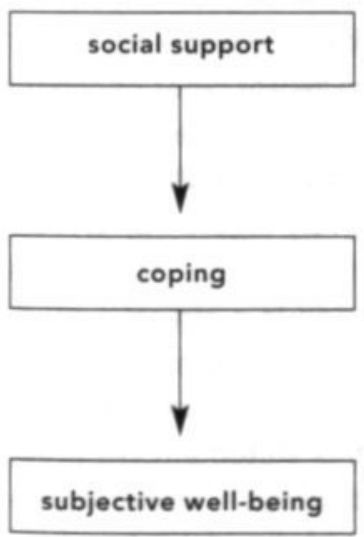

B

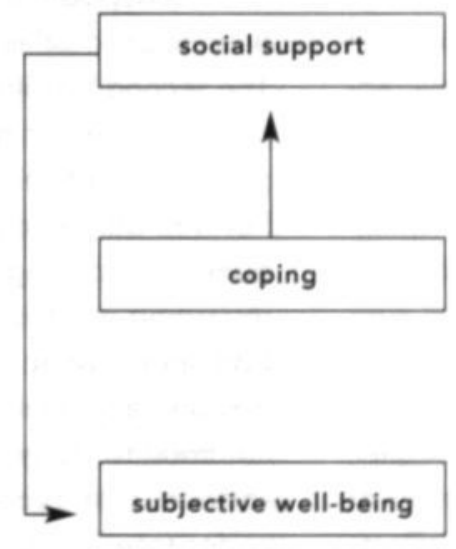

C

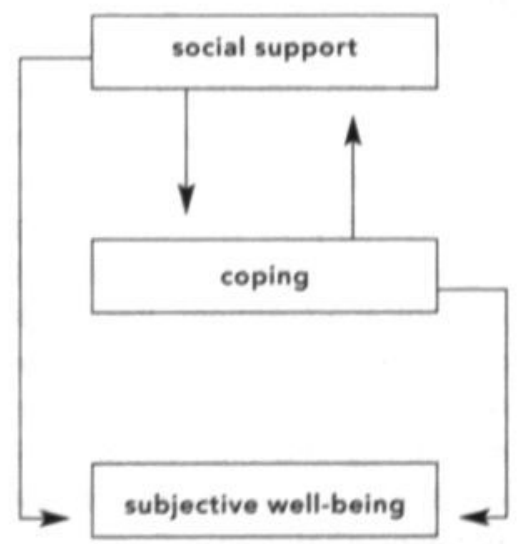

Figure 1. Three hypotheses for the relationship between social support, coping and subjective well-being. 
Because the results from previous studies were ambiguous, the hypotheses represent three contrasting ways in which coping and social support are related and influence well-being. The hypotheses are restricted to the influence of social support on well-being via coping (figure $1 \mathrm{~A})$, the influence of coping on well-being via social support (figure 1B), and a reciprocal relationship between social support and coping with both concepts influencing well-being (figure 1C). Empirical evidence for the hypotheses will be discussed below. For the sake of clarity, the coping strategies and behaviors assessed in the studies described below are classified according to two basic coping dimensions shown in figure 2: emotion-focused versus problem-focused coping and approach versus avoidance $[24,25]$. As problem-focused coping is usually considered as approach and not as avoidance, and emotion-focused coping can be both approach and avoidance, three different types of coping can be distinguished (figure 2).

The first hypothesis we postulated is that support from others may help people to cope effectively, which improves their well-being (figure 1A). Foundations for this hypothesis can be found in a cross-sectional study in women with rheumatoid arthritis (RA) [21]. Negative social support, as measured by the number of critical remarks the husband of a patient made during an interview, significantly predicted the coping strategy "wishful thinking". Wishful thinking significantly predicted poor psychological adjustment. Besides this, positive social support from the spouse, as indicated by the RA-patient, was found to be predictive of engaging in more cognitive restructuring and information-seeking coping strategies, and this combined factor was found to be predictive of better psychological adjustment. Moreover, direct effects of negative support on psychological adjustment were nonsignificant after accounting for their indirect effects through coping, as were direct effects of positive support after accounting for their indirect effect through coping. Also, in a review on this topic [18], it was concluded that the function of social support as a coping resource may be a very important one. This conclusion is based on the study we discussed above and the following two prospective studies. In a study of lung-cancer patients, emotional support had a positive effect on well-being in patients who coped with their disease emotionally and in a helpless manner (depressed reactions, ventilating feelings of anger, avoidance). Informational support influenced well-being positively in patients who coped actively (action-directed coping, reassuring thoughts) [22]. The social support reported by patients with a cardiac illness was associated with fewer depressive symptoms one year later brought about indirectly by enhancing approach coping (positive reappraisal and problem solving) in relation to avoidance coping (cognitive avoidance and emotional discharge) [20]. Social support in this study [20] also influenced depressive symptoms directly. The direct influence of social support on well-being, however, is not in the first hypothesis because the test is restricted to the influence of social support on well-being via coping.

The second hypothesis is that the different types of coping used by a person may encourage others to be either supportive or critical of that person which influences his or her well-being positively or negatively (figure 1B). It is argued that coping behavior provides interpersonal cues regarding what is wanted or needed in a stressful situation and that the members of the social environment respond accordingly [26]. The results of a cross-sectional community study [26] on which this statement is based, showed that problem-focused coping in stressful episodes (seeking social support, problem solving, positive reappraisal and confronting the problem), was associated with significantly more informational support, aid, and 
Problem-focused Approach coping: problem solving [20] Information seeking [21]

Active coping: action-directed [22]

Problem-focused coping: seek social support, problem solving, confrontive coping [26]

Emotion-focused Approach coping: positive reappraisal [20] Cognitive restructuring [21]

Active coping: reassuring thoughts [22] Problem-focused coping: positive reappraisal [26]*

Emotion-focused coping: accept responsibility [26]

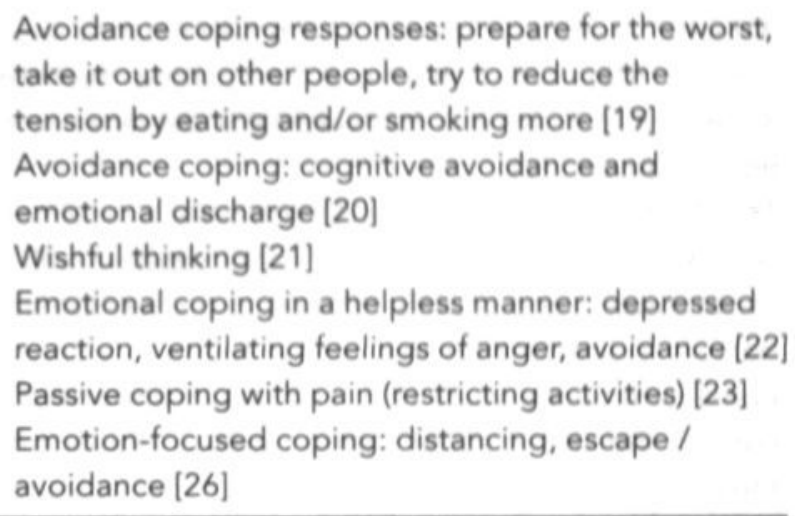

*According to the authors, positive reappraisal in the data presented by them is problem-focused as it involves reconceptualizing the problem cognitively in order to make it more solvable. The items, however, in our opinion, represent emotion-focused coping (e.g. "I changed or grew as a person in a good way", "I came out of the experience better than I went into it", "I found new faith", "I rediscovered what is important in life"

Figure 2. A classification of coping.

emotional support, and significantly more sources of help. Use of emotion-focused coping (distancing, escape / avoidance, accepting responsibility), was associated with significantly less informational support, marginally less aid, and marginally less emotional support. Path analyses in a prospective study [23] showed that passive coping with pain by patients with RA (e.g. restricting activities), led to a decrease in perceived quality of emotional support, which enhanced psychosocial impairment one year later. Besides, the social support variables did not contribute directly to the prediction of coping, although a path from social support to coping was predicted by the model tested. Support was found, however, for a direct path from passive coping to psychosocial impairment. 
The direct influence of coping on well-being is not in the second hypothesis because the test is restricted to the influence of coping on well-being via social support. As for this second hypothesis, in a review on this topic [18], one of the conclusions was that some ways of coping seem to have a detrimental effect on social support. This conclusion is based on a study which is discussed above [23], and another study with lung-cancer patients in which patients' emotional coping in a predominantly helpless manner (depressed reactions, ventilating feelings of anger, avoidance), was followed by a decrease in emotional support [22].

The third hypothesis (figure $1 \mathrm{C}$ ) suggests a reciprocal relationship between coping and social support with both social support and coping influencing the well-being of a person. Indications for this can be found in a cross-sectional community study [19]. The results show that after coping, indices of social support added significantly to the prediction of personal functioning. Coping responses and social resources both accounted for comparable amounts of variance in personal functioning. Additional analyses showed that approximately one half of the criterion variance explained by coping and by social resources was shared between these two sets of measures, for example, people who used avoidance coping responses (e.g. prepared for the worst, took it out on other people, tried to reduce the tension by eating and/or smoking more), had fewer social resources and these two factors combined to detrimentally influence their personal functioning. The existence of a possible circular effect of coping on social support was also one of the conclusions in a review on this topic [18].

Because there is as yet no cure for rheumatic diseases, it is important to concentrate on increasing the patients' well-being. Given the existing evidence of coping and social support influencing rheumatic patients' well-being, an intervention aimed at these variables seems to be appropriate. To develop such an intervention it is useful, however, to find out how coping and social support are related and how these concepts influence the patients' well-being. The purpose of the present study was to examine the relationship between social support, coping and subjective well-being in patients with rheumatic diseases. The research question we wished to answer was: How are coping and social support related and how do these concepts relate to the subjective well-being of patients with rheumatic diseases? This was done by testing with path analyses the three aforementioned hypotheses (see figure 1). Because the study concerns patients with a chronic disease, we controlled for the influence of functional health status by including this variable as a determinant of both social support and subjective well-being. Pain and weariness were included as determinants of functional health status.

\section{Methods}

\section{Participants and procedure}

During a three-month period, adult patients ( $>17$ years) who visited their rheumatologist in an outpatient rheumatology clinic of two regional hospitals received a questionnaire $(N=2792)$. Rheumatologists asked their patients to fill out this questionnaire at home and send it back to the researchers. The response rate was $68 \%$ : 1901 of the 2792 patients who received a questionnaire filled it out and sent it back. Participation was voluntary and without payment. Patients who did not want to participate were asked to indicate their age, sex, kind of rheumatic disease, and duration of this disease on a "nonresponse form". This was done to collect data on possible differences between respondents and nonrespondents. 
In consultation with a rheumatologist, only patients were included with at least one rheumatic disorder that was chronic as well as affecting the joints. Thus, patients with the following diagnoses were included: RA; osteoarthritis (OA); ankylosing spondylitis (AS); a combination of two or three of these diagnoses; a combination of one, two, or three of these diagnoses with another rheumatic disease (no fibromyalgia); and the following less common diagnoses with symptoms similar to RA, OA and AS: psoriatic arthritis, juvenile chronic arthritis, systemic onset Still's disease, spondylosis, seronegative spondylarthropathy (associated with Crohn's disease), and diffuse idiopathic skeletal hyperostosis (DISH). For the analyses, only data from respondents with no missing values on the variabies in the hypotheses were used. Consequently, data were used from respondents within the above mentioned diagnostic groups ( $n=1307$ ), with no missing values on questions about pain, weariness, functional health status, social support, coping, and subjective well-being. The total number of respondents from whom data were analyzed was 628 .

\section{Measures}

\section{Patient characteristics}

The patient characteristics measured were age, being single or not, sex, educational level, family income, and employment status.

\section{Disease characteristics}

Rheumatologists were asked to indicate the patient's diagnosis on the questionnaire (all other variables were measured by asking the patient). Duration of the disease was indicated in months. Also, respondents were asked whether they had one or more other chronic disease(s) besides their rheumatic disease. Besides this, pain (fre- quency and intensity) and weariness (frequency and intensity), were measured. Frequency was measured on a five-point scale from "never in pain" / "never tired" (score 0), to "constantly in pain " / "constantly tired" (score 4). No time frame was mentioned; frequencies of pain and weariness were measured in general [27]. Intensity was measured on a visual analog scale (VAS) ranging from 0 , indicating "not at all tired" / "not at all in pain", to 10, indicating "the severest pain you can imagine" / "the worst tiredness you can imagine" $[27,28]$. Respondents were asked to indicate intensity of pain and weariness for the last month [27]. For analyses, the variable "pain" was used, indicated by frequency $x$ intensity of pain $(r=.59)$ and the variable "weariness", the product of frequency and intensity of weariness $(r=.67)$.

\section{Functional health status}

Functional health status was measured with the SIP68, a condensed version of the Sickness Impact Profile $[29,30]$. There are 68 items in the SIP68, measuring health-related behavioral problems. For each item, respondents are asked whether a certain "sickness impact" exists on the day they fill out the list (yes $=1 /$ no $=0$ ). The sum of the scores makes up the total score of the impact of the rheumatic disease on daily functioning. The higher the score, the worse the functional health status. The scale obtained a high reliability coefficient in this study (Cronbach's $\alpha=$ .92).

\section{Coping}

Coping was measured with a short version of the Utrecht Coping Questionnaire [31]. The Utrecht Coping Questionnaire is based on the assumption that individuals prefer particular coping behaviors in different situations; coping is seen as a personality trait. The short version [32] consists of 15 items which can be classified into four sub- 
scales: (1) action-directed coping (5 items, Cronbach's $\alpha$ (in this study) $=.83$; problem-focused approach coping in figure 2); (2) seeking social support (5 items, Cronbach's $\alpha=$.75; problem-focused approach coping in figure 2); (3) awaiting / avoidance (3 items, Cronbach's $\alpha=.62$; emotion-focused avoidance coping in figure 2); and (4) palliative coping (2 items, Cronbach's $\alpha=.33$; emotion-focused avoidance coping in figure 2). Because of its low internal consistency, the subscale to measure palliative coping was not incorporated in the analyses. The respondents indicated how often in general they execute the different coping behaviors when facing a stressful situation (from "seldom or never" (score 1), to "very often" (score 4)). A total score was computed for each of the three subscales by adding scores on all items from these subscales separately [33].

\section{Social support}

The Social Support List - Discrepancies (SSL-D) was used to measure social support received $[34,35]$. This list consists of 34 items measuring, on a four-point scale, the individual's satisfaction with the supportive interactions provided. The scores on all six subscales of the SSL-D were added to indicate satisfaction with all kinds of supportive interactions (Cronbach's $\alpha=.95$ ).

\section{Loneliness}

The Loneliness Scale [36] was incorporated in the questionnaire to measure loneliness. The Loneliness Scale consists of five positive and six negative items on a fivepoint scale. The positive items assess feelings of belonging, whereas the negative items apply to three separate aspects of missing relationships. Increasing scores on this scale indicate more loneliness. Path analyses were repeated with scores on the Loneliness Scale from respondents with missing values on social support. In these analyses, loneliness was conceived as a concept related to social support. In this study, Cronbach's $\alpha$ was .88 .

\section{Subjective well-being}

Subjective well-being in our study was conceptualized in accordance with Fuhrer as the individuals' global judgements of their life experience along a continuum that ranges from positive to negative [37]. Two questions were used to measure subjective well-being. The first question measured perceived happiness in general during the last month (answers on a seven-point scale from very happy to very unhappy). The other question was about perceived satisfaction with life in general during the last month (answers on a seven-point scale from very satisfied to very unsatisfied). The questions correspond with the emotionally toned and cognitive judgements respectively, which, according to Fuhrer [37], are inherent in subjective well-being. In this respect, the questions are analogous to Andrew and Withey's two questions on happiness and life satisfaction [38]. However, they measure a more momentary state and use the same seven-point answering scale for both questions on happiness and life satisfaction with three extra alternatives for "missing" answers (neutral, neither satisfied or dissatisfied - does not apply to me - I never thought about it).

The value of Pearson's $r$ between the two questions on happiness and satisfaction with life in our study was .80 . Subjective well-being was measured by summing the scores on the two questions as was done in another study [27]. Before this, answers were coded in such a way that higher scores correspond with higher subjective well-being. Internal consistency appeared to be high; Cronbach's $\alpha$ was .88 . 


\section{Data analysis}

First, frequencies and means for the scores on patient characteristics, disease characteristics, functional health status, coping, social support, loneliness, and subjective well-being were computed. Then, correlations among variables selected for their relevance to the hypothetical models (pain, weariness, functional health status, coping. social support, loneliness, and subjective well-being), were computed. Next, we further examined the patterns of covariation among the variables of the hypothetical models (pain, weariness, functional health status, coping, social support, and subjective well-being), by using path analyses in LISREL 8 [39]. Path analysis is an extension of multiple regression, in which more than one dependent variable can be included. The results of the analysis do or do not confirm the hypothesized associations among the variables. Differing from multiple regression, relationships between dependent variables are specified in path analyses, and the "fit" of the specified model as a whole is examined. A model is said to fit if the relationships in a hypothesized model generate an estimated covariance matrix that closely matches the covariance matrix obtained from the data [40]. Several indices express the degree to which a model fits the data. For this study, a Pvalue higher than .05 was used as a criterion. Because the Chi-square value is sensitive to the number of variables in the model and the sample size, two other indices of fit were used: the Adjusted Goodness of Fit Index (AGFI), which should be higher than 90, and the Root Mean Square Error of Approximation (RMSEA), which should be lower than .08. Path coefficients are also computed in path analyses, which are comparable to Beta-values in multiple regression analyses. These path coefficients are tested for significance because even though a model fits, certain parts of the hypothesis may not be confirmed [40]. LISREL input was a polychoric correlation matrix that was analyzed using the weighted least squares method [39]. Path analyses with data on loneliness as a concept that is related to social support were used afterwards as a check for the results from path analyses with social support.

\section{Results}

\section{Respondents}

Patient characteristics, disease characteristics, functional health status, coping, social support, loneliness, and subjective well-being of the respondents are described in table 1. Table 1 shows that respondents in the study population were significantly younger, less often single, and more often male compared to respondents who were not included in the study because of too many missing values on the variables pain, weariness, functional health status, social support, coping, or subjective well-being. They also had a higher level of education and a higher income, and they were less often unemployed. Patients in the study population less often had RA and OA and more often AS. Besides, in the study population there were less patients with other chronic diseases, and they were also in less intense pain. Also, patients in the study population used more action-directed coping, coping by seeking social support, and coping by awaiting / avoidance and their satisfaction with life was lower. 
Table 1 Characteristics of the respondents $(n=1307)$

Study population $(n=628)$

$53 \pm 13.80$

16.4

45.4

Male* $(\%)$

Level of education $: 1$ (\%)

- low

48.4

- medium

- high

- other

Montly family income $<€ 1182,-/ \$ 1053,-^{-}(\%)$

Unemployed" (\%)

Unemployed because of rheumatic disease (\%)

Disease Characteristics

Diagnosis" (\%)

- rheumatoid arthritis (RA)

- osteoarthritis (OA)

- ankylosing spondylitis (AS)

- combination of RA/OA/AS/other

- less common diagnoses ${ }^{2}$

Duration of disease, mean $\pm \mathrm{SD}$ (years)

Other chronic disease(s) ${ }^{*}(\%)$

Pain frequency (\%)

- never in pain

- seldom in pain

- sometimes in pain

- regularly in pain

- constantly in pain

Pain intensity $>5^{*}(1-10)^{3}(\%)$

Pain intensivity, mean

Weariness frequency (\%)

- never tired

- seldom tired

- sometimes tired

- regularly tired
50.6

9.9

19.0

8.8

12.0

$14 \pm 11.66$

57.5

0.0

2.1

13.7

47.5

36.8

47.8

5.2

0.0

3.7

23.1

53.8
Others $(n=679)$

$63 \pm 12.40$

28.4

25.5

58.8

19.9

8.5

12.8

56.7

88.7

23.7

57.4

16.2

7.0

11.0

7.9

$15 \pm 11.97$

65.6

1.1

2.1

16.1

46.7

34.0

48.3

5.5

3.6

2.5

22.7

53.2 
- constantly tired

Weariness intensity $>5(1-10)^{3}(\%)$

Weariness intensity, mean

Functional health status

Impact on functional health status, mean (0-68) ${ }^{3}$

\section{Coping}

Action-directed coping ${ }^{*}$, mean $(5-20)^{3}$

Seeking social support ${ }^{*}$, mean $(5-20)^{3}$

Awaiting / avoidance", mean (3-12) ${ }^{3}$

Social support

Lack of social support, mean $(34-136)^{3}$

\section{Loneliness}

Loneliness, mean (0-11) 3

\section{Subjective well-being}

Subjective well-being, mean $(2-14)^{3}$

Happiness (\%)

- (very) unhappy

- quite unhappy

- neither happy nor unhappy

- quite happy

- (very) happy

Happiness, mean (1-7) ${ }^{3}$

Satisfaction with life* $(\%)$

- (very) dissatisfied

- quite dissatisfied

- neither satisfied nor dissatisfied

- quite satisfied

- (very) satisfied

Satisfaction with life, mean (1-7)
19.4

46.2

5.2

13.4

13.3

10.2

6.3

45.0

9.6

4.6

9.6

23.2

33.3

29.3

4.8

4.8

8.9

21.5

30.4

34.4

4.8
18.0

45.4

5.4

14.0

12.9

9.7

6.0

45.1

9.8

7.5

7.2

23.3

28.7

33.3

4.8

5.0

6.6

16.5

32.6

39.3

5.0

SD = standard deviation

- Significant differences between both groups

${ }^{1}$ Low refers to primary school only or vocational training, medium means lower general secondary education or advanced vocational training, and high indicates higher vocational training or college/university training

${ }^{2}$ Psoriatic arthritis, juvenile chronic arthritis, adult onset M.Still, spondylarthrosis, spondylarthropathy, and diffuse idiopathic skeletal hyperostosis (DISH)

${ }^{3}$ Theoretical range 


\section{Correlations between variables}

Table 2 gives the correlations between the variables relevant to the hypothetical models. As shown in table 2, the disease characteristics that correlate significantly with subjective well-being are pain (less pain correlates with higher scores on subjective well-being), and weariness (less weariness correlates with higher scores on subjective well-being). Better functional health status correlates with higher scores on subjective well-being. More coping by action-directed behavior correlates with higher scores on subjective well-being, whereas less coping by awaiting and avoidance correlates with higher scores on subjective well-being. Moreover, table 2 indicates that more social support and less loneliness correlate with higher scores on well-being.

\section{Table 2}

Correlations between study variables $(n=505)$

\section{Well-being}

$-.34^{* *}$

1. Pain

2. Weariness

$-.39 *$

$.56 *$

\section{Functional health status}

3. Functional health status

$.43^{*} \quad-.54^{* *}-.52^{* *}$

\section{Coping}

4. Action-directed coping

5. Seeking social support

.05

6. Awaiting / avoidance

$-.22 *$

$$
-.02
$$

$$
\begin{array}{rrr}
-.02 & -.04 & .12^{*} \\
-.01 & .04 & -.01
\end{array}
$$

.06

\section{Social support}

7. Social support

\section{Loneliness}

8. Loneliness 
Relationships between social support, coping, and subjective well-being

In figures 3 to 5 , the results of the path analyses to test the three hypotheses on the relationships between social support, coping, and subjective well-being are depicted. Significant path coefficients in figures 3 to 5 are indicated with an asterisk (").

Pain and weariness as determinants of functional health status did not improve any of the hypothetical models and consequently were not entered in the final path models. Figure 3 shows the path model of the possible influence of social support on subjective well-being via coping (first hypothesis). This model did not fit the data very well ( $x^{2}=$ 121.95, $\mathrm{df}=7, \mathrm{p}=.00 ;$ RMSEA $=.16$, and AGFI $=.84$ ). Improvements to the model suggested by LISREL were an error covariance between the coping variables "action-directed coping" and "seeking social support", and a path from social support to subjective well-being. As
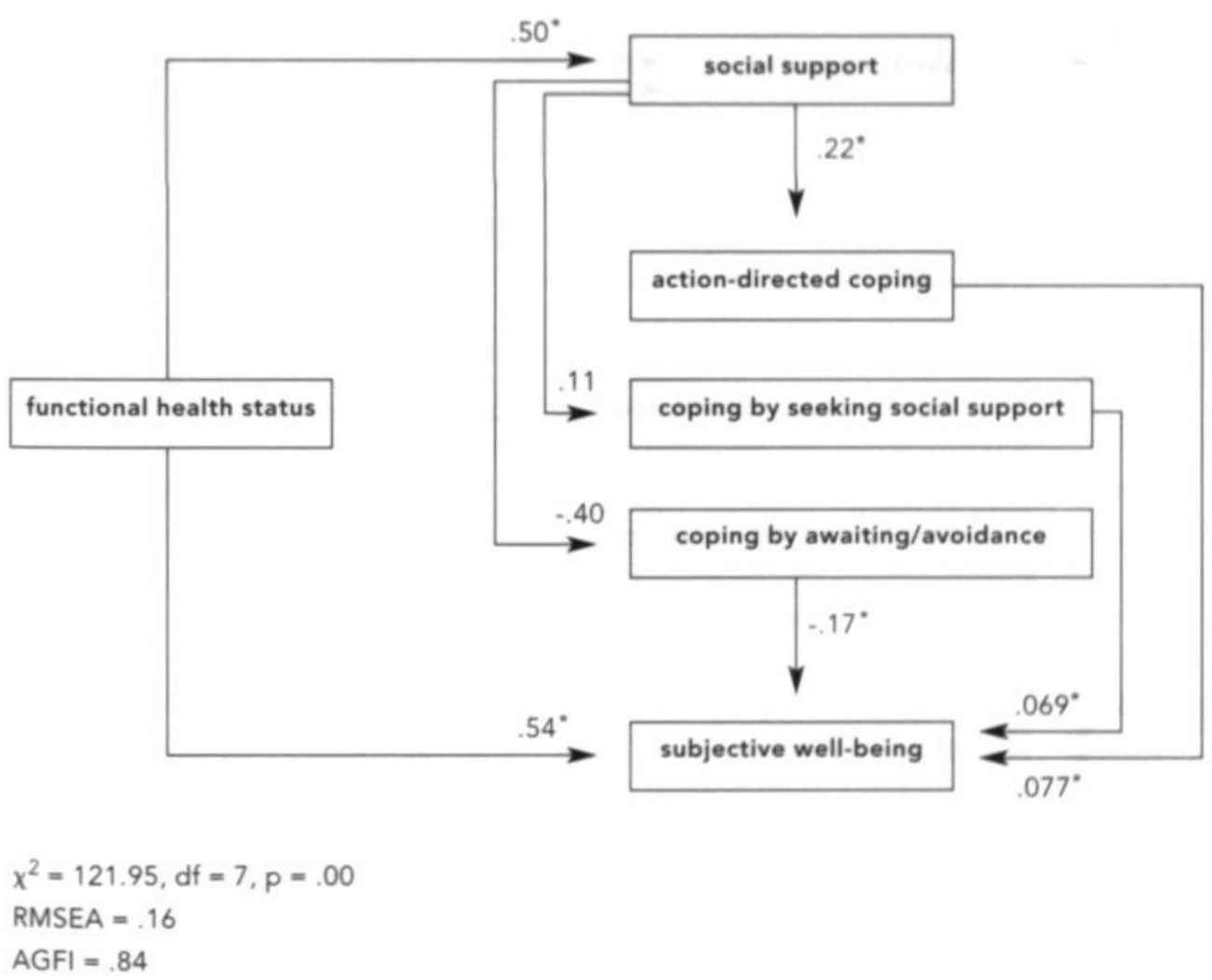

Figure 3. Path model of social support, coping and subjective well-being (first hypothesis). 
this last suggestion was not in accordance with the first hypothesis, only the inclusion of an error covariance between the coping variables was tested. Following this, however, the model still did not fit the data $\left(x^{2}=62.88\right.$, $\mathrm{df}=6, \mathrm{p}=.00 ;$ RMSEA = .12, and AGFI = .90).

Path analysis for testing the second hypothesis resulted in the best fitting model (figure 4), as was indicated by it meeting all three criteria. The Chi-square value was 5.83 with three degrees of freedom and a P-value higher than $.05(p=.12)$. Also, RMSEA was lower than .08 (.039) and
AGFI was higher than $.90(.98)$. Of all three coping strategies in the model, only coping by awaiting / avoidance influenced social support. More specifically, coping by awaiting / avoidance led to less social support. Social support, in turn, positively influenced subjective well-being. Also, functional health status positively influenced both social support and the patients' subjective well-being. The amounts of explained variance were .30 for subjective well-being, and 20 for social support.

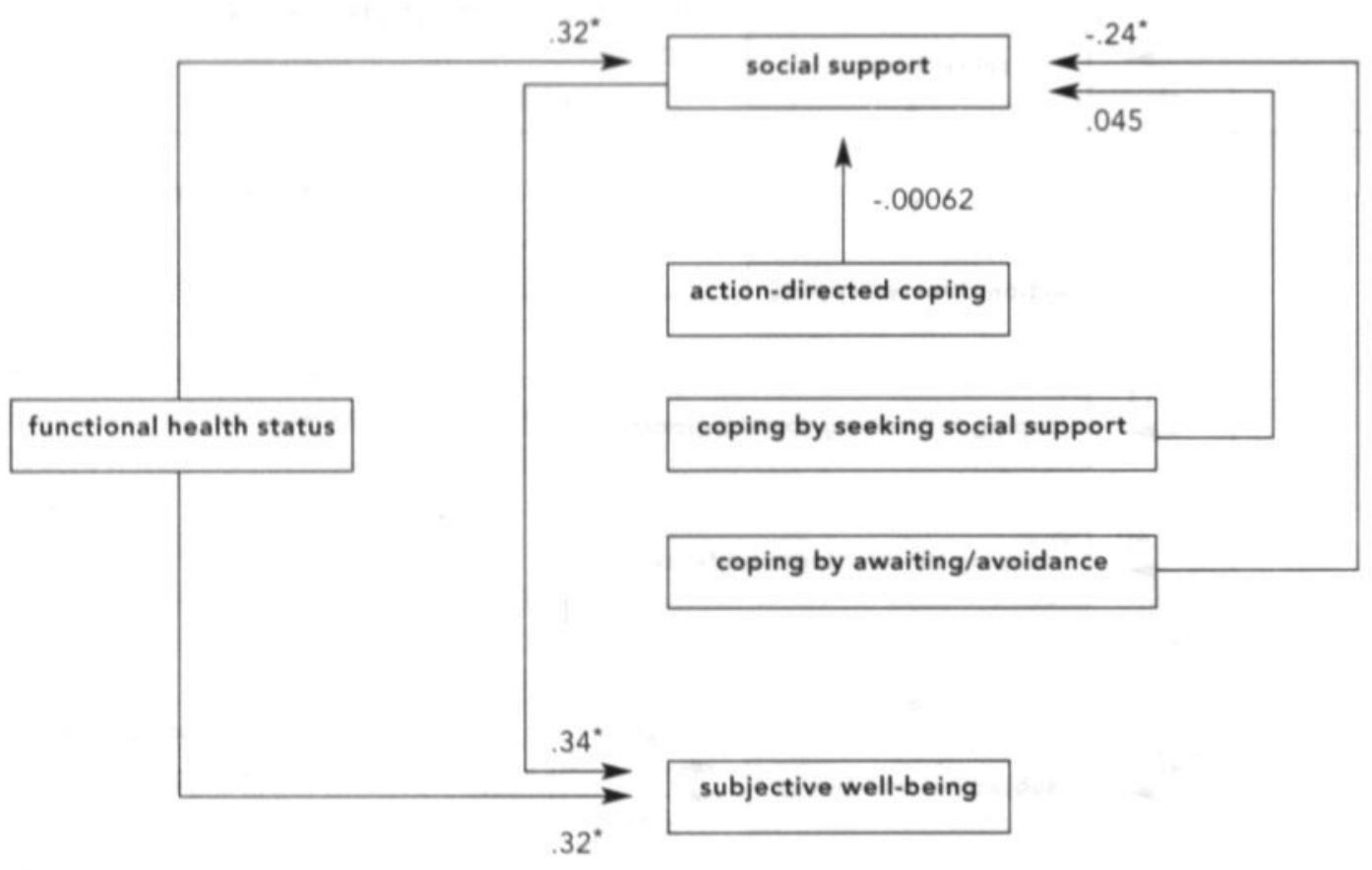

$\chi^{2}=5.83, d f=3, p=.12$

RMSEA $=.039$

$\mathrm{AGFI}=.98$

Figure 4. Path model of social support, coping and subjective well-being (second hypothesis). 
Figure 5 gives the results from the path analyses to test a reciprocal relationship between social support and coping which, in turn, influences the patients' subjective wellbeing (third hypothesis). The results show that this model is no fair representation of the data; the P-value was not higher than $.05(.00)$, RMSEA was not lower than .08 (.13), and AGFI was not higher than .90 (.89). Suggested improvements by LISREL were paths from subjective wellbeing to action-directed coping and from functional health status to action-directed coping. Because these suggestions were not in accordance with the third hypothesis, they were not tested. Suggested improvements which did not change the third hypothesis were an error covariance between action-directed coping and seeking social support and also between action-directed coping and coping by awaiting / avoidance. The model with the inclusion of an error covariance between action-directed coping and seeking social support still did not fit the data $(p=.0046$ and RMSEA $=.084)$. Adding an error covariance between action-directed coping and coping by

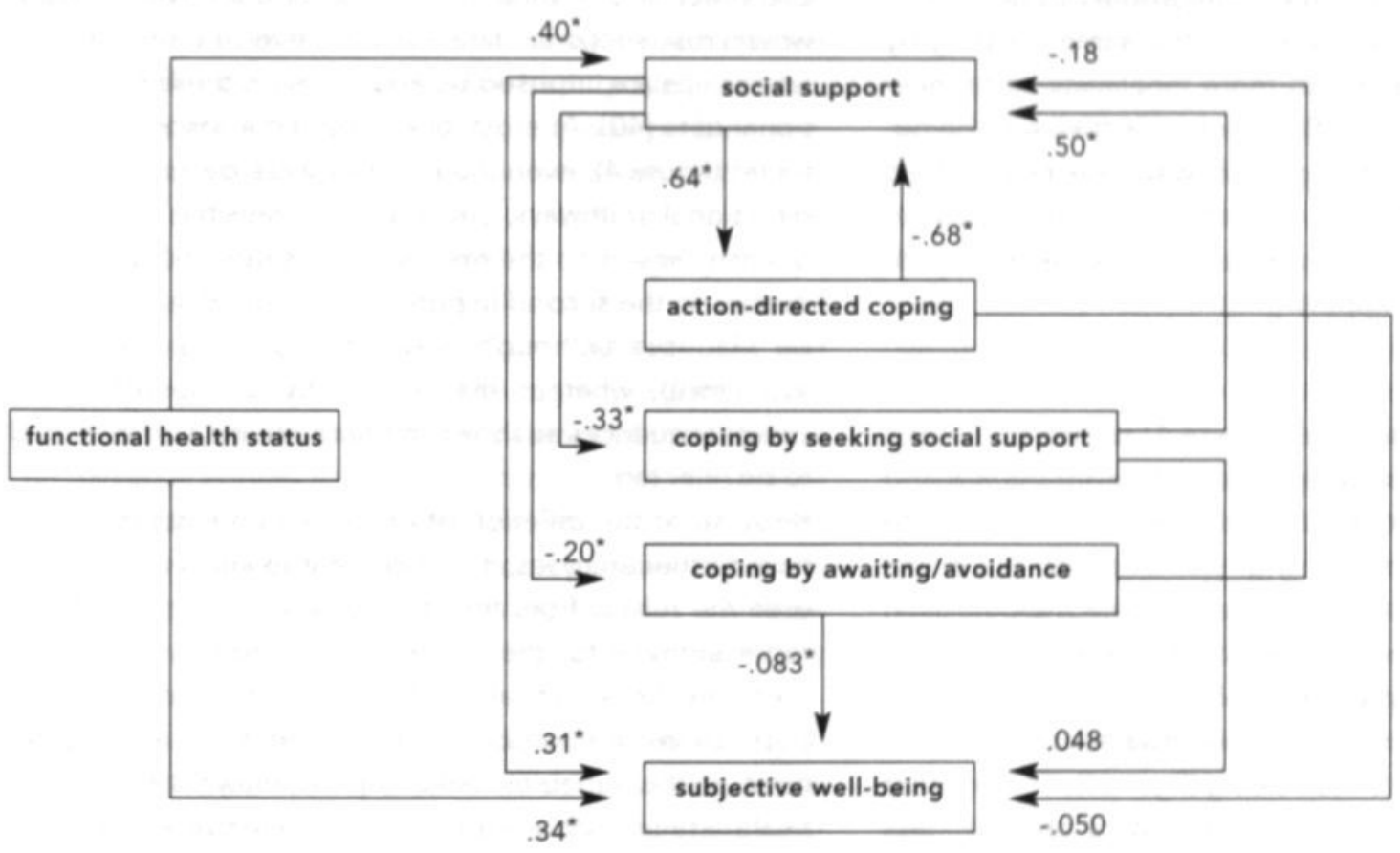

$\chi^{2}=37.19, \mathrm{df}=3, \mathrm{p}=.00$

RMSEA $=.13$

$A G F I=.89$

Figure 5. Path model of social support, coping and subjective well-being (third hypothesis). 
awaiting / avoidance led to a model that fitted the data but with only one degree of freedom left. Moreover, there were no paths from coping to subjective well-being and also no paths from coping to social support which meant that these parts of the hypothesis could not be confirmed.

Repetition of the path analyses with data on loneliness from respondents with missing values on social support (n $=219$ ), led to the same results if loneliness was conceived as the opposite of social support. The second hypothesis could be confirmed and the relationships between the concepts in this model were also the same: Coping by awaiting / avoidance led to more loneliness and loneliness, in turn, negatively influenced subjective well-being. The other two hypothetical models with loneliness instead of social support did not fit the data without changing the hypotheses. These results were also the same as in path analyses with social support.

\section{Discussion}

We tested three hypotheses (figure 1) to find an answer to the following research question: How are coping and social support related and how do these concepts relate to the subjective well-being of patients with rheumatic diseases? Confirmation was found for the hypothesis in figure 1B, though only for coping by awaiting / avoidance. The results imply that coping by awaiting / avoidance influences social support negatively which, in turn, decreases the patients' well-being (figure 4). The fact that repetition of the path analyses with data on loneliness from respondents with missing values on social support led to the same results, confirms this finding, as loneliness is a concept that is related to social support. The conclusion that can be drawn is that passive coping by a patient leads to a decrease in subjective well-being by influencing the social environment not to be supportive of that person. For action-directed coping and seeking social support, the hypothesis in figure 1B cannot be confirmed as there were no significant influences of actiondirected coping and seeking social support. This is congruent with the finding in a review on this topic [18] that it is not so much that patients who have found a balance between being able to ask for help and not being helpless benefit from more social support, but rather that bad copers do not seem able to elicit the support they need. However, causal inferences based on path analyses about the effect of one variable on another are never possible when cross-sectional data are used, even if directional relationships are imposed on and tested in these cross-sectional data [40]. At most, the within-time associations we found (figure 4), even though they were depicted as unidirectional pathways, represent a plausible causal sequence. Based on the results in our study, the causal sequence in the second hypothesis (figure 1B) appeared to be plausible (although only for coping by awaiting / avoidance), whereas the plausibility of the other two causal sequences as shown in figure $1 \mathrm{~A}$ and figure $1 \mathrm{C}$ had to be rejected.

Because of the deletion of many respondents $(n=679)$ from further analyses, it is important to know to what degree the results from the study population $(n=628)$ are representative for the whole group. Table 1 shows that there are no significant differences between the study population and respondents deleted from analyses in most of the variables used in path analyses (functional health status, social support and subjective well-being). Besides, there are only small differences in action-directed coping, coping by seeking social support, and coping by awaiting / avoidance. Consequently, there is no strong indication for the results not being representative for the whole group of respondents originally included in this study $(n=1307)$. Characteristics of the nonrespondents 
are largely unknown; only 104 of the 891 nonrespondents filled out a "nonresponse form" and as a result, the degree to which the results are representative for rheumatic patients who visit their rheumatologist regularly, is unknown. What can be deduced from the nonresponse forms is that the group of respondents contained relatively more patients with RA and AS $(54 \%$ versus $31 \%$ in the nonrespondents and $13 \%$ versus $11 \%$ in the nonrespondents, respectively), and the respondents' mean age was lower ( 58 years versus 63 years in the nonrespondents). The relative number of men and women in both groups and the mean duration of the rheumatic disease did not differ significantly between both groups.

Measuring social support and coping was problematic. The original group of 1307 respondents was decreased to 628 , mainly because of many missing values on the SSL-D (480 respondents did not fill out enough questions on the SSL-D), and on the subscales of the short version of the Utrecht Coping Questionnaire (between 224 and 266 respondents did not fill out enough questions on the subscales). Also, the internal consistency of the subscale on palliative coping from the short version of the Utrecht Coping Questionnaire was very low. The fact that we did not find any correlation between coping by seeking social support and social support may imply that this questionnaire was not very valid for measuring coping in our study population.

In considering determinants of subjective well-being in people with rheumatic and other chronic diseases, a multitude of influences may be relevant. We included functional health status as a determinant of subjective wellbeing as the study concerns patients with a chronic disease. Indeed, support was found for functional health status as a determinant of subjective well-being in our study population (figure 4). Similar results have been found in a study in which respondents were patients with RA [41].
These findings point to the necessity of addressing disease-related factors when dealing with determinants of well-being in a chronic illness population.

Based on the results of this study, an intervention aimed at teaching patients with rheumatic diseases not to avoid problems seems to be appropriate. It seems reasonable that in this intervention patients should learn to use more active ways of dealing with their problems, although in this study active coping did not influence social support. If the effects of such an intervention were evaluated in an experimental study, the results could contribute to the knowledge about causal relationships between social support, coping and well-being and future interventions could be adapted accordingly. To test the causality of the relationships between coping, social support and subjective well-being found in this study (figure 4), an observational study, even if it is prospective, would not be sufficient; actively manipulating coping as a variable in an experimental study would be more useful in this respect. The experimental study should concentrate on the effects on social support of an intervention aimed at teaching people with rheumatic diseases not to cope by avoiding problems. The analyses should focus on the causal relationships between coping, social support and subjective well-being for which we found indications in this study and also address disease-related factors.

\section{References}

[1] Gibson T, Clark B. Use of simple analgesics in rheumatoid arthritis. Ann Rheum Dis 1985;44:27-9.

[2] Cornelissen PGJ, Rasker JJ, Valkenburg H. The arthritis sufferer and the community: A comparison of arthritis sufferers in rural and urban areas. Ann Rheum Dis 1988;47:150-6. 
[3] Anderson KO, Bradley LA, Young LD, McDaniel LK. Rheumatoid arthritis: Review of psychological factors related to etiology, effects, and treatment. Psychol Bull 1985;98:358-87.

[4] Brown GK, Wallston KA, Nicassio PM. Social support and depression in rheumatoid arthritis: A one-year prospective study. J Appl Soc Psychol 1989;19:1164-81.

[5] Doeglas D, Suurmeijer T, Krol B, Sanderman R, van Rijswijk M, van Leeuwen M. Social support, social disability, and psychological well-being in rheumatoid arthritis. Arthritis Care Res 1994;7:10-5.

[6] Fitzpatrick R, Newman S, Archer R, Shipley M. Social support, disability and depression: A longitudinal study of rheumatoid arthritis. Soc Sci Med 1991;33:605-11.

[7] Goodenow C, Reisine ST, Grady KE. Quality of social support and associated social and psychological functioning in women with rheumatoid arthritis. Health Psychol 1990;9:266-84.

[8] Newman SP, Fitzpatrick R, Lamb R, Shipley M. The origins of depressed mood in rheumatoid arthritis. J Rheumatol 1989;16:740-4.

[9] Penninx BWJH, van Tilburg T, Deeg DJH, Kriegsman DMW, Boeke AJP, van Eijk JTM. Direct and buffer effects of social support and personal coping resources in individuals with arthritis. Soc Sci Med 1997; 44:393-402.
[10] Revenson TA, Schiaffino KM, Majerovitz SD, Gibofsky A. Social support as a double-edged sword: The relation of positive and problematic support to depression among rheumatoid arthritis patients. Soc Sci Med 1991;33:807-13.

[11] Weinberger M, Tierney WM, Booher P, Hiner SL. Social support, stress and functional status in patients with osteoarthritis. Soc Sci Med 1990;30:503-8.

[12] Affleck G, Urrows S, Tennen H, Higgins P. Daily coping with pain from rheumatoid arthritis: Patterns and correlates. Pain 1992;51:221-9.

[13] Bendtsen P, Hornquist JO. Rheumatoid arthritis, coping and well-being: Cross-sectional sub-group comparisons and correlational analyses. Scand J Soc Med 1994;22:97-106.

[14] Burke M, Flaherty MJ. Coping strategies and health status of elderly arthritic women. J Adv Nurs 1993;18:7-13.

[15] Hampson SE, Glasgow RE, Zeiss AM. Coping with osteoarthritis by older adults. Arhritis Care Res 1996;9:133-41.

[16] Keefe FJ, Affleck G, Lefebvre JC, Starr K, Caldwell DS, Tennen H. Pain coping strategies and coping efficacy in rheumatoid arthritis: A daily process analysis. Pain 1997;69:35-42. 
[17] van Lankveld W, van 't Pad Bosch P, van de Putte L, Naring G, van der Staak C. Disease-specific stressors in rheumatoid arthritis: Coping and well-being. Br J Rheumatol 1994;33:1067-73.

[18] Schreurs KMG, de Ridder DTD. Integration of coping and social support perspectives: Implications for the study of adaptation to chronic diseases. Clin Psychol Rev 1997;17:89-112.

[19] Billings AG, Moos RH. The role of coping responses and social resources in attenuating the stress of life events. J Behav Med 1981;4:139-57.

[20] Holohan CJ, Moos RH, Holohan CK, Brennan PL. Social support, coping and depressive symptoms in a late-middle aged sample of patients reporting cardiac illness. Health Psychol 1995;14:152-63.

[21] Manne SL, Zautra AJ. Spouse criticism and support: Their association with coping and psychological adjustment among women with rheumatoid arthritis. J Pers Soc Psychol 1989;56:608-17.

[22] Ros WJG. Social support in cancer patients. Utrecht: Utrecht University, 1989.

[23] Smith CA, Wallston KA. Adaptation in patients with chronic rheumatoid arthritis: Application of a general model. Health Psychol 1992;11:151-62.

[24] de Ridder DTD, Schreurs K. Coping en sociale steun van chronisch zieken. [Coping and social support in people with chronic diseases] Zoetermeer: Nationale Commissie Chronisch Zieken, 1994.
[25] Parker JDA, Endler NS. Coping with coping assessment: A critical review. Eur J Pers 1992;6:321-44.

[26] Dunkel-Schetter C, Folkman S, Lazarus RS. Correlates of social support receipt. J Pers Soc Psychol 1987;53:71-80.

[27] de Witte LP, Tilli DJP, Ticheler AJG, Winants BAC, van der Horst FG, van der Linden S. Leven met een reumatische aandoening: Een onderzoek naar de ervaren kwaliteit van het leven bij 372 mensen met een reumatische aandoening. [Living with a rheumatic disease: A study into subjective well-being of 372 patients with rheumatic diseases] Hoensbroek: Instituut voor Revalidatie Vraagstukken, 1989.

[28] Huskisson EC. Visual analog scales. In: Melzack R, editor. Pain measurement and assessment. New York: Raven Press, 1983.

[29] de Bruin AF, Diederiks JPM, de Witte LP, Stevens FCJ, Philipsen $\mathrm{H}$. The development of a short generic version of the sickness impact profile. J Clin Epidemiol 1994;47:407-18.

[30] de Bruin AF, de Witte LP, Diederiks JPM. The sickness impact profile: SIP 68, a short generic version. First evaluation of the reliability and reproducibility. $\mathrm{J}$ Clin Epidemiol 1994;47:863-71.

[31] Schreurs PJG, Tellegen B, van de Willige G. Gezondheid, stress en coping: De ontwikkeling van de Utrechtse Copinglijst. [Health, stress and coping: The development of the Utrecht Coping Questionnaire] Tijdschr Psychol 1984;12:101-17. 
[32] Janssen M, Bal RM, Komproe I, Philipsen H, Furda J. Evaluatie van de 15-item versie van de Utrechtse Coping Lijst. [Evaluation of the 15-item version of the Utrecht Coping Questionnaire] Maastricht: Maastricht University, 1997.

[33] Schreurs PJG, van de Willige G, Tellegen B, Brosschot JF. De Utrechtse Coping Lijst: UCL-handleiding. [The Utrecht Coping Questionnaire: Manual] Lisse: Swets en Zeitlinger, 1988.

[34] van Sonderen E. Het meten van sociale steun met de Sociale Steun Lijst - Interacties (SSL-I) en de Sociale Steun Lijst - Discrepanties (SSL-D): Een handleiding. [Measuring social support with the Social Support List - Interactions (SSL-I) and the Social Support List - Discrepancies (SSL-D): Manual] Groningen: Noordelijk Centrum voor Gezondheidsvraagstukken, 1993.

[35] van Sonderen E, Ormel J. Het meten van aspecten van sociale steun en hun relatie met welbevinden: Een onderzoek naar de bruikbaarheid van de SSL-I en de SSL-D. [Measuring aspects of social support and their relation with well-being: A study into the feasibility of the Social Support List - Interactions (SSL-1) and the Social Support List -Discrepancies SSL-D] Gedrag en Gezondheid 1997;25:190-200.

[36] de Jong-Gierveld J, Kamphuis F. The development of a Rasch-type Loneliness Scale. Appl Psychol Measur 1985;9:289-99.
[37] Fuhrer MJ. Subjective well-being: Implications for medical rehabilitation outcomes and models of disablement. Am J Phys Med Rehabil 1994;73:358-64.

[38] Andrews FM, Withey SB. Social indicators of well-being. New York / London: Plenum, 1978.

[39] Jöreskog K, Sörbom D. LISREL 8: Structural equation modeling with the SIMPLIS command language. Chicago: Scientific Software International, 1993.

[40] Newcomb MD. What structural equation modeling can tell us about social support. In: Sarason BR, Sarason IG, Pierce GR, editors. Social support: An interactional view. New York: Wiley, 1990: 26-63.

[41] Brenner GF, Melamed BG, Panush RS. Optimism and coping as determinants of psychosocial adjustment to rheumatoid arthritis. J Clin Psychol Med Settings 1994;1:115-34. 


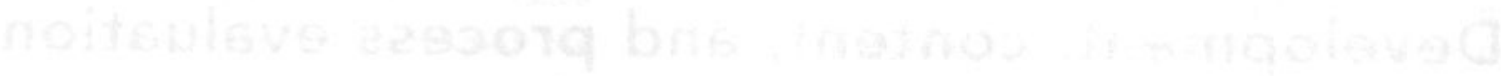

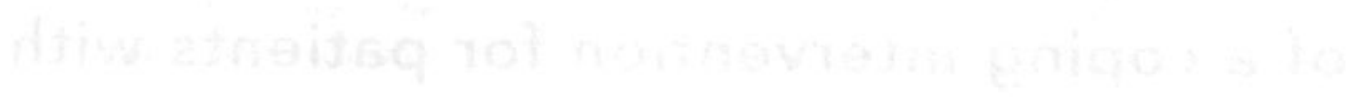




\section{4 \\ Development, content, and process evaluation of a coping intervention for patients with rheumatic diseases}

Manon Savelkoul' and Luc de Witte ${ }^{2}$

Patient Education and Counseling 2001;45:163-72

'Department of Health Education and Promotion, Maastricht University, Maastricht, The Netherlands ${ }^{2}$ Institute for Rehabilitation Research, Hoensbroek, The Netherlands 


\begin{abstract}
Rheumatic diseases, like many other chronic diseases, represent an important public health problem. To reduce the impact of rheumatic and other chronic diseases, the appropriate management of these conditions should be encouraged through the use of established educational programs.

This article describes the development and content of a coping intervention for groups of patients with rheumatic diseases aimed at increasing social support and quality of life. Patients' and supervisors' perceptions of the coping intervention as the results of a process evaluation will also be discussed. The purpose of this paper is to provide information for health educators who want to use the coping intervention with patients with rheumatic diseases or who want to develop a similar intervention for other target populations.

Results of the process evaluation show that the intervention was well received by the patients as well as the supervisors.
\end{abstract}

\section{Introduction}

The prevalence of rheumatic diseases is expected to increase worldwide with age [1-7]. Since no cure exists, rheumatic diseases like many other chronic impairments, represent an important public health problem. It is wellknown that rheumatic diseases can cause disability $[4,8$ 10]. More specifically, people with rheumatic diseases suffer from decreases in physical, social and emotional functioning and from pain [11]. Other possible effects of rheumatic diseases are fatigue [12], depression [13], and a diminished capacity to work [14].

It is obvious that people with rheumatic diseases may experience a decline in the quality of their life [15]. Nevertheless, there are indications from the literature that social support can have a positive impact on quality of life $[16,17]$. Social support, in turn, can be increased by active coping as opposed to passive coping (avoidance) [18-21]. Active coping means managing a stressful situation by dealing with the problem itself (active problemfocused coping), or by changing the meaning of a problem (active emotion-focused coping) $[22,23]$. Active problemfocused coping includes action-directed coping (solving a problem in a systematic purposeful way [24]), and coping by seeking social support [21]. Examples of active emotion-focused coping are positive reappraisal, cognitive restructuring, and reassuring thoughts [21]. Active coping in the form of teaching patients specific self-management skills are frequently a component of group interventions for people with rheumatic diseases [25-28]. The basic focus of these interventions is on skills in managing specific aspects of rheumatic diseases (e.g. exercise, joint protection); they are not explicitly devoted to teaching patients a method to cope actively with whatever problem they may encounter, and coping as a variable is seldom measured. In the intervention described in this article, in contrast to other group interventions in the field, patients are stimulated to action-directed coping and coping by seeking social support by teaching them a method in systematic problem solving (i.e. action-directed coping) and to find solutions for problems by seeking social support (i.e. coping by seeking social support). Social support is explained to the patients as emotional support, practical help, as well as information from other people [20]. Later in the intervention, patients are also stimulated to find other solutions in the realm of active coping (e.g. positive reappraisal). In sum, patients are being taught skills to determine what their individual problems are and how to go about solving these. Similar problemsolving therapies have been applied for the treatment of depression and helping cancer patients cope [29-32]. In fact, there is an example of a problem-solving interven- 
tion for patients with arthritis [33], but this was not a group intervention and patients were not extensively trained in applying a systematic method for problem solving.

A randomized controlled trial of the coping intervention described in this article showed that immediately after the intervention, it increased action-directed coping and the functional health status of the patients. In patients who had attended at least five of the ten sessions, the coping intervention also contributed to decreased loneliness right after the intervention and improvements in social interactions and life satisfaction at six-months followup [34].

This article describes the development and content of the coping intervention and patients' and supervisors' perceptions of the coping intervention in terms of the results of a process evaluation. The article concludes with some practical implications. Most of the intervention studies among people with rheumatic diseases do not report extensively on the development and content of the interventions. Moreover, the patients' and supervisors' perceptions of different aspects of the interventions are hardly ever described. The potential usefulness of patient education, however, increases with the growing prevalence of chronic disease. To reduce the impact of rheumatic and other chronic diseases, the appropriate management of these impairments through the use of established educational programs should be encouraged [14]. The purpose of this paper is to provide information for health educators who want to use the coping intervention with patients with rheumatic diseases or who want to develop a similar intervention for other target populations.

\section{Development of the coping intervention}

The five steps in developing the coping intervention and the corresponding results are given in figure 1 and will be described below.

\section{Expert meeting}

A national expert meeting was organized to determine the conditions for the content and design of the coping intervention. People were invited who had research and/or practical experience in the field of supporting patients with rheumatic or other chronic diseases. The aim was to gather information concerning current scientific and practical insights. This took place in the form of presentations and group discussions which are documented in a report [35]. In total, 21 people participated. The goals which were laid down for the content and structure of the coping intervention are given in figure 1.

\section{Literature study}

A literature study was carried out on the determinants of action-directed coping and seeking social support and on methods to influence this behavior and the behavioral determinants (figure 1). The purpose of this literature study was to create a base to fill in the content and methods used in the intervention.

The determinants of action-directed coping and seeking social support are the self-efficacy of the patient (the extent to which the patient thinks that he or she will manage to actually carry out the behavior) [19], problem-solving skills and social skills [36].

"Modeling with guided enactment" [37] is a method for increasing self-efficacy, learning skills, and changing the behavior (coping). It consists of the following: (1) complex skills are divided into sub-skills; (2) one observes the behavior being acted out ("modeling"); (3) one first practices the behavior in simple situations with supervision 


\section{Expert meeting}

\section{Content of the coping intervention}

- First session aimed at getting to know one another

- Action-directed coping and seeking social support

- Becoming aware of one's own social situation

- Insight into the possibilities of social support

- Learning to talk about the disease

\section{Structure of the coping intervention}

- Maximum 10 participants per group with two supervisors

- Ten sessions of two hours with a limited number of subjects

- Active participation

- Methods: role plays, homework assignments and modeling

- Phases: motivation, behavioral change, maintaining behavior

- Implementable in outpatient hospital care

\section{Literature study}

Behavior: active coping

Determinants: self-efficacy, problem-solving and social skills

\section{Methods for behavioral change}

- Modeling with guided enactment

- Goal setting and agreements on implementing behavior

- Prompts

\section{Methods for maintaining behavior}

- Attribution and reattribution

- Learning to recognize and deal with risk situations

- Repeat session

\section{Developing the draft versions of the instruction book and the course book}
Action-directed coping (step 1-4)
1. Describe a problem
Seeking social support (step 2a)
2. Think of different solutions
a) In the area of seeking social support
b) Also solutions in other areas
3. Choose one or more solutions
4. Implement a solution and evaluate the results

\section{Reference group}

Adaptations in the draft versions of the instruction book and the course book (preparing the coping intervention for the pilot test)

Supervision by a therapist experienced in behavioral therapy and a nurse or social worker experienced in rheumatology Hospital setting

\section{Pilot test}

Adapting the instruction book and course book

Figure 1. Development of the coping intervention. 
("guided enactment") and with feedback (e.g. in role plays); (4) then one practices in difficult situations (e.g. at home) under supervision and with feedback. Setting challenging, realistic goals ("goal setting") can also help achieve the intended behavioral change [38]. In addition, an agreement can be reached concerning carrying out the behavior in order to reach the behavioral change desired [39]. Furthermore, the behavior desired can be encouraged by reminders at the right moment and at the right place of one's intentions ("prompts") [40]. In the literature, the methods described for maintaining the behavior are: making sure that people do not attribute a possible failure in maintaining the behavior to themselves alone, but also to the situation in which they are at that moment ("attribution and reattribution") [41]; learning to recognize situations in which the temptation not to carry out the behavior is large ("risk situations"); and learning to deal with these risk situations [42]. It is recommended that attention is paid to the latter in refresher sessions. Refresher sessions are also of importance in order to analyze difficulties which arise when carrying out the behavior [43],

\section{The development of a draft version of the instruction book and the course book}

A draft version of the instruction book for the coping intervention contained the following methods: "modeling with guided enactment"; "goal setting" with these goals made known to the group and with supervisors providing reminders of these goals ("prompts"); and the aforementioned methods for maintaining the behavior. The conditions mentioned during the expert meeting were also taken into account.

It was decided that the instruction book should be structured according to four steps for solving problems which are based on D'Zurilla and Goldfried's steps in problem solving [44]. The four steps are (figure 1): (1) describe a problem in your own words; (2) think about all kinds of possible solutions, especially in the area of seeking social support (talking to someone to learn more about the situation, talking to someone who can do something concrete about the situation, talking to someone about how you feel, sharing your worries with someone); (3) choose one or more solutions most acceptable to you; (4) implement a solution and evaluate the results of this implementation.

A course book for the patients was also developed. This contains the agenda for each session, important information which is explained by the supervisors during the coping intervention, and space for making notes during the sessions and for homework assignments.

\section{Reference group}

The draft versions of the instruction book and the course book were further adapted using a reference group. The majority of the members of the reference group were people who would use the coping intervention in practice. This was in order to focus attention on the intended implementation of the coping intervention. The reference group consisted of two social workers, a nurse who was specialized in rheumatology, two patients with rheumatic diseases, two psychologists, a psychotherapist, a rheumatologist and a nurse specializing in home care for patients with rheumatic diseases. There were three sessions in total. In the reference group, the following two supervisors were chosen to lead the coping intervention groups: a therapist experienced in behavioral therapy and a nurse who was specialized in rheumatology or a social worker experienced in rheumatology. The therapist was supposed to follow the agenda for each session. The nurse or social worker was chosen to participate as a cofacilitator who was supposed to observe during the sessions, 
support the therapist and keep in touch with people who were absent. As the coping intervention is intended for outpatient care within a hospital (figure 1: results of the expert meeting), the nurse or social worker chosen worked in a hospital. For the same reason, it was decided that the coping intervention should take place in the hospital during the study.

\section{Pilot test}

Before an evaluation of the effect and process of the coping intervention on a larger scale, a pilot test of the coping intervention was carried out. For the pilot test, the coping intervention was taken by 12 patients with rheumatic diseases. Data for this pilot test were obtained by evaluations with the participants directly after each session, an evaluation of each session held by the supervisors (a behavioral therapist and the researcher), and a questionnaire filled out by the participants after the end of the intervention. As a result of the pilot test, the instruction book and the course book were modified and made clearer.

\section{Content of the coping intervention}

The content of the final version of the instruction book is summarized in figure 2 . There are 10 sessions of two hours each. The first sessions are geared towards becoming aware of the social situation, learning to recognize possible sources of social support and desired changes in social support which are described by the patients in their course book. Attention is also paid to learning to explain

\section{Session: Goal:}

1

2

3

4

$5,6,7,8$

9

Figure 2. Content of the coping intervention: goals per session.

- Getting to know one another

- Explaining about rheumatic diseases

- Listing risk situations
- Information about the coping intervention

- Becoming aware of your own social situation and possible sources of social support

- Clarifying desired changes in social support

- Becoming aware of different ways of solving problems

- Introduction to four steps for solving problems

- Practicing the four steps for solving problems

- Discussing the application of problem solving in the previous two weeks

- Repeating the most important issues which have arisen

- Discussing the application of problem solving in the previous three weeks 
what it means to have a rheumatic disease in order to effectively use sources of social support. This takes place by following a set of instructions (figure 3 ) and is practiced using role plays in the group and then put into practice at home. From session 4, the coping intervention is aimed at learning the coping strategies "action-directed coping" and "coping by seeking social support". The steps for solving problems (figure 1) are presented and as far as the second step is concerned, the emphasis is initially on "seeking social support" (step 2a). In order to introduce this topic, the issue of becoming aware of different ways of solving problems is first dealt with. The supervisors emphasize the advantages of active coping and the disadvantages of avoiding the problem. From session 5 , the participants go through the steps at their own pace. Applying the steps to solving problems partly takes place at home through preparatory exercises and partly in the group in which everyone actively helps. The solutions that are chosen in the second step serve as goals which the participants set for themselves and make known to the group. A solution could include a desired change in social support which was raised in the first part of the coping intervention (e.g. if someone wants more support from a family member, during this step, it can be seen whether this family member can help solve the problem). Before solving the problem in reality (step 4), this can be practiced in the group as a role play in which feedback is given by supervisors and fellow participants. From session 8, other solutions in the realm of active coping, besides seeking social support, are sought (step $2 \mathrm{~b}$ in figure 1). In sessions 9 and 10, the application of problem solving since the last session is discussed. Besides this, in session 9, the most important issues are repeated and in session 10, attention is paid to risk situations. To prevent

\section{Tips for explaining about rheumatic diseases to people in your social circle}

- Don't talk about your illness indiscriminately:

- Choose the right place

- Choose the right person

- Choose the right moment

- Don't complain or moan but:

- Discuss the characteristics of rheumatic diseases which are important for your contacts with people in your social circle (pain, rheumatic diseases are not always visible, variable course of the disease, uncertain future), and the consequences of these for your contacts with people (arrangements which have to be canceled, people who don't understand this; feeling better from one moment to the next, people who don't understand this and don't take you seriously)

Figure 3. Tips for explaining about rheumatic disease. 
relapse, the time between sessions 8 and 9 , and that between 9 and 10 is two and three weeks, respectively. The first eight sessions are weekly sessions.

\section{Process evaluation}

\section{Methods}

\section{Participants}

Fifty-six patients who were randomly assigned to the coping intervention took part in an effect evaluation (randomized controlled trial). The procedure of recruitment of these 56 patients from the outpatient rheumatology clinics of two regional hospitals is described elsewhere [34]. The attendance rate was five or more sessions for a majority (66\%) of these patients. The mean attendance was six sessions. Six patients visited no sessions at all as they dropped out before the coping intervention started, because of illness, psychological problems, and problems with transportation. Consequently, 50 patients participated in the process evaluation. The left-hand column of table 1 shows the characteristics of these patients. Also, the supervisors of all five coping intervention groups participated in the process evaluation. These were five therapists experienced in behavioral therapy and five cofacilitators (three nurses and two social workers, all experienced in rheumatology).

\section{Measures}

To identify possible improvements in the intervention under study, group evaluations were conducted with the patients after every session of the coping intervention as well as a questionnaire patients were supposed to fill out after participating in the coping intervention. Group evaluations with the patients were open discussions led by the supervisors, which were focused on patients' opinions about the content and structure of the session in question. These were recorded by the supervisors, who stressed the importance of giving an honest opinion. The questionnaire consisted of 41 questions ( 33 multiple choice and 8 open-ended questions), eliciting the patients' opinions about the content of the coping intervention, the supervisors, the intervention structure, group composition, and the course book.

In addition, several measures have been used to collect suggestions for improvements from the supervisors, and also to check if the intervention was executed in accordance with the predetermined program. First of all, supervisors were asked after every session to write down in the instruction book their answers to the questions: "Did you reach the goal of this session?" and "Which of the issues raised by the participants during this session are important in the light of the coping intervention?". Secondly, notes were made by the researcher during telephone interviews after every session with one of the supervisors of every group to discuss any problems in executing the intervention. Lastly, the researcher discussed the program in detail during meetings with all supervisors, which took place halfway and at the end of the coping intervention and recorded their opinions.

\section{Data analysis}

The statistical package for the social sciences (SPSS) has been used for computing percentages of patients who chose any given possible answer in reply to multiple choice questions in the questionnaire. In the case of questions on appreciation of supervisors and intervention content on a scale of 1-10, means were computed with SPSS. SPSS was also used to compare patients who did and did not fill out the questionnaire for age, disease duration, social support, and functional health status by using t-tests, for income and level of education by using MannWhitney $U$ tests, and with regard to gender, marital status, and diagnosis by using Chi-square tests. 


\section{Table 1}

Patient characteristics of the coping intervention group and of patients in this group who filled out the questionnaire for the process evaluation

\section{Coping intervention group \\ ( $n=50$ )}

\section{Age, mean \pm SD (years)}

Male (\%)

Single (\%)

Monthly family income < $€ 1591,-$ / \$ 1417,- (\%)

Level of education ${ }^{2}(\%)$

- low

- medium

- high

Diagnosis (\%)

- rheumatoid arthritis (RA)

- osteoarthritis (OA)

- ankylosing spondylitis (AS)

- less common diagnoses ${ }^{3}$

- combination of RA/OA, OA/other

Duration of disease, mean \pm SD (years)

Social support, mean \pm SD (years)

- positive social interactions (34-136 ${ }^{4}$

- negative social interactions $(7-28)^{4}$

- Ioneliness (0-11) 4

Impact on functional health status,

mean \pm SD $(0-68)^{4}$
$51.7 \pm 8.39(37-65)^{1}$

24.0

14.3

71.1

48.8

39.5

11.6

60.0

4.0

16.0

14.0

7.2

$13.0 \pm 11.26(1.2-49.0)^{1}$

$72.7 \pm 14.49$

$10.1 \pm 3.31$

$4.3 \pm 3.91$

$16.9 \pm 7.05$
Patients who filled out the questionnaire $(n=36)$

$52.1 \pm 7.85(37-64)^{1}$

27.8

17.1

72.7

43.3

46.7

10.0

52.8

5.6

16.7

16.7

8.4

$12.9 \pm 12.33(1.2-49.0)^{1}$

$72.4 \pm 14.84$

$10.1 \pm 3.59$

$3.9 \pm 3.89$

$16.7 \pm 7.57$

SD = standard deviation

${ }^{1}$ Minimum-maximum

${ }^{2}$ Low refers to primary school only or vocational training, medium means lower general secondary education or advanced vocational training, and high indicates higher vocational training or college/university training

${ }^{3}$ Psoriatic arthritis, juvenile chronic arthritis, adult onset M.Still, spondylarthrosis, spondylarthropathy, and diffuse idiopathic skeletal hyperostosis (DISH)

${ }^{4}$ Theoretical range 
The answers given in response to open-ended questions of the questionnaire were collected, interpreted, and divided into categories before the categories were described. The same procedure has been followed in analyzing all data provided by the supervisors.

\section{Patients' perceptions of the coping intervention as in- dicated in the questionnaire}

Of all 56 patients who were assigned to the coping intervention, 36 patients filled out the questionnaire for the process evaluation. The characteristics of these patients are described in the right-hand column of table 1. There were no significant differences between patients who filled out the questionnaire and patients who did not in age, gender, marital status, income, level of education, diagnosis, disease duration, social support, and functional health status. None of the 36 patients who filled out the questionnaire attended fewer than two sessions of the coping intervention. The majority of the patients $(63.9 \%)$ attended nine or all ten sessions. Most $(n=12)$ of the 14 patients who attended at least one session and who did not fill out the questionnaire attended fewer than five sessions.

\section{Content}

On a scale of 1-10, the patients evaluated the intervention as 7.6. In general, sessions 5-10 were evaluated as being slightly more useful than the first sessions ( figure 4) because, according to the patients, during these sessions the patients learned to use the four steps in problem solving, their problems were considered thoroughly, and solutions were found. The fourth session was chosen as being the least useful session (figure 4). A large part of this session is dedicated to the introduction of the steps in problem solving. Some patients indicated that they did not like the lack of interaction during this session. The mutual support of the patients was mentioned frequently as the most valuable aspect of the intervention. Also, the supervisors were frequently reported as being the aspect which was most valued (figure 4).

Table 2 gives information on patients' perceptions of what they learned during the coping intervention.

\section{Supervisors}

Almost all $(97.1 \%)$ patients thought the supervisors guided the conversations well. Moreover, all patients felt that they always had the opportunity to ask any question they wanted, that the cooperation between the supervisors was (very) good, that the supervisors gave the impression of being motivated, that they could share their opinions with the supervisors, and that the supervisors showed an interest in the group (figure 4). The patients rated the supervisors' performance as 8.9 on a scale of 1-10.

\section{Intervention structure}

Most patients (85.3\%) found the number of sessions sufficient. Also, the majority of the patients $(82.4 \%)$ thought the frequency of the first eight sessions (once in a week) was good. The two-week interval between the eighth and ninth session was too long according to $30.3 \%$ of the patients. The three-week interval between the last two sessions was too long according to even more patients (45.5\%). The sessions lasted two hours and $91.4 \%$ of the patients perceived this as sufficient. Sessions took place in the evenings (7.30-9.30 p.m.) and this was experienced as the right time by $88.6 \%$ of the patients (figure 4 ). 


\section{Positive aspects}

\section{Content}

Supervisors

Intervention structure

Course book

Sessions 5-10:

Mutual support

Attitude

Time of sessions

Group composition working with steps in problem solving

Method of supervising

Atmosphere created

Cooperation between supervisors

Supplementary disciplines

Number of sessions

Duration of each session

Group size (8-10 patients)
Negative aspects

\section{Session 4:}

method of introducing steps in problem solving
Time period between last three sessions

Too much variety in disease duration, age Inequality in gender distribution

Demotivated patients (long disease duration)

Not much used

Figure 4. Patients' and supervisors' perceptions of the coping intervention.

\section{Table 2}

Patients' perceptions of what they learned during the coping intervention $(n=36)$

\section{Skills}

Solve problems well

Share problems with others

How to ask for support

Generating many possible solutions for problems

Awareness of importance of seeking social support

Awareness of different sources of social support

How to describe problems in own words

Useful ways to deal with rheumatic disease
Acquired by patients (\%)

\section{2}

65.7

68.6

71.4

71.5

71.5

75.8

91.4 


\section{Group composition}

The group size varied from 10 to 12 participants, but because of dropouts, most groups were actually smaller (810 patients). The majority $(79.4 \%)$ of the patients indicated that this group size was just right.

The five intervention groups were composed of the patients described in the left-hand column of table 1, who were all randomly assigned to one of the five intervention groups and participated in at least one session. Most patients $(62.9 \%)$ indicated that they liked their group the way it was, but $37.1 \%$ did not like the composition of their group. Some of these patients indicated that there was too much variety in disease duration and they did not like the inequality in gender distribution. In addition, some patients thought the age differences were too great (figure 4). However, $91.7 \%$ of the patients felt at ease or very much at ease in their group and also $91.7 \%$ of the patients felt supported or very much supported by their group. Also, the majority of the patients $(86.2 \%)$ felt comfortable enough in their group to share their emotions.

\section{Course book for the patients}

Most patients (73.6\%) thought it was (very) useful to have a course book. The majority $(73.6 \%)$ of the patients thought it was an easy-reference course book and all patients indicated that there was enough room to make notes and that the information about the content of the coping intervention which was given in the course book was (very) clear (figure 4).

\section{Patients' perceptions of the coping intervention as indicated during group evaluations}

The group evaluations with the patients showed that the patients, in general, thought the sessions to be pleasant, interesting, useful, informative, supportive, and very instructive. Learning to work with the four steps for solving problems was mainly evaluated positively ("a workable method"), and patients indicated that they used the steps in their everyday life. However, a few patients said they felt problems were being forced on them (ordered to describe a problem while they were not aware of any particular problem that needed to be solved). Other patients criticized the four steps they were taught by emphasizing that some problems cannot be solved. Some patients felt resistance to describing problems and dealing with them during the coping intervention, including to solving them by seeking social support.

Some patients thought the intervention was most useful for patients who had only recently been diagnosed with a rheumatic disease and not so useful for patients with a longer disease duration. Other patients indicated that they thought the intervention was more useful for the more disabled patients. Also, some patients regarded the intervention as being more useful for the lonelier patients.

The problems discussed during the coping intervention were very diverse and the patients said it was useful and instructive to discuss their own and other patients' problems. Several patients indicated that their assertiveness and self-confidence had grown and that they had become more active in dealing with problems. Patients also said that they had learned to look at things differently and that they had realized that alterations could be made.

\section{Supervisors' opinions of the coping intervention}

\section{Supervisors' notes in the instruction book}

In general, the supervisors indicated that the coping intervention was well received by the patients and that the patients participated well. During the coping intervention, supervisors noticed patients becoming more and more conscious of their situation. They also saw a lot of 
emotional reactions from patients, followed by support from other patients. Not only emotional support, but also the exchange of information was common during the sessions. Patients gave the impression of enjoying listening to each other's stories and being in need of mutual support. Supervisors had the impression that patients learned a lot from each other and in one group, supervisors indicated that the fact that patients were in different phases of dealing with their disease was helpful in this.

Resistance to recognizing a problem as a "problem" was seen in different groups by the supervisors, especially at the start of discussing problems patients had to describe and solve. Additionally, some resistance towards discussing social support and seeking social support was seen by supervisors. However, the resistance to handling problems by using the four steps in problem solving in the group and at home disappeared during the intervention in almost all patients as was indicated by the supervisors. Besides, supervisors saw patients getting more and more skillful in using the four steps in solving problems. Some supervisors remarked that the way patients were taught the four steps in solving problems in session 4 was too teacher-centered (not enough interaction with the group), which was not appropriate for some patients and was not appreciated by the supervisors either.

All supervisors valued working together with another supervisor with a different area of expertise (in behavioral therapy and rheumatology, respectively). This was experienced as very complementary and pleasant (figure 4).

\section{Telephone interviews}

The telephone interviews with the supervisors yielded information that was also reported in the supervisors' notes in the instruction book and/or during group sessions with the supervisors (see next paragraph).

\section{Group sessions with the supervisors}

In general, supervisors indicated that they were able to reach the goal of every session. Teaching patients actiondirected coping and coping by seeking social support were recognized as being important by the supervisors. Supervisors stressed the importance of selecting motivated patients for the coping intervention. Nevertheless, supervisors reported that some unmotivated and reluctant patients seemed to benefit from the intervention. Some supervisors, like some patients described above, thought the intervention to be most useful for patients who had only recently been diagnosed with a rheumatic disease, and not so useful for patients with a longer disease duration. The reason for this, according to the supervisors, was that these patients had solved most of their problems and reached satisfying levels of social support.

Supervisors noticed that some patients did not use the course book (figure 4) or do their homework (no time, did not feel like it, too difficult), although most patients participated actively during the group sessions.

\section{Discussion}

An important conclusion is that the patients and the supervisors were pleased with the content of the intervention. The last five sessions were evaluated by the patients as being slightly more useful than the first sessions, possibly because in the last sessions concrete action took place. Attendance is an objective way of finding out whether participants respond favorably to an intervention, and in this study the attendance rate was rather good $166 \%$ of the patients attended at least five sessions and the mean attendance was six sessions), especially when taking into account that participants were all chronic patients.

Another important finding is that supervisors, group interactions and group composition were a significant part of the intervention. The patients and supervisors obvi- 
ously were very satisfied with the supervision by a therapist experienced in behavioral therapy and a nurse or a social worker specialized in rheumatology. Guiding the conversations well, openness, good cooperation between supervisors, enthusiasm, and empathy, were indicated by the patients as supervisors' qualities. Empathy and acceptance, in fact, are very important for positive changes $[45,46]$, and supervisors selected because of their warmth, empathy, and enthusiasm were perceived positively also by patients with rheumatoid arthritis in another group intervention [47]. Mutual support was valued very much by many patients, although this was not an explicitly planned part of the intervention. This same result was found in other group interventions for patients with chronic [48] and rheumatic diseases $[25,49]$. Other studies on group interventions for patients with rheumatic diseases found potentially negative aspects of the group process in that patients were threatened by the fear of meeting others affected with more severe disease than they had $[47,50]$. Although some patients did not like the composition of their group (e.g. inequality in disease duration, gender distribution and age), this fear was never reported by patients in our study.

Some patients, in fact most only in the beginning, were reluctant to apply the four steps in solving problems. An explanation for this avoidance may be the absence of explicit training in problem orientation; the first step in the original problem-solving model on which the coping intervention is based [44]. It aims to increase the ability to recognize problems, minimize the negative influence of immediate emotional distress on further problem solving, adopt the philosophical perspective that problems in living are commonplace and inevitable and that using a systematic approach to problem solving is an effective means of coping with them, facilitates one's expectation of successful coping, and inhibits the tendency to react impul- sively or to avoid dealing with problems [51]. In fact, in treatment of unipolar depression inclusion of training in problem orientation added to the levels of confidence regarding problem-solving ability and perceptions of higher personal control [31].

Different methods were used in this study to reach the conclusions described above. The questionnaire which was filled out by the patients provides us with especially indicative results of the patients' perceptions, because these results are not influenced by other patients, supervisors or the researchers as the questionnaire was filled out anonymously. There were no significant differences in patient characteristics between participants in the coping intervention who filled out this questionnaire and participants who did not. However, most $(n=12)$ of the 14 patients who attended at least one session and who did not fill out the questionnaire attended fewer than five sessions, which may be related to dissatisfaction with the intervention. Evaluations in the patient groups led by the supervisors, as a supplement to the questionnaires, had the advantage that patients could relate to each other's comments. Chances are low that a desire to please on the part of the patients had an influence on the results when discussing the intervention with the supervisors, as the supervisors were presented as mere executors of the coping intervention which, in fact, they were. The reasons why six patients did not participate in these group evaluations were dropout before the intervention started caused by illness, psychological problems, and problems with transportation. Obviously, these reasons are not related to their perceptions of the intervention. Supervisors' reports of perceptions may have been influenced by social desirability towards the researcher, although the researcher explicitly asked for the intervention's limitations and the importance of giving honest impressions was stressed. In general, there is a possible professional 
bias to the conclusions based on the results of the present study, which would have been prevented if the development of the intervention and the subsequent evaluation had been performed by two separate, independent parties. Keeping possible limitations in mind, this study gives a useful insight into patients' and supervisors' perceptions of the intervention and provides us with suggestions for future implementation.

As the coping intervention appears to be feasible in a hospital outpatient setting, suits the needs of rheumatic patients, was positively evaluated by both patients and supervisors, and was also effective [34], it seems to be a good intervention to implement in standard hospital outpatient services. The following, however, needs addressing in future implementation. If time and budget allow, the coping intervention may be expanded with training in problem orientation as an added first part of the problem solving skills training to decrease reluctance evident in some patients towards the application of the steps in problem solving. This extension, however, is not necessary as the reluctance disappeared in most patients during the intervention and, moreover, the intervention had positive effects on coping, functional health status, social support, and life satisfaction [34]. Also, in future implementation, patients need to be made aware of the enthusiasm they feel about helping each other (mutual support), as this may be helpful in seeking social support for themselves.

Subgroup analyses did not confirm the patients' opinion nor in the case of disease duration the supervisors' opinion - that the coping intervention would be most useful for patients with a relatively short disease duration, higher disability and more loneliness. Consequently, this does not need addressing in selecting patients for future implementation.

Supervisors stressed the importance of selecting motivated patients for the coping intervention, which also is an important aspect for future implementation. In the present study, patients agreed to participate in a randomized controlled trial, meaning they would be assigned to "an intervention in dealing with a rheumatic disease" (the coping intervention or mutual support) or a waiting list control group; patients were not specifically recruited for the coping intervention after receiving detailed information on this particular intervention. This may have increased dropout during the intervention, which may be prevented in future implementation by intake conversations with patients who are interested.

\section{Acknowledgements}

We would like to thank all patients who commented on the coping intervention for their valuable contributions. Also, we gratefully acknowledge the commitment of the supervisors, the advice of the participants in the expert meeting and the contributions of the members of the reference group.

\section{References}

[1] CDC. Arthritis prevalence and activity limitations United States, 1990. MMWR 1994;43:433-8.

[2] Lawrence RC, Helmick CG, Arnett FC, Deyo RA, Felson DT, Giannini EH, Heyse SP, Hirsch R, Hochberg MC, Hunder GG, Liang MH, Pillemer SR, Steen VD, Wolfe F. Estimates of the prevalence of arthritis and selected musculoskeletal disorders in the United States. Arthritis Rheum 1998;41:778-99.

[3] Glover J, Woollacott T. A social health atlas of Australia. Adelaide: South Australian Health Commission, 1992. 
[4] Badley EM, Wang PP. Arthritis and the aging population: Projections of arthritis prevalence in Canada 1991 to 2031. J Rheumatol 1998;25:138-44.

[5] Parker CJ, Morgan K, Dewey ME. Physical illness and disability among elderly people in England and Wales: The Medical Research Council Cognitive Function and Ageing Study. The Analysis Group. J Epidemiol Community Health 1997;51:494-501.

[6] Maas IAM, Gijsen R, Lobbezoo IE, Poos MJJC, editors. Volksgezondheid Toekomst Verkenning 1997. I De gezondheidstoestand: Een actualisering. [Future scenarios for public health 1997. I Update on the state of public health] Maarssen: Elsevier / De Tijdstroom, 1997.

[7] Badley EM, Crotty M. An international comparison of the estimated effect of the ageing of the population on the major cause of disablement, musculoskeletal disorders. J Rheumatol 1995;22:1934-40.

[8] CDC. Prevalence of disabilities and associated health conditions - United States, 1991-1992. MMWR 1994;43:730-1,737-9.

[9] Verbrugge LM, Lepkowski JM, Konkol LL. Levels of disability among U.S. adults with arthritis.

J Gerontol 1991;46:S71-83.

[10] Collins JG. Prevalence of selected chronic conditions: United States, 1990-1992. Vital Health Stat 10 1997; 194:1-89.
[11] Hill CL, Parsons J, Taylor A, Leach G. Health related quality of life in a population sample with arthritis. J Rheumatol 1999:26:2029-35.

[12] Wolfe F, Hawley DJ, Wilson K. The prevalence and meaning of fatigue in rheumatic disease.

J Rheumatol 1996;23:1407-17.

[13] DeVellis BM. Depression in rheumatological diseases. Baillieres in Rheumatol 1993;7:241-58.

[14] Callahan LF, Rao J, Boutaugh M. Arthritis and women's health: Prevalence, impact, and prevention. Am J Prev Med 1996;12:401-9.

[15] Anderson KO, Bradley LA, Young LD, McDaniel LK. Rheumatoid Arthritis: Review of psychological factors related to etiology, effects, and treatment. Psychol Bull 1985;98:358-87.

[16] Doeglas D, Suurmeijer T, Krol B, Sanderman R, van Rijswijk M, van Leeuwen M. Social support, social disability, and psychological well-being in rheumatoid arthritis. Arthritis Care Res 1994;7:10-5.

[17] Penninx BWJH, van Tilburg T, Deeg DJH, Kriegsman DMW, Boeke AJP, van Eijk JTM. Direct and buffer effects of social support and personal coping resources in individuals with arthritis. Soc Sci Med 1997;44:393-402.

[18] Ros WJG. Social support in cancer patients. Utrecht: Utrecht University, 1989. 
[19] Smith CA, Wallston KA. Adaptation in patients with chronic rheumatoid arthritis: Application of a general model. Health Psychol 1992;11:151-62.

[20] Dunkel-Schetter C, Folkman S, Lazarus RS. Correlates of social support receipt. J Pers Soc Psychol 1987;53:71-80.

[21] Savelkoul M, Post M, de Witte L, van den Borne B. Social support, coping and subjective well-being in patients with rheumatic diseases. Patient Educ Couns 2000;39:205-18.

[22] de Ridder DTD, Schreurs K. Coping en sociale steun van chronisch zieken. [Coping and social support in people with chronic diseases] Zoetermeer: Nationale Commissie Chronisch Zieken, 1994.

[23] Parker JDA, Endler NS. Coping with coping assessment: A critical review. Eur J Pers 1992;6:321-44.

[24] Schreurs PJG, van de Willige G, Tellegen B, Brosschot JF. De Utrechtse Coping Lijst: UCL-handleiding. [The Utrecht Coping Questionnaire: Manual] Lisse: Swets and Zeitlinger, 1988.

[25] Barlow JH, Barefoot J. Group education for people with arthritis. Patient Educ Couns 1996;27:257-67.

[26] Sullivan T, Allegrante JP, Peterson MGE, Kovar PA, MacKenzie CR. One-year follow-up of patients with osteoarthritis of the knee who participated in a program of supervised fitness walking and supportive patient education. Arthritis Care Res 1998;11:228-33.
[27] Lorig K, Feigenbaum P, Regan C, Ung E, Chastain RL, Holman HR. A comparison of lay-taught and professional-taught arthritis self-management courses. J Rheumatol 1986;13:763-7.

[28] Lindroth Y, Bauman A, Brooks PM, Priestley D. A 5year follow-up of a controlled trial of an arthritis education programme. Br J Rheumatol 1995;34:647. 52.

[29] Arean PA, Perri MG, Nezu AM, Schein RL, Christopher F, Joseph TX. Comparative effectiveness of social problem-solving therapy and reminiscence therapy as treatment for depression in older adults. J Consult Clin Psychol 1993;61:1003-10.

[30] Nezu AM. Efficacy of a social problem-solving therapy approach for unipolar depression. J Consult Clin Psychol 1986;54:196-202.

[31] Nezu AM, Perri MG. Social problem-solving therapy for unipolar depression: An initial dismantling study. J Consult Clin Psychol 1989;57:408-13.

[32] Nezu AM, Nezu CM, Friedman SH, Faddis S, Houts PS. Helping cancer patients cope: A problem-solving approach. Washington DC: American Psychological Association Press, 1999.

[33] DeVellis BM, Blalock SJ, Hahn PM, DeVellis RF, Hochbaum GM. Evaluation of a problem-solving intervention for patients with arthritis. Patient Educ Couns 1988;11:29-42. 
[34] Savelkoul M, de Witte LP, Candel MJJM, van der Tempel H, van den Borne B. Effects of a coping intervention on patients with rheumatic diseases: Results of a randomized controlled trial. Arthritis Care Res 2001;45:69-76.

[35] Sociale steun reumapatiënten: Verslag van een studiedag. [Social support for patients with rheumatic diseases: Report of a workshop] Hoensbroek: Coördinatiecentrum Chronisch Zieken - Limburg, 1995.

[36] Lazarus RS, Folkman S. Stress, appraisal and coping. New York: Springer, 1984.

[37] Bandura, A. Social Foundations of thought and action: A social cognitive theory. Englewood Cliffs: Prentice Hall, 1986.

[38] Locke EA, Latham GP. A theory of goal setting and task performance. Englewood Cliffs: Prentice Hall, 1990.

[39] Kiesler CA. The psychology of commitment. New York: Academic Press, 1971.

[40] Zimbardo PG, Leippe MR. The psychology of attitude change and social influence. New York: McGraw Hill, 1991.

[41] den Boer, DJ. Attribution and reattribution: An examination of the ideas underlying reattribution practice. Maastricht: Maastricht University, 1992.

[42] Marlatt GA, Gordon JR. Relapse prevention: Maintenance strategies in the treatment of addictive behaviors. New York: The Guilford Press, 1985.
[43] Flay BR, Koepke D, Thomson SJ, Sani S, Best JA, Brown KS. Six year follow-up of the first Waterloo school smoking prevention trial. Am J Public Health 1989;79:1371-6.

[44] D'Zurilla TJ, Goldfried MR. Problem solving and behavior modification. J Abnorm Psychol 1971;78:107. 26.

[45] Bury M. The sociology of chronic illness: A review of research and prospects. Sociol Health Illness 1991;13:451-68.

[46] Rogers CR. The necessary and sufficient conditions of therapeutic personality change. J Consult Psychol 1957;21:95-103.

[47] Shearn MA, Fireman BH. Stress management and mutual support groups in rheumatoid arthritis. Am J Med 1985;78:771-5.

[48] Campbell BF, Sengupta S, Santos C, Lorig KR. Balanced incomplete block design: Description, case study, and implications for practice. Health Educ Q 1995;22:201-10.

[49] Lorig K, Gonzalez VM, Laurent DD, Morgan L, Laris BA. Arthritis self-management program variations: Three studies. Arthritis Care Res 1998;11:448-54.

[50] Potts M, Brandt KD. Analysis of education-support groups for patients with rheumatoid arthritis. Patient Counsel Health Ed 1983;4:161-6.

[51] Nezu AM, Nezu CM, Perri MG. Problem-solving therapy for depression: Theory, research, and clinical guidelines. New York: Wiley, 1989 
5

\section{Effects of a coping intervention on patients with rheumatic diseases: Results of a randomized controlled trial}

Manon Savelkoul', Luc de Witte ${ }^{2}$, Math Candel ${ }^{3}$, Hille van der Tempel ${ }^{4}$, and Bart van den Borne'

Arthritis Care and Research 2001;45:69-76

'Department of Health Education and Promotion, Maastricht University, Maastricht, The Netherlands ${ }^{2}$ Institute for Rehabilitation Research, Hoensbroek, The Netherlands

${ }^{3}$ Department of Methodology and Statistics, Maastricht University, Maastricht, The Netherlands ${ }^{4}$ Department of Rheumatology, Maasland Hospital, Sittard, The Netherlands 


\section{Abstract}

The objective of the present study was to test the effects (on coping, social interactions, loneliness, functional health status, and life satisfaction) of an intervention aimed at teaching people with rheumatic diseases to cope actively with their problems.

A total of 168 patients with chronic rheumatic disorders affecting the joints were randomly assigned to a coping intervention group, a mutual support control group, or a waiting list control group. Measurements were by selfreport questionnaires.

Post-intervention measurements showed that the coping intervention increased action-directed coping and functional health status, but these effects did not persist up to six-months follow-up. In patients who attended at least half of the 10 sessions, the coping intervention contributed to decreased loneliness at post-intervention and to improvements in social interactions and life satisfaction at six-months follow-up.

Teaching patients with rheumatic diseases to cope actively with their problems had positive impacts. Consequently it is recommended that the coping intervention be incorporated into regular care. Maintenance sessions are advisable.

\section{Introduction}

Because of the far-reaching impact, variability, and duration of many forms of arthritis, it seems reasonable to teach patients a method to solve the many different problems that they may face, to gain a sense of control and confidence in their abilities to solve their problems, and to get support for themselves. In fact, there are indications that teaching patients with rheumatic diseases to cope actively with their problems may have a positive influence on their well-being. Cross-sectional and prospective studies have shown that active coping may increase social support, which in turn improves the quality of life of the patient, although the exact relationships between these variables remain unclear [1-4].

Coping can be classified according to two basic dimensions: managing the stressful situation (active coping) versus avoidance (passive coping), on the one hand, and emotion-focused coping (aimed at restraining emotions caused by the stressful situation) versus problem-focused coping (aimed at changing the cause of the stressful situation) on the other $[5,6]$. Active coping can be both emotion-focused (aimed at changing the significance of the stressor, e.g. positive reappraisal, cognitive restructuring, reassuring thoughts) and problem-focused (aimed at changing the situation that is causing the stress, e.g. action-directed coping, seeking social support). Passive coping is always emotion-focused (aimed at avoidance, e.g. wishful thinking, palliative coping) $[5,6]$.

Based on the results of previous studies [1-4], the effects of a coping intervention aimed at teaching patients active problem-focused coping in the form of action-directed coping and coping by seeking social support were investigated in a randomized controlled trial. Primary outcome measures were action-directed coping and coping by seeking social support; secondary outcome measures were positive and negative social interactions, loneliness, functional health status, and life satisfaction. The present trial compared the effects of the coping intervention with the effects in a mutual support control group and a waiting list control group. The mutual support control group was included in order to control for nonspecific treatment effects in the coping intervention. 


\section{Methods}

\section{Participants and procedure}

Over a period of three months, patients aged 18 years or older who visited the outpatient rheumatology clinics of two regional hospitals in the Netherlands received a questionnaire $(N=2792$ ). Rheumatologists indicated the patient's diagnosis on the questionnaire. Of the $1901 \mathrm{pa}-$ tients who filled out the questionnaire (68\%), 463 were selected on the basis of the following features: (1) at least one chronic rheumatic disorder affecting the joints (rheumatoid arthritis (RA), osteoarthritis (OA), ankylosing spondylitis (AS), psoriatic arthritis, juvenile chronic arthritis, systemic onset Still's disease, spondylosis, seronegative spondylarthropathy, diffuse ideopathic skeletal hyperostosis (DISH)); (2) a disease duration of more than one year; (3) age between 35 and 65 years; (4) a higher than median score of all eligible patients on impact of the rheumatic disease on functional health status; and (5) a higher than median score of all eligible patients on at least one of the following characteristics: loneliness, lack of social support, or impact of the rheumatic disease on social behavior. The selection criteria on diagnosis and age were chosen to obtain a homogeneous group of patients with respect to rheumatic disease and age. Because the first year of having a rheumatic disease can be turbulent, we selected only patients with a disease duration of more than one year. To reach the target population of our coping intervention, patients were selected with a relatively high impact of the rheumatic disease on their functional health status in general and on their social life in particular.

Of the 463 patients who were selected for the study, 430 were actually invited for participation because 15 patients had already taken part in a pilot test of the coping intervention and 18 patients indicated on the question- naire that they did not want to participate in the trial. Of the 430 patients who were invited, 428 received an invitation, as 2 patients could not be located. A total of 183 patients agreed to participate, of whom 15 withdrew from the study after randomization but before the first measurement (pre-intervention). Consequently, the final study sample consisted of 168 patients.

The study was approved by the medical ethics committees of the participating hospitals. Informed consent was obtained after the procedure had been fully explained to the patients. At no time, however, did patients receive any information on the expected outcomes of the study nor did they receive any advance information on the procedure in the coping intervention and mutual support the coping intervention and mutual support were presented as having the same goal (learning how to cope with a rheumatic disease) but differing in procedure. The supervisors of the coping intervention and mutual support did not know the expected outcomes either Furthermore, the supervisors of the coping intervention were not informed about the procedure in the mutual support control group, and vice versa. Patients did not receive incentive payment for participation. During the study, patients' current medical treatment was continued. Three credibility questions were administered at the start of the coping intervention and mutual support to ensure that the coping intervention was as credible as the mutual support control group condition. The credibility questions addressed the following topics: patients' perceptions of the logic of the program, patients' confidence regarding their likelihood of success in the program, and patients' willingness to recommend the program to others. 


\section{Study design}

Concealed randomization was performed in which patients were randomly and blindly assigned to a coping intervention group $(n=56)$, a mutual support control group ( $n=56$ ), or a waiting list control group $(n=56$ ).

Data were collected by questionnaires that were mailed to the participating patients before the start of the coping intervention and mutual support (pre-intervention), after the end of the coping intervention and mutual support (post-intervention), and again six months later (followup).

\section{Study groups}

As is described below, the procedures followed in the coping intervention and in the mutual support control group differed significantly, in that teaching patients active coping was the focus of the coping intervention, whereas no deliberate attention was paid to coping in the mutual support control group. To control for nonspecific treatment effects in the coping intervention group, the coping intervention group and the mutual support control group followed the same structure. Both the coping intervention and the mutual support took place in groups of 10-12 patients who participated in 10 sessions, supported by a manual for the patients and led by two supervisors. All sessions lasted two hours. The first eight sessions were weekly sessions, the ninth session was two weeks after the eighth session, and the tenth session was three weeks after the ninth session. Manuals detailing treatment procedures and methods of administration for the coping intervention and the mutual support were given to and discussed with the supervisors. Also, supervisors were trained in using the manuals and supervised in their adherence to the manuals. At the end of every session (except for the very last session), homework assignments were given, which were discussed and evaluat- ed in the next session. These homework assignments were described in the manual. Group sharing was encouraged during group sessions. Patients in the coping intervention and the mutual support control group met at different times and places, in order to avoid any possibility of intergroup communication.

\section{Coping intervention group}

Patients in the coping intervention group participated in an intervention aimed at increasing action-directed coping and coping by seeking social support. The exchange of information, experiences, feelings, and emotions was also important. Each group was led by a therapist experienced in behavioral therapy, who structured and directed all activities. A nurse who was specialized in rheumatology or a social worker who was experienced in rheumatology participated as a cofacilitator.

The purpose of the first part of the coping intervention was to make patients aware of all the possible sources of social support and the changes that they desired in the social support they received (goals). As the coping intervention was aimed at teaching patients action-directed coping and coping by seeking social support, the second part of the coping intervention was structured in accordance with four steps of problem solving [7], with special attention being paid to seeking social support in the second step: (1) describe the problem; (2) think about all kinds of possible solutions; (3) choose one or more solutions; and (4) implement the solution or solutions and evaluate the results. Patients were given the opportunity to pass through the four steps of problem solving at their own pace. Homework assignments contained exercises designed to help the patients apply the content of the sessions to their own lives. 


\section{Mutual support control group}

In the mutual support group the aim was to exchange information, experiences, feelings, and emotions. The sessions were led by two patients who were trained in supervising mutual support groups. Sessions were structured in accordance with instructions for designing mutual support groups formulated by the Federation of Patient and Consumer Organizations in the Netherlands (FPCN). Mutual support groups based on this structure are widely applied for chronic illness in the Netherlands. The supervisors' role was to facilitate interaction. The topics of conversation for all sessions were determined by the patients during the first session; in the fourth session, patients were given the opportunity to change the topics for the remaining sessions. Instead of discussing a new topic in the very last session, important experiences and events of the previous period were discussed. For homework assignments the patients were to think about the topic of conversation of the next session. No coping skills were trained.

\section{Waiting list control group}

Patients in the waiting list control group were not exposed to either the coping intervention or the mutual support group program during the study. After the last measurement (follow-up) had taken place, which was about nine months after the first measurement (pre-intervention), the waiting list control group was invited to participate in mutual support sessions.

\section{Measures}

Action-directed coping and coping by seeking social support

Action-directed coping and coping by seeking social support were measured with two subscales of a short ver- sion of the Utrecht Coping Questionnaire [8], whose reliability and validity have been reported to be acceptable [9]. The subscale to measure action-directed coping consists of five items (Cronbach's $\alpha=.82$ in the present study). Seeking social support was measured with a subscale also consisting of five items (Cronbach's $\alpha=.80$ ). A total score was computed for these subscales by adding scores on all items within the subscale [10].

\section{Positive social interactions}

Positive social interactions were measured with the Social Support List - Interactions (SSL-1) [11]. The SSL-I is reliable and valid [12-14] and consists of 34 items measuring the amount experienced of six types of positive social interactions or supportive interactions: daily emotional support, problem-oriented emotional support, esteem support, instrumental support, social companionship, and informational support. The scores on all six subscales measuring positive social interactions were summed to indicate the total amount of positive social interactions (Cronbach's $\alpha=$.93).

\section{Negative social interactions}

Also included were seven additional items of the SSL-I to measure the amount of negative social interactions. Reliability and validity have been found to be sufficient $[12-14]$. The scores on the subscale measuring negative social interactions were added to determine the total amount of negative social interactions (Cronbach's $\alpha=.97$ ).

\section{Loneliness}

The Loneliness Scale [15] was used to measure loneliness. The Loneliness Scale consists of five positive and six negative items. The positive items assess feelings of belonging, whereas the negative items apply to three separate aspects of missing relationships. The higher the 
score on this scale, the greater the loneliness. The Loneliness Scale has been found to be reliable and valid [15] and has also been successfully used in previous research with patients with rheumatic diseases $[16,17]$. In the present study, Cronbach's $\alpha$ was .91 .

\section{Functional health status}

Functional health was measured with the SIP68, a condensed version of the Sickness Impact Profile $[18,19]$. The SIP68 consists of 68 items measuring health-related behavioral problems on the following six scales: somatic autonomy, mobility control, emotional stability, psychological autonomy and communication, mobility range, and social behavior. The reliability and validity of the scale have proved to be high $[19,20]$. In the present study, Cronbach's $\alpha$ of the whole scale was .85, whereas Cronbach's $\alpha$ of the subscales ranged from .63 to .77 .

\section{Life satisfaction}

Life satisfaction was measured with the Life Satisfaction Questionnaire (LSQ) $[21,22]$. The LSQ consists of nine items measuring satisfaction with life in general and with the following eight life domains: self-care ability, leisure situation, vocational situation, financial situation, sexual life, partnership relations, family life, and contacts with friends and acquaintances. The LSQ has been used for the general public [21] and for several rehabilitation groups [23-27]. Adequate reliability and validity of the LSQ were found in these studies. Cronbach's $\alpha$ in the present study was .79 .

\section{Data analysis}

The three groups were compared with regard to patient characteristics and outcome measures at pre-intervention, using one-way analyses of variance (ANOVA), KruskallWallis tests, and Chi-square tests.
To find out whether the coping intervention was as credible as the mutual support control group condition, MannWhitney $U$ tests were used to test significant differences between the coping intervention group and the mutual support control group on three credibility questions.

Multiple regression analyses were performed to assess whether the coping intervention contributed positively to the outcome measures. Pre-intervention characteristics that were significantly related to the outcome measures and that also showed a significant difference between the study groups at pre-intervention were considered potential confounders and were included as predictors in the regression model. These characteristics include the patient characteristics given in table 1 and variables such as social network size, self-efficacy in problem solving and in seeking social support, health locus of control, social skills, patients' own judgments of functioning and health, suffering from other chronic conditions, having recently experienced interfering incidents (e.g. divorce), participation in mutual support groups during the previous period, and social desirability in responding to the questions in the questionnaire. As patients were taught in groups, we also tested for intra-class correlation with one-way analyses of variance (ANOVA) [28] in order to check whether a term for group assignment needed to be included in the regression model. Finally, the dependent variable at preintervention was incorporated in the regression model as a predictor. The results presented below only include those predictors that turned out to be significant. In multiple regression, tests were done to check for high collinearity, outliers were removed from the analyses, and skewed dependent variables were transformed by taking square roots or logarithms of the values. If the coping intervention contributed positively to an outcome measure, the accompanying effect size (ES) was calculated. 
Intention-to-treat analyses were performed in which dropouts ( $n=12$ at post-intervention and $n=4$ at follow-up) were given the mean value of the lowest quartile for a particular measure. Intention-to-treat analyses did not include those patients who decided not to enter the study after randomization but before the pre-intervention measurement $(n=15)$.

Additional analyses were performed for those patients in the coping intervention and the mutual support control group who attended at least half of the 10 sessions (perprotocol analyses). The decision to use five sessions as a cutoff point was based on the assumption that five sessions is the minimum exposure to the intervention that is necessary to be influenced by it.

\section{Results}

\section{Treatment credibility}

There were no significant differences between the coping intervention group and the mutual support control group on the credibility questions. This suggests that the results of the study were not significantly influenced by differences in treatment credibility.

\section{Intra-class correlation}

Intra-class correlations were not significant for any of the outcome measures. Consequently, no term for group assignment was included in the regression modeling.

\section{Pre-intervention comparisons on patient characteris- tics and outcome measures}

Table 1 shows pre-intervention comparisons on patient characteristics, whereas table 2 shows pre-intervention comparisons on outcome measures of the coping intervention group, the mutual support control group, and the waiting list control group. The three study groups did not differ significantly in either patient characteristics or outcome measures at pre-intervention.

\section{Intention-to-treat analyses}

\section{Attendance}

The number of patients who attended no sessions at all was equal for the coping intervention group and the mutual support control group ( $n=6)$, and the number of patients who attended all 10 sessions was almost equal for both groups ( $n=14$ and $n=15$, respectively). In addition, the number of patients who attended fewer than five meetings was 19 in the coping intervention group and 18 in the mutual support control group. The average attendance was 6.1 sessions in the coping intervention group and 6.4 sessions in the mutual support control group. There was no significant difference in average attendance between the coping intervention group and the mutual support control group.

\section{Effects of the coping intervention}

As can be seen in table 3, the coping intervention had a significant positive effect on action-directed coping at post-intervention $(\beta=.16, p<.05 ; E S=.18)$, compared with mutual support. The other significant predictor of action-directed coping at post-intervention was actiondirected coping at pre-intervention ("pre-measurement" in table $3 ; \beta=.71, p<.001$ ). Although not statistically significant, the coping intervention also proved to be superior to the waiting list control group in improving action-directed coping at post-intervention. Table 3 also shows that the coping intervention had a significant positive effect on functional health status at post-intervention $(\beta=.12, p<.05 ; E S=.08)$, compared with the waiting list control group. Besides the coping intervention, post-in- 


\section{Table 1}

Patient characteristics, at pre-intervention, of the coping intervention group (CIG), the mutual support control group (MSCG), and the waiting list control group (WLCG)

\begin{tabular}{|c|c|c|c|}
\hline 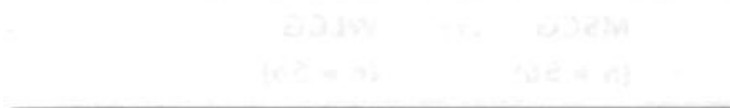 & $\begin{array}{l}\text { CIG } \\
(n=56)\end{array}$ & $\begin{array}{l}\text { MSCG } \\
(n=56)\end{array}$ & $\begin{array}{l}\text { WLCG } \\
(n=56)\end{array}$ \\
\hline Age, mean \pm SD (years) & $52.5 \pm 8.31$ & $51.1 \pm 8.91$ & $50.5 \pm 8.65$ \\
\hline Male (\%) & 23.2 & 41.1 & 32.1 \\
\hline Single (\%) & 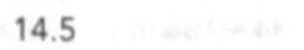 & 10.7 & 12.5 \\
\hline Monthly family income $<€ 1591,-/ \$ 1417,-(\%)$ & 74.0 & 76.4 & 78.0 \\
\hline \multicolumn{4}{|l|}{ Level of education' ${ }^{1}(\%)$} \\
\hline - low & 54.2 & 40.4 & 51.1 \\
\hline - medium & 35.4 & 46.8 & 28.9 \\
\hline - high & 10.4 & 12.8 & 20.0 \\
\hline \multicolumn{4}{|l|}{ Diagnosis (\%) } \\
\hline - rheumatoid arthritis (RA) & 60.7 & 54.5 & 55.4 \\
\hline - osteoarthritis (OA) & 3.6 & 9.1 & 10.7 \\
\hline - ankylosing spondylitis (AS) & 14.3 & 16.4 & 17.9 \\
\hline - less common diagnoses ${ }^{2}$ & 14.3 & 10.9 & 5.4 \\
\hline - combination of RAVOA, RAVOA/other & 7.2 & 9.1 & 10.8 \\
\hline Duration of disease, mean \pm SD (years) & $12.6 \pm 10.75$ & $14.1 \pm 11.25$ & $13.9 \pm 10.56$ \\
\hline
\end{tabular}

\section{$\mathrm{SD}=$ standard deviation}

${ }^{1}$ Low refers to primary school only or vocational training, medium means lower general secondary education or advanced vocational training, and high indicates higher vocational training or college/university training

${ }^{2}$ Psoriatic arthritis, juvenile chronic arthritis, adult onset M.Still, spondylarthrosis, spondylarthropathy (associated with M. Crohn), and diffuse ideopathic skeletal hyperostosis (DISH)

tervention functional health status was also explained by functional health status measured at pre-intervention ("pre-measurement"; $\beta=.77, p<.001$ ). Analysis of coping intervention effects on subscales of functional health status revealed a significant positive effect on mobility range at post-intervention $(\beta=.19, p<.01 ; E S=.23)$.
Pre-intervention mobility range was the only other significant predictor ("pre-measurement"; $\beta=.70, p<.001$ ). Although not statistically significant, the coping intervention also proved to be superior to mutual support in that it led to a higher functional health status at post-intervention. 


\section{Table 2}

Outcome measures, at pre-intervention, of the coping intervention group (CIG), the mutual support control group (MSCG), and the waiting list control group (WLCG)*

\begin{tabular}{lcccc}
\hline & $\begin{array}{l}\text { Theoretical } \\
\text { range }\end{array}$ & $\begin{array}{l}\text { CIG } \\
(\mathbf{n}=\mathbf{5 6})\end{array}$ & $\begin{array}{l}\text { MSCG } \\
(\mathbf{n}=\mathbf{5 6})\end{array}$ & $\begin{array}{l}\text { WLCG } \\
(\mathbf{n}=\mathbf{5 6})\end{array}$ \\
\hline Action-directed coping & $5-20$ & $12.7 \pm 2.97$ & $13.3 \pm 2.42$ & $12.7 \pm 2.94$ \\
Coping by seeking social support & $5-20$ & $9.8 \pm 2.82$ & $10.0 \pm 2.59$ & $9.9 \pm 2.78$ \\
Positive social interactions & $34-136$ & $73.4 \pm 14.92$ & $73.5 \pm 13.48$ & $76.7 \pm 13.06$ \\
Negative social interactions & $7-28$ & $10.2 \pm 3.22$ & $10.1 \pm 3.40$ & $9.5 \pm 2.61$ \\
Loneliness & $0-11$ & $4.3 \pm 3.88$ & $3.9 \pm 3.46$ & $2.8 \pm 3.16$ \\
Life satisfaction & $1-6$ & $4.3 \pm 0.77$ & $4.4 \pm 0.70$ & $4.4 \pm 0.64$ \\
Impact on functional health status & $0-68$ & $17.2 \pm 7.18$ & $14.4 \pm 8.04$ & $15.6 \pm 7.19$ \\
\hline
\end{tabular}

"Values are mean \pm standard deviation

\section{Table 3}

Intention-to-treat results of multiple regression analyses

\begin{tabular}{|c|c|c|c|c|c|}
\hline \multirow{2}{*}{$\begin{array}{l}\text { Dependent variables } \\
\text { at post-intervention }\end{array}$} & \multicolumn{3}{|c|}{ Independent variables: B } & \multirow[t]{2}{*}{$\mathbf{R}^{2}$} & \multirow[t]{2}{*}{$n$} \\
\hline & $\overline{C I G}$ versus WLCG & CIG versus MSCG & Pre-measurement & & \\
\hline Action-directed coping & n.s. & $.16^{\circ}$ & $.71 \cdots$ & .50 & 158 \\
\hline Functional health status & $.12^{*}$ & n.s. & $.77^{\cdots}$ & .71 & 158 \\
\hline - Mobility range & $.19^{* *}$ & n.s. & $.70 \cdots$ & & \\
\hline
\end{tabular}

CIG = coping intervention group; WLCG = waiting list control group; MSCG = mutual support control group n.s. = not significant p $<.05, \cdots p<.01, \cdots p<.001$ 
At post-intervention, no effect of the coping intervention could be found on coping by seeking social support. Also, despite the contact with other patients during the coping intervention, no significant effects were found on social interactions or loneliness.

At follow-up, the coping intervention was not found to contribute to any of the outcome measures. Obviously, the improvements in action-directed coping and functional health status brought about by the coping intervention did not persist. In addition, there were apparently no long-term effects of the coping intervention on any of the other outcome measures in patients assigned to the coping intervention.

\section{Per-protocol analyses}

\section{Attendance}

The average attendance among patients who attended at least five of the ten sessions was 8.5 sessions in the coping intervention group and 8.8 sessions in the mutual support control group. There was no significant difference in average attendance between the coping intervention group and the mutual support control group.

\section{Effects of the coping intervention}

Just like the intention-to-treat analyses, the per-protocol analyses showed that the coping intervention significantly increased action-directed coping $(\beta=.19, \mathrm{p}<.05 ; \mathrm{ES}=$ .39) and functional health status $(\beta=.16, p<.01 ; E S=$ $.22)$, more specifically the mobility range $(\beta=.22, p<.01$; $E S=.24)$, at post-intervention. These results of per-protocol multiple regression analyses are shown in table 4. Table 4 also shows that the per-protocol analyses found additional positive effects of the coping intervention on loneliness at post-intervention $(\beta=-.15, p<.05 ; E S=.04)$ and on life satisfaction at follow-up $(\beta=.15, p<.05 ; E S=$
.13), compared with mutual support. Besides the coping intervention, loneliness and life satisfaction at pre-intervention were also significant predictors ("pre-measurement" in table $4 ; \beta=.73, p<.001$, and $\beta=.80, p<.001$ ). In addition, the coping intervention significantly decreased negative social interactions at follow-up ( $\beta=$ $-.16, p<.05 ; E S=.25)$, compared with no intervention (the waiting list control group). Negative social interactions at follow-up were also predicted by negative social interactions at pre-intervention ("pre-measurement "; $\beta$ = $.66, \mathrm{p}<.001)$. Although the coping intervention reached statistical significance in explaining action-directed coping, functional health status, loneliness, life satisfaction, and negative social interactions only when compared with one of the control conditions, the coping intervention in all cases proved to be superior to both the control conditions. 


\section{Table 4}

Per-protocol results of multiple regression analyses

\begin{tabular}{|c|c|c|c|c|c|c|}
\hline \multirow{2}{*}{$\begin{array}{l}\text { Dependent variables } \\
\text { at post-intervention }\end{array}$} & \multicolumn{3}{|c|}{ Independent variables: B } & & \multirow[t]{2}{*}{$\mathbf{R}^{2}$} & \multirow[t]{2}{*}{ n } \\
\hline & CIG versus WLCG & CIG versus MSCG & Pre-measurement & & & \\
\hline Action-directed coping & n.s. & $.19^{*}$ & $.71 \cdots$ & & .53 & 125 \\
\hline Functional health status & $.16^{* *}$ & n.s. & $.81^{\cdots}$ & & .75 & 126 \\
\hline - Mobility range & $.22^{* *}$ & n.s. & $.73^{\cdots}$ & & .59 & 122 \\
\hline \multirow[t]{2}{*}{ Dependent variables } & \multicolumn{3}{|c|}{ Independent variables: B } & & $\mathbf{R}^{2}$ & $\mathbf{n}$ \\
\hline & CIG versus WLCG & CIG versus MSCG & Pre-measurement & $\begin{array}{l}\text { Functional } \\
\text { health }\end{array}$ & & \\
\hline Loneliness & & & & & & \\
\hline $\begin{array}{l}\text { at post-intervention } \\
\text { Negative social } \\
\text { interactions }\end{array}$ & n.s. & $-.15^{*}$ & $.73 \cdots$ & $.13^{\circ}$ & .61 & 124 \\
\hline at follow-up & $-.16^{\circ}$ & n.s. & $.66^{\cdots}$ & & .46 & 126 \\
\hline $\begin{array}{l}\text { Life satisfaction } \\
\text { at follow-up }\end{array}$ & n.s. & $.15^{\circ}$ & $.80^{\cdots}$ & & .64 & 126 \\
\hline
\end{tabular}

CIG = coping intervention group; WLCG = waiting list control group; MSCG = mutual support control group

n.s. $=$ not significant

" $p<.05, " * p<.01, \cdots p<.001$

\section{Discussion}

This randomized controlled trial aimed to investigate the effects of teaching patients with rheumatic diseases action-directed coping and coping by seeking social support. In the present trial, a coping intervention was compared with a mutual support control group and a waitinglist control group. The results show that, at post-intervention, the coping intervention resulted in more action-directed coping than in the mutual support groups and that, compared with standard medical care (the waiting list control group), the coping intervention improved the patients' functional health status. The same results were found when we included only those patients who attended at least five of the ten sessions of the coping intervention. Moreover, in these patients additional positive effects of the coping intervention were found, on loneliness at post-intervention and on life satisfaction at follow-up, compared with mutual support. In these patients, the 
5 Effects of a coping intervention on patients with rheumatic diseases: Results of a randomized controlled trial

coping intervention also resulted in fewer negative social interactions at follow-up, in comparison with standard medical care.

The question whether the changes achieved are meaningful can be discussed on the basis of the effect sizes. Because all patients in the coping intervention group were being treated with standard medical care, effect sizes represent the additional effects beyond those achieved by regular treatments. Intention-to-treat effect sizes in this study were .18 for action-directed coping, .08 for functional health status in general, and .23 for mobility range, which is low but normal for this kind of trial [29]. Moreover, the effect size on mobility range was higher than effect sizes on disability achieved in other patient education trials in rheumatic diseases; meta-analyses of psychobehavioral [30] and psychoeducational [31] interventions found weighted average effect sizes of .05 and .10 , respectively. It is unclear whether these effect sizes are based on intention-to-treat analyses. Moreover, the effect sizes of drug treatments on disability are somewhat higher, .34, or even similar, .21, to the effect size on mobility range in our study, whereas the drug studies are likely to be subject to publication bias (failure to publish negative findings) $[30,31]$.

What constitutes a "clinically meaningful change" is very hard to define; it depends on the level and the character of the health problem [20]. For a patient population suffering from a chronic disease affecting the patients' lives in many aspects, the effects achieved would appear to be valuable. With regard to functional health status in rheumatic diseases, lack of a decrease is important and a modest effect may be clinically significant. Moreover, the positive effects on functional health status and quality of life that were found in the present study are in accordance with the standards for arthritis patient education developed by a task force of the National Arthritis
Advisory Board in the United States: "In order for a program to meet the standards ... it must demonstrate its effectiveness in maintaining or improving health status (i.e. pain, functional ability, psychological state, social functioning and/or quality of life)" [32,33]. Consequently, we recommend that patient education interventions like the coping intervention described in this article be incorporated into regular care. However, as the effects on actiondirected coping and functional health status did not persist up to follow-up, maintenance sessions are recommended.

To reach the patients who were most likely to benefit from the coping intervention, selection criteria with regard to diagnosis, disease duration, age, social support, and functional health status were applied. The results should be interpreted accordingly; based on the results of the present study we can conclude that the effects described can be obtained in a selected group of patients. The coping intervention increased action-directed coping but, unexpectedly, did not increase coping by seeking social support, although it specifically aimed at teaching patients both types of coping. Nevertheless, the focus on action-directed coping and coping by seeking social support in the coping intervention obviously had a positive influence on the patients' functional health status. More specifically, our study suggests that teaching patients to cope with their disease by solving problems in a systematic and social-support seeking way not only leads to more action-directed coping, but also increases the patients' functional health status.

In studies comparing the effects of two or more interventions, differences in treatment credibility can influence the outcome. This did not seem to be the case in the present study, as the coping intervention group and the mutual support control group did not differ in treatment credibility. This finding is supported by the fact that the 
numbers of patients who attended fewer than five meetings of the coping intervention and the mutual support groups were almost equal ( $n=19$ and $n=18$, respectively). Also, the results were probably not due to a social desirability response set, as social desirability was measured for incorporation as a possible confounder in multiple regression analyses, as described in the paragraph on statistical analyses. Furthermore, the supervisors as well as the participating patients were naive to the expected outcomes and to the procedure in the other study group, both the coping intervention and the mutual support were presented to patients and supervisors as being equal in faithfulness, and the supervisors of the mutual support sessions (placebo intervention) were selected by an external organization. Extensive process evaluation revealed that the implementation of both the coping intervention and the mutual support was in accordance with the program and that the patients were equally satisfied with both programs, as were the supervisors.

The intention-to-treat analyses did not include those patients who decided not to enter the study after randomization but before pre-intervention $(n=15)$. The randomization process assigned 6 of these patients to the waiting list control group, 5 to the coping intervention group, and 4 to the mutual support control group, which may indicate that the decision not to enter the study was not made because these patients did not agree with the study group in which they were placed. The intention-totreat study sample seems to be representative of the original group of participants, as the two groups did not differ significantly in personal or disease characteristics (age, sex, marital status, family income level, level of education, diagnosis, and duration of the rheumatic disease or diseases). The main reasons that patients gave for not entering the study were illness, personal problems, and family problems. There were no differences in the reasons for not entering the study between patients who had been placed in different study groups.

Long-term effects of the coping intervention could only be found in patients who had attended at least five sessions; intention-to-treat analyses revealed no effects on any of the outcome measures at follow-up. The patients who were excluded from the per-protocol analyses ( $n=$ 37) because they had attended fewer than five sessions of the coping intervention ( $n=19$ ) or mutual support ( $n=$ 18) had a significantly higher score on loneliness at preintervention than the per-protocol study group $(n=131)$. The two groups did not differ significantly on any of the other patient characteristics or outcome measures at preintervention. This indicates that the per-protocol study group was comparable to the intention-to-treat study group in most characteristics, except for experiencing significantly less loneliness. It is remarkable that the patients of this per-protocol study group showed improvements in loneliness at post-intervention and in negative social interactions at follow-up, despite the fact that it was precisely these patients who were less lonely at the start of the intervention.

This study is not without limitations. Data were obtained from as large a sample as was economically and practically feasible. Power calculations for arthritis patient education studies are often based on an effect size of .20 [30]. To achieve a power of $80 \%$, based on an effect size of .20, a total sample of 1176 patients ( $n=392$ in each study group) would have been necessary [29], which was not feasible in the present study. Consequently, the power to detect effects in this study is less than $60 \%$, making it difficult to avoid a Type II error. This may explain why the coping intervention did not differ significantly from the mutual support control group as well as from the waiting list control group for the outcome measures investigated, although results from multiple regression analyses with 
each outcome measure did suggest superior effects of the coping intervention when compared with both control groups.

In summary, the results indicate that a coping intervention aimed at increasing action-directed coping and coping by seeking social support in adult patients who have had one or more rheumatic diseases for more than one year, and who have a somewhat limited social environment and functional health status, increases these patients' action-directed coping and functional health status. The study suggests that patients who attend at least half of all sessions of the coping intervention obtain additional benefits in that loneliness and negative social interactions decrease and life satisfaction improves. Because of the positive effects of the coping intervention, this may be a good intervention to incorporate in standard health services. However, maintenance sessions are recommended to make the positive effects endure.

\section{Acknowledgements}

The authors wish to thank the rheumatologists of Atrium Medical Center (Heerlen, The Netherlands) and Maasland Hospital (Sittard, The Netherlands) and the supervisors of the coping intervention and the mutual support groups. We would also like to thank the patients who participated in this study for their valuable contributions.

\section{References}

[1] Dunkel-Schetter C, Folkman S, Lazarus RS. Correlates of social support receipt. J Pers Soc Psychol 1987;53:71-80.

[2] Ros WJG. Social support in cancer patients. Utrecht: Utrecht University, 1989.
[3] Smith CA, Wallston KA. Adaptation in patients with chronic rheumatoid arthritis: Application of a general model. Health Psychol 1992;11:151-62.

[4] Savelkoul M, Post M, de Witte L, van den Borne B. Social support, coping and subjective well-being in patients with rheumatic diseases. Patient Educ Couns 2000;39:205-18.

[5] Parker JDA, Endler NS. Coping with coping assessment: A critical review. Eur J Pers 1992;6:321-44.

[6] de Ridder DTD, Schreurs K. Coping en sociale steun van chronisch zieken. [Coping and social support in people with chronic diseases] Zoetermeer: Nationale Commissie Chronisch Zieken, 1994.

[7] D'Zurilla TJ, Goldfried MR. Problem solving and behavior modification. J Abnorm Psychol 1971;78:107. 26.

[8] Schreurs PJG, Tellegen B, van de Willige G. Gezondheid, stress en coping: De ontwikkeling van de Utrechtse Copinglijst. [Health, stress and coping: The development of the Utrecht Coping Questionnaire] Tijdschr Psychol 1984;12:101-17

[9] Janssen M, Bal RM, Komproe I, Philipsen H, Furda J. Evaluatie van de 15-item versie van de Utrechtse Coping Lijst. [Evaluation of the 15-item version of the Utrecht Coping Questionnaire] Maastricht: Maastricht University, 1997. 
[10] Schreurs PJG, van de Willige G, Tellegen B, Brosschot JF. De Utrechtse Coping Lijst: UCL-handleiding. [The Utrecht Coping Questionnaire: Manual] Lisse: Swets en Zeitlinger, 1988.

[11] van Sonderen E. Het meten van sociale steun met de Sociale Steun Lijst-Interacties (SSL-I) en de Sociale Steun Lijst-Discrepanties (SSL-D): Een handleiding. [Measuring social support with the Social Support List - Interactions (SSL-I) and the Social Support List - Discrepancies (SSL-D): Manual] Groningen: Noordelijk Centrum voor Gezondheidsvraagstukken, 1993.

[12] van Sonderen E, Sanderman R. Social support. In: Vingerhoets AJJM, editor. Advances in behavioral medicine assessment. In press.

[13] van Sonderen E, Ormel J. Het meten van aspecten van sociale steun en hun relatie met welbevinden: Een onderzoek naar de bruikbaarheid van de SSL-I en de SSL-D. [Measuring aspects of social support and their relation with well-being: A study into the feasibility of the Social Support List - Interactions (SSL-1) and the Social Support List -Discrepancies SSL-D] Gedrag en Gezondheid 1997;25:190-200.

[14] van Sonderen E. Measuring social support. Groningen: University of Groningen, 1991.

[15] de Jong-Gierveld J, Kamphuis F. The development of a Rasch-type loneliness scale. Appl Psych Meas 1985;9:289-99.
[16] de Witte LP, Tilli DJP, Ticheler AJG, Winants BAC, van der Horst FG, van der Linden S. Leven met een reumatische aandoening: Een onderzoek naar de ervaren kwaliteit van het leven bij 372 mensen met een reumatische aandoening. [Living with a rheumatic disease: A study into subjective quality of life in 372 patients with rheumatic diseases] Hoensbroek: Instituut voor Revalidatie Vraagstukken, 1989.

[17] Bal RM. Health deviation and daily functioning in elderly rheumatoid arthritis patients. Maastricht: Maastricht University, 1992.

[18] de Bruin AF, Diederiks JPM, de Witte LP, Stevens FCJ, Philipsen $\mathrm{H}$. The development of a short generic version of the Sickness Impact Profile. J Clin Epidemiol 1994;47:407-18.

[19] de Bruin AF, de Witte LP, Diederiks JPM. The Sickness Impact Profile: SIP68, a short generic version. First evaluation of the reliability and reproducibility. J Clin Epidemiol 1994;47:863-71.

[20] de Bruin AF, Diederiks JPM, de Witte LP, Stevens FC, Philipsen H. Assessing the responsiveness of a functional status measure: The Sickness Impact Profile versus the SIP68. J Clin Epidemiol 1997;50:529-40.

[21] Fugl-Meyer AR, Bränholm IB, Fugl-Meyer KS. Happiness and domain-specific life satisfaction in adult northern Swedes. Clin Rehabil 1991;5:25-33. 
[22] Post MWM, van Dijk AJ, van Asbeck FWA, Schrijvers AJP. Life satisfaction of persons with spinal cord injury compared to a population group. Scand J Rehab Med 1998;30:23-30.

[23] Bränholm IB. On life satisfaction, occupational roles and activity preferences: Occupational therapy aspects. Umeá: University of Umeá, 1992.

[24] Bränholm IB, Erhardsson M. On life satisfaction and activity preferences in subjects with multiple sclerosis: A comparative study. Scand J Occup Ther $1994 ; 1: 17-23$

[25] Fugl-Meyer AR, Eklund M, Fugl-Meyer KS. Vocational rehabilitation in northern Sweden. III Aspects of life satisfaction. Scand J Rehab Med $1991 ; 23: 83-7$

[26] Viitanen M, Fugl-Meyer KS, Bernspång B, FuglMeyer AR. Life satisfaction in long-term survivors after stroke. Scand J Rehabil Med 1988;20:17-24.

[27] Post M. Living with spinal cord injury: A study of health status and life satisfaction of independently living people with a spinal cord injury. Utrecht: Utrecht University, 1997.

[28] Snijders IAB, Bosker RJ. Multilevel analysis: An introduction to basic and advanced multilevel modeling. London: Sage, 1999.

[29] Polit DF, Hungler BP. Nursing research: Principles and methods. Philadelphia: J.B. Lippincott, 1995.
[30] Superio-Cabuslay E, Ward MM, Lorig KR. Patient education interventions in osteoarthritis and rheumatoid arthritis: A meta-analytic comparison with nonsteroidal antiinflammatory drug treatment. Arthritis Care Res 1996:9:292-301.

[31] Mullen PD, Laville EA, Biddle AK, Lorig K. Efficacy of psychoeducational interventions on pain, depression, and disability in people with arthritis: A metaanalysis. J Rheumatol 1987; 14:33-9.

[32] Burckhardt CS. Arthritis and musculoskeletal patient education standards. Arthritis Care Res 1994;7:1-4.

[33] Lorig K, Visser A. Arthritis patient education standards: A model for the future. Patient Educ Couns $1994 ; 24: 3-7$. 


\section{6 \\ Social support as a mediator between active coping and quality of life in patients with rheumatic diseases: Results of a longitudinal study}

Manon Savelkoul', Luc de Witte ${ }^{2}$, Math Candel ${ }^{3}$, and Gerjo Kok ${ }^{4}$

Submitted for publication

'Department of Health Education and Promotion, Maastricht University, Maastricht, The Netherlands ${ }^{2}$ Institute for Rehabilitation Research, Hoensbroek, The Netherlands

${ }^{3}$ Department of Methodology and Statistics, Maastricht University, Maastricht, The Netherlands ${ }^{4}$ Faculty of Psychology, Maastricht University, Maastricht, The Netherlands 


\section{Abstract}

Active coping is hypothesized to increase social support, which in turn improves quality of life in patients with rheumatic diseases. This mediating role of social support in the relationship between active coping and quality of life was tested in a longitudinal study $(n=152)$.

Data were collected by self-report questionnaires. Results indicated a mediational path from loneliness to quality of life (life satisfaction as well as functional health status) with action-directed coping as an independent variable.

The results open new perspectives for patient care.

\section{Introduction}

People with rheumatic diseases face many adaptive challenges. Not only do they have to cope with pain [1], fatigue [2], and physical activity restrictions [3], they also have to come to terms with the meaning of the illness for their life and the progression of the disease [4-6]. Although some problems in rheumatic diseases are unique, many of the difficulties faced by patients with rheumatic diseases are also common in people with other chronic progressive and unpredictable diseases like AIDS, multiple sclerosis, cancer, and diabetes mellitus $[3,7,8]$.

According to the stress and coping theory of Lazarus and Folkman [9], the impact of stress due to chronic diseases on well-being is influenced by social support and coping. As the population in the Western world ages, the number of chronically ill people will increase. With no cure for chronic disease and indications for coping and social support influencing the patients' well-being, the relationship between coping, social support and well-being becomes very important. Lazarus and Folkman [9] claim that wellbeing can be influenced by coping and that social support can influence an individual's coping efforts by being a coping resource. McColl, Lei, and Skinner [10], and Manne and Zautra [11], however, suggest an opposite direction between coping and social support by arguing that coping could be a factor which influences the social support received. In fact, Lazarus and Folkman [9] also claimed that a person's overall social functioning, which, besides the ways the individual fulfills his or her various roles, also is defined as satisfaction with interpersonal relationships, is largely determined by the effectiveness with which he or she appraises and copes with the events of day-to-day living. Moreover, some cross-sectional and prospective non-intervention studies have shown that active coping may increase social support which, in turn, improves the well-being in individuals in the community, people with cancer, and individuals with rheumatic diseases [12-15]. The coping literature indicates that active coping implies managing a stressful situation (approach), whereas passive coping means avoidance. Another basic dimension for classifying coping besides the active-passive dimension is emotion-focused coping (aimed at changing the significance of a stressor) versus problemfocused coping (aimed at changing the situation that causes the stress). As passive coping is aimed at avoidance, it is always emotion-focused (e.g. wishful thinking, palliative coping). Active coping can be both emotion-focused (e.g. positive reappraisal, cognitive restructuring, reassuring thoughts), and problem-focused (e.g. action-directed coping, seeking social support) $[16,17]$. If more convincing indications for social support as a mediator between active coping and well-being can be found, this will provide opportunities for improving social support and well-being by teaching individuals to cope actively. It will also contribute to an insight into the mechanisms that make such an intervention effective, which is important for future interventions. Baron and Kenny [18] define a mediator as a factor that represents the mechanism 
through which a focal independent variable is able to influence the dependent variable of interest (figure 1).

The aim of this study was to test a theoretical model suggesting that social support is a mediator for the relationship between active coping and the rheumatic patient's quality of life. The procedure of establishing mediation developed by MacKinnon [19], which is based upon Baron and Kenny [18], was followed using data from a randomized controlled trial. In this trial, a coping intervention aimed at teaching patients active problem-focused coping, (namely, action-directed coping and coping by seeking social support), was used to manipulate coping. To our knowledge no longitudinal study has been reported that tests whether social support plays a mediating role in the relation between active coping and quality of life.

Quality of life in our model has been operationalized by functional health status, representing the health-related quality of life as defined by the World Health Organisation [20]. In addition, we used a more subjective indicator of quality of life represented by evaluations of satisfaction with life. The amount of supportive interactions was used as an operationalization of social support. Besides, loneliness was used as an indicator of social support as it is the unpleasant experience that occurs when a person's network of social relationships is deficient in some important way [21], and can be treated as a cognitive assessment of the adequacy of one's social network and support [22].

\section{Methods}

\section{Participants}

During a three-month period, patients aged 18 years or older who visited the outpatient rheumatology clinics of two regional hospitals received a questionnaire $(\mathrm{N}=$ 2792). Rheumatologists were asked to indicate the pa- tients' diagnoses on the questionnaire. A total of 1901 patients filled out the questionnaire $(68 \%)$. The reasons for not filling out the questionnaire as indicated by part of the remaining $32 \%$ of the patients were that the questions did not apply to them because their health was good; some patients declared they had more diseases and because of that were not able to indicate the consequences of the rheumatic disease(s); other patients thought the questionnaire was too difficult to fill out, or the questions were too personal. From the 1901 patients who filled out the questionnaire, 463 patients were selected on the basis of the following five features: (1) at least one chronic rheumatic disorder affecting the joints (rheumatoid arthritis, osteoarthritis, ankylosing spondylitis, psoriatic arthritis, juvenile chronic arthritis, systemic onset Still's disease, spondylosis, seronegative spondylarthropathy, or diffuse idiopathic skeletal hyperostosis (DISH)); (2) a disease duration of more than one year; (3) age between 35 and 65 years; (4) a higher than median (of all eligible patients) impact of the rheumatic disease on functional health status; and (5) a higher than median score of all eligible patients on loneliness, lack of social support or on impact of the rheumatic disease on social behavior. Patients with fibromyalgia were excluded. These selection criteria were applied to obtain a homogeneous study population. Besides, the last two criteria (4 and 5) were also used to reach those patients who are most in need of a higher quality of life and more social support (i.e. the coping intervention's target population). Of the 463 patients who were selected for the study, 430 were actually invited for participation because 15 patients had already taken part in a pilot test of the coping intervention and 18 patients indicated on the questionnaire that they did not want to participate. Of the 430 patients who were invited, 428 received an invitation as 2 patients could not be located. A total of 183 patients agreed to 
participate, of whom 15 withdrew from the study after randomization but before the first measurement (pre-intervention) took place. The main reasons for not entering the study were illness, personal problems, and family problems. The final study sample consisted of $168 \mathrm{pa}$ tients.

\section{Procedure}

Concealed randomization was performed in which patients were assigned to a coping intervention group ( $n=$ 56 ), a mutual support control group $(n=56)$, or a waiting list control group $(n=56$ ). Data were collected by questionnaires that were mailed to the participating patients before the start of the intervention (pre-intervention), right after the end of the intervention (post-intervention), and again six months after the end of the intervention (follow-up). At post-intervention 12 patients did not fill out the questionnaire of whom 4 patients filled out the questionnaire again at follow-up. Also, at follow-up, 4 other patients did not fill out the questionnaire. Data from the remaining 152 patients were used for the present study.

The study was approved by the Medical Ethics Committees of the participating hospitals. Informed consent was obtained after the procedure had been fully explained to the study participants. However, at no time did patients receive any information on the theoretical model of the study. Also, the supervisors of the coping intervention and mutual support did not know the theoretical model that was investigated. During the study, patients' current medical treatment was continued. Patients did not receive incentive payment for participation.

\section{Coping Intervention and Mutual Support}

The coping intervention was aimed at teaching patients action-directed coping and coping by seeking social sup- port. Each group was led by a therapist experienced in behavioral therapy who structured and directed all activities. A nurse who was specialized in theumatology or a social worker experienced in rheumatology participated as a cofacilitator. Detailed information on the content of the coping intervention is described elsewhere [23]. The mutual support control group was included in the randomized controlled trial in order to control for nonspecific treatment effects in the coping intervention. In the mutual support groups the aims were to exchange information, experiences, feelings, and emotions. No coping skills were trained. The coping intervention and mutual support followed the same structure. Both took place in groups of 10-12 patients who participated in 10 sessions. All sessions lasted two hours.

From the measurement of the effects of the coping intervention, it appeared that the coping intervention increased action-directed coping and functional health status. In patients who visited at least five of all ten sessions, the coping intervention also decreased loneliness, increased the amount of social interaction, and improved life satisfaction [24].

\section{Measures}

\section{Coping}

Coping was measured with a short version of the Utrecht Coping Questionnaire about which acceptable reliability and validity have been reported [25]. The Utrecht Coping Questionnaire is based on the assumption that coping is a personality trait, which means that individuals prefer particular coping behaviors in different situations $[26,27]$. Respondents are asked to rate how often in general they execute each of the different ways described in the questionnaire in which one can think or react when facing any given stressful situation ("Indicate for each sentence how 
often you find yourself reacting in this way when you are confronted with a problem or an unpleasant event"). Possible answers range from "seldom or never" to "very often". The short version of the questionnaire consists of 15 items which can be classified into four subscales: (1) action-directed coping (5 items (e.g. using a direct approach in order to solve the problem), Cronbach's $\alpha$ (in this study) $=.82$ ); (2) seeking social support (5 items (e.g. asking someone to help), Cronbach's $\alpha=.80$ ); (3) awaiting / avoidance ( 3 items (e.g. giving-in in order to avoid difficult situations), Cronbach's $\alpha=.69$ ); and (4) palliative coping (2 items (e.g. directing one's thoughts towards other matters), Cronbach's $\alpha=.30$ ). For testing mediation in the present study, only the subscales to measure action-directed coping and coping by seeking social support have been incorporated in the analyses. A total score was computed for each of these two subscales by adding scores on all items from these subscales separately [27].

\section{Social support}

Social support was measured by positive and negative social interactions, and by loneliness.

Positive and negative social interactions were measured with the Social Support List - Interactions (SSL-1) [28]. The SSL-I consists of 34 items measuring the amount experienced of six types of positive social interactions: daily emotional support, problem-oriented emotional support, esteem support, instrumental support, social companionship, and informational support. Also included are seven items to measure negative social interactions. These items measure negative reactions from people in the social environment, such as being very standoffish, breaking engagements, being unfair, criticism, reproach, or overprotection. Reliability and validity are sufficient [29-31]. The scores on all six subscales measuring positive social inter- actions and the scores on the subscale measuring negative social interactions were added separately to indicate the amount of positive social interactions (Cronbach's $\alpha=$ .93) and the amount of negative social interactions (Cronbach's $\alpha=$.97), respectively.

To measure the perceived adequacy of social interactions, the respondents' sense of loneliness was measured. Loneliness was measured with the Loneliness Scale [32]. The Loneliness Scale is based on the assumption that loneliness involves situations in which the number of achieved relationships is smaller than desired, or when the existing relationships fail to attain the desired degree of intimacy [32]. The scale consists of five positive and six negative items. The positive items assess feelings of belonging (e.g. "There is always someone around me that I can talk to about my day-to-day problems"), whereas the negative items apply to aspects of missing relationships (e.g. "I experience a sense of emptiness around me"). The higher the score on this scale, the greater the loneliness. The Loneliness Scale has been found to be reliable and valid [32]. In this study, Cronbach's $\alpha$ was .91 .

\section{Quality of life}

Subjective quality of life was measured with the Life Satisfaction Questionnaire (LSQ) $[33,34]$. The LSQ consists of nine items measuring satisfaction with life in general and with the following eight life domains: self-care ability, leisure situation, vocational situation, financial situation, sexual life, partnership relations, family life, and contacts with friends and acquaintances. The LSQ has been used for the general public [33], and for several rehabilitation groups [35-39]. Adequate reliability and validity of the LSO was found in these studies. Cronbach's $\alpha$ in the present study was .79 .

Functional health status, as a more health-related indicator of quality of life, was measured with the SIP68, a con- 
6 Social support as a mediator between active coping and quality of life in patients with rheumatic diseases:

Results of a longitudinal study

densed version of the Sickness Impact Profile $[40,41]$. The SIP68 consists of 68 items measuring health-related behavioral problems on the following six scales: somatic autonomy, mobility control, emotional stability, psychological autonomy and communication, mobility range, and social behavior. The reliability and validity of the scale has proved to be high $[40,42]$. In this study, Cronbach's $\alpha$ of the whole scale was .85 .

\section{Patient characteristics and social desirability}

Besides coping, social support and quality of life as key variables in the mediational model, patient characteristics like age, gender, being single or not, monthly family income, diagnosis, education, disease duration, suffering from other chronic diseases, having recently experienced interfering incidents (e.g. divorce), as well as social desirability in responding to the questions in the questionnaires have been measured. Diagnosis was indicated by rheumatologists on the questionnaires when the patients visited the outpatient rheumatology clinic at the very beginning of the study (see also the paragraph on participants in the methods section). All other patient character- istics were each measured by asking the patients with a single question in the questionnaire.

Social desirability was measured with an 11-item translation [43] of the Crowne and Marlowe test [44]. Examples of the items used are "Sometimes it irritates me when I don't get my own way", "Now and again I take advantage of someone", and "I am always polite, even to unpleasant people". Ten point graphical scales (agree versus disagree) were used. Reliability has proven to be satisfactory and support for the validity of the scale is supplied by relationships found to hold with patient gratitude [43]. Cronbach's $\alpha$ in the present study was .63.

\section{Data Analysis}

Mediation analysis as suggested by MacKinnon [19], which is based upon a test of mediation developed by Baron and Kenny [18], has been conducted. MacKinnon [19] states that the following conditions must hold to establish a mediated effect of social support on the relationship between active coping and quality of life in our mediational model (figure 1): (1) active coping affects social support indicated by the significance of the regres-

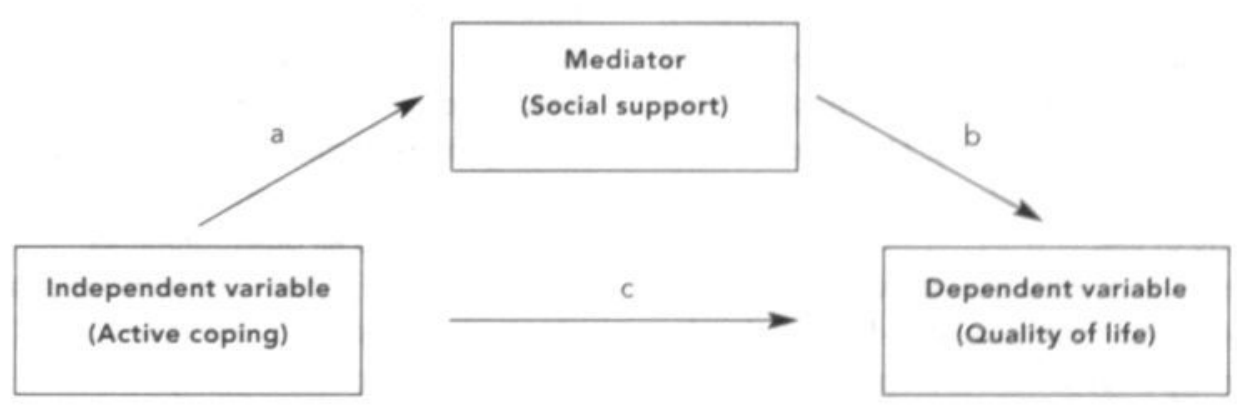

Figure 1. Basic causal chain in mediation. 
sion coefficient (path a in figure 1); (2) social support must be shown to affect quality of life, controlling for active coping in a second regression equation where this mediating variable is included as another independent variable, indicated by the significance of the mediator's regression coëfficiënt (path b in figure 1); and (3) the mediated effect of social support is statistically significant. The statistical significance of the mediated effect was calculated by using the standard error (SE) of the mediated effect, where $\operatorname{SE}(a b)^{2}=\operatorname{SE}(a)^{2}(b)^{2}+\operatorname{SE}(b)^{2}(a)^{2}[18,45]$. An approximate $\mathrm{z}$ statistic of this mediated effect was found by dividing the mediated effect (a)(b) by its standard error, SE(ab). An approximate z statistic above 1.96 (absolute value) was considered to be significant. Baron and Kenny [18] also state as a condition for mediation that active coping must be shown to affect quality of life directly. MacKinnon [19], however, argues that it is possible to have mediation without a direct effect between the independent variable (i.e. active coping) and the outcome variable (quality of life) because of opposing mediators in the model.

The analyses were performed within a longitudinal design. Data on action-directed coping and coping by seeking social support collected at post-intervention were used as an indicator of active coping. For social support, the average of measurements at post-intervention and follow-up of positive social interactions, negative social interactions, and loneliness were used. Measurements at follow-up for functional health status and life satisfaction were used for quality of life.

If patient characteristics and social desirability in responding to the questions were significantly related to both the dependent and the independent variables in the regression equations, they were considered potential confounders and consequently included as predictors. Also in every regression analysis performed, the dependent variable at pre-intervention was incorporated as a predictor.

In all regression analyses, tests were done to check for high collinearity, outliers were removed from the analyses, and skewed dependent variables were transformed by taking square roots or logarithms of the values. An alpha level of .05 was used for all statistical tests.

\section{Results}

\section{Study Sample}

Patients who agreed to participate in the study were significantly older and higher educated than patients who were selected but did not want to take part. Also, the proportion of women was higher in the group of participants.

In the group of patients who agreed to participate, there were no significant differences in patient characteristics (age, gender, being single or not, family income level, level of education, diagnosis, and duration of the rheumatic disease(s)) between the 15 patients who decided not to enter the study after randomization but before preintervention and the 168 patients who participated. Of these 168 patients, 16 patients did not fill out the questionnaire at post-intervention and/or at follow-up. This group of dropouts, which is not included in the analyses described in the present manuscript, contained proportionally more patients with rheumatoid arthritis but did not differ in other patient characteristics from patients who completed all questionnaires.

Table 1 shows patient characteristics and table 2 shows scores on variables in the mediational model of the 152 patients in the present study. 


\section{Table 1}

\section{Patient characteristics}

Age, mean \pm SD (years)

Male (\%)

Single (\%)

Monthly family income $<€ 1591,-/ \$ 1417,-(\%)$

Level of education ${ }^{1}(\%)$

- low

- medium

- high

Diagnosis (\%)

- rheumatoid arthritis (RA)

- osteoarthritis (OA)

- ankylosing spondylitis (AS)

- less common diagnoses ${ }^{2}$

- combination of RAVOA, RA/other, OA/other

Duration of disease, mean \pm SD (years)

\section{$51.0 \pm 8.56$}

32.9

13.9

75.7

45.6

39.2

15.2

54.3

7.9

17.9

10.0

9.9

$13.9 \pm 10.91$

$\mathrm{SD}=$ standard deviation

${ }^{1}$ Low refers to primary school or vocational training, medium means lower general secondary education or advanced vocational training, and high indicates higher vocational training or college/university training

2 Psoriatic arthritis, juvenile chronic arthritis, adult onset M.Still, spondylarthrosis, spondylarthropathy (associated with M.Crohn), and diffuse idiopathic skeletal hyperostosis (DISH) 


\section{Table 2}

Means and standard deviations (SD) of variables in the mediational model

\begin{tabular}{lccc}
\hline & $\begin{array}{l}\text { Theoretical } \\
\text { range }\end{array}$ & Mean & SD \\
& & & \\
\hline Coping & $5-20$ & 13.2 & 2.63 \\
- Action-directed & $5-20$ & 10.0 & 2.53 \\
- Seeking social support & & & \\
Social support & $34-136$ & 74.5 & 13.92 \\
- Positive social interactions & $7-28$ & 9.4 & 2.69 \\
- Negative social interactions & $0-11$ & 3.3 & 3.32 \\
- Loneliness & $1-6$ & 4.4 & 0.68 \\
Quality of life & $0-68$ & 14.7 & 9.11 \\
\hline - Life satisfaction & & \\
\hline
\end{tabular}

\section{Mediational Model}

The correlation matrix among the variables in the mediational model is shown in table 3.

Two models tested the relations between the independent variable (active coping), the mediator (social support), and the dependent variable (quality of life). Both models included action-directed coping and coping by seeking social support as indicators of active coping and positive social interactions, negative social interactions and loneliness as indicators of social support. In the first model, quality of life was represented by life satisfaction and in the second model quality of life was indicated by functional health status. The results of testing mediation in the first model are shown in figure 2. The model shows that action-directed coping had a significant path to positive social interactions $(B=.12, p<.01)$ and loneliness $(B$ $=-.12, p<.01)$. Besides, there was a significant path from coping by seeking social support to positive social inter- actions $(B=.15, p<.01)$. In addition, the model in figure 2 indicates a mediational path from loneliness to life satisfaction with action-directed coping as the independent variable. This mediated effect was statistically significant with a $z$ statistic of $2.50(p<.05)$. The effects of action-directed coping and coping by seeking social support on life satisfaction, when controlling for social support, were not significant (figure 2). In addition, the direct effects of action-directed coping and coping by seeking social support on life satisfaction were not significant. The results did not change if items from the Life Satisfaction Questionnaire pertaining to social relations (measuring satisfaction with sexual life, partnership relations, family life, and contacts with friends and acquaintances) were deleted from the analyses in order to get conceptually distinct intermediate and outcome variables.

Results on the mediational model in which functional health status indicates quality of life as an outcome vari- 


\section{Table 3}

Intercorrelations between variables measuring coping, social support and quality of life

\section{Variables}

\section{Coping}

1. Action-directed coping

2. Coping by seeking social support

\section{Social support}

3. Positive social interactions

4. Negative social interactions

5. Loneliness
$18^{*}$

$.26 *$
$.47^{* *}$

3

3

4

$\begin{array}{lll}5 & 6 & 7 \\ & & \\ -.19^{*} & .08 & .12 \\ -.32^{* *} & -.04 & .22 *\end{array}$

4

\section{Quality of life \\ 6. Functional health status \\ 7. Life satisfaction}

$\begin{array}{cccc}-.14 & -.58^{* *} & .04 & .36^{* *} \\ & .50^{* *} & -.20^{*} & -.34^{* *} \\ & & -.34^{* *} & -.64^{* *}\end{array}$

$" p<.05, " * p<.01$

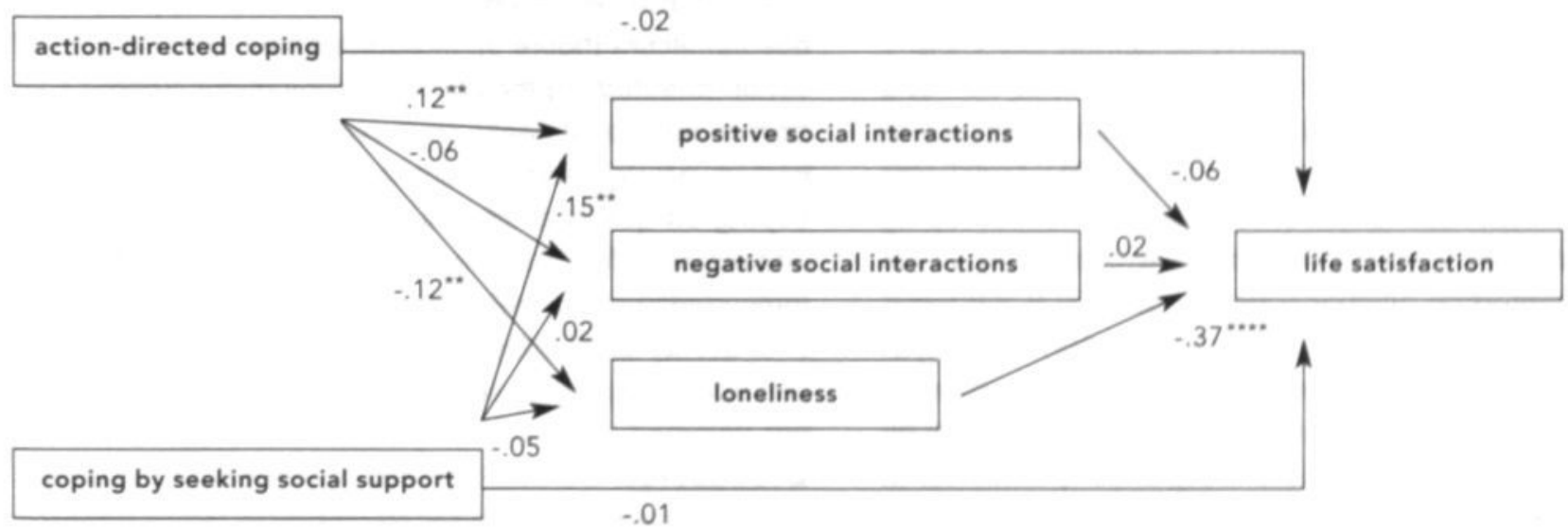

"p<.05, “p<.01, $\cdots p<.001, \cdots p<.0001$

Figure 2. Mediational model with life satisfaction as an outcome variable. 


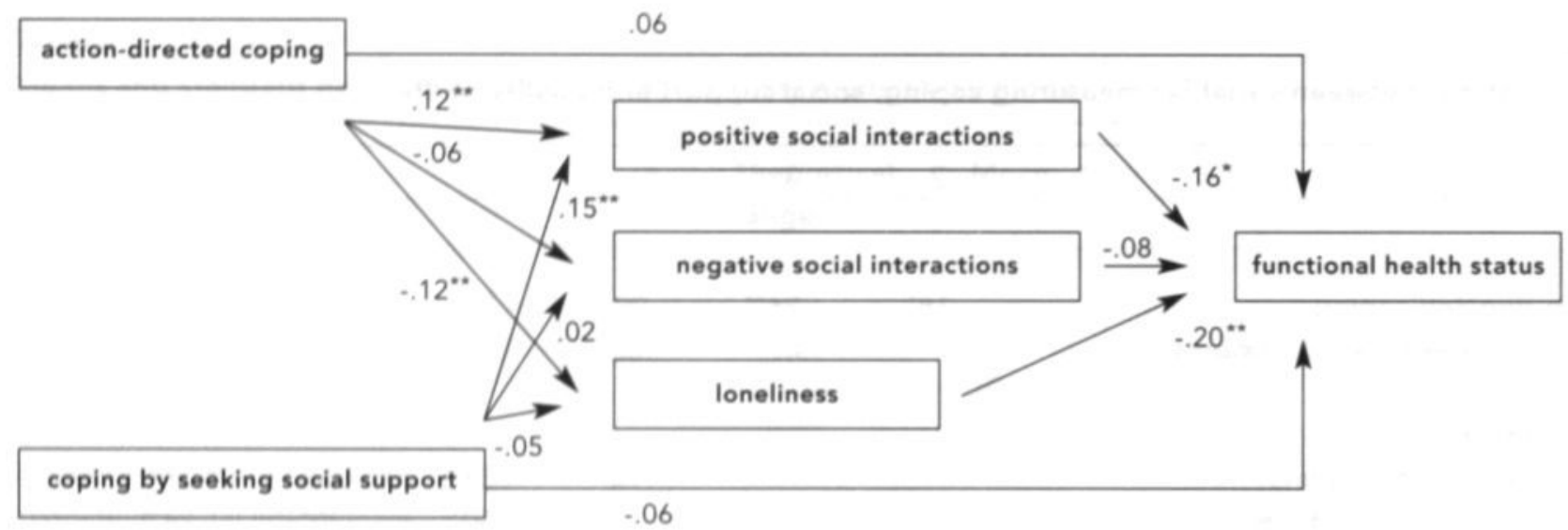

"p<.05, " $" p<.01$

Figure 3. Mediational model with functional health status as an outcome variable.

able can be seen in figure 3 . The left-hand part of this model is the same as the model with life satisfaction as an outcome variable, showing a significant path from actiondirected coping to both positive social interactions $(B=$ $.12, p<.01)$ and loneliness $(B=-.12, p<.01)$, as well as a significant path from coping by seeking social support to positive social interactions $(B=.15, p<.01)$. Loneliness mediates the relationship between action-directed coping and quality of life also in this model, where quality of life is represented by functional health status $(z=2.00, p<$ .05). Besides, the model in figure 3 indicates mediational paths from positive social interactions to functional health status with both action-directed coping and coping by seeking social support as the independent variables. In this model, active coping increases positive social interactions, which in turn decrease functional health status. However, the $z$ statistics of these mediating effects were not statistically significant $(z=1.83, p=.07$ and $z=1.94$, $p=.06$ respectively). The effects of action-directed coping and coping by seeking social support on functional health status, when controlling for social support, were not significant (figure 3 ). In addition, the direct effects of action-directed coping and coping by seeking social support on functional health status were not significant.

In sum, no significant effects have been found of active coping on quality of life via positive and negative social interactions. There are indications, however, that loneliness mediates the relationship between active coping and quality of life, but only for action-directed coping and not for coping by seeking social support.

\section{Discussion}

The purpose of the analyses described in the present paper was to test a theoretical model suggesting that active coping increases social support and consequently improves the quality of life of patients with rheumatic 
diseases. Based on mediation analysis as suggested by MacKinnon [19], we found that decreased loneliness serves as a mediator for a positive relationship between action-directed coping and both life satisfaction and functional health status. Baron and Kenny [18] state that, as a condition for mediation, the independent variable (active coping) must be shown to affect the outcome variable (quality of life) directly. There is no such direct effect in our study, however. According to MacKinnon [19], there may be theoretical or practical reasons for estimating mediated effects, even when the direct effect of the independent variable on the outcome variable is not significant. For testing mediation in our study, theoretical as well as practical reasons are present. The literature [1215] reports indications that social support serves as a mediator between active coping and quality of life. If evidence for this sequence can be found, it will provide opportunities for improving social support and quality of life by teaching individuals to cope actively and also contribute to an insight into the mechanisms that make such an intervention effective. A possible explanation for a nonsignificant overall effect of the independent variable when mediation actually exists is that some mediators reduce and others increase the outcome variable: a suppressor effect [19]. In fact, we found that social support if indicated by positive social interactions reduces quality of life, whereas the other social support variables have no effect or a positive effect on quality of life. Consequently, there may be a suppressor effect in the models tested in the present study. In other studies in which the amount of received support is assessed, the relation between this indicator of support and quality of life is often not significant and sometimes even negative, indicating that higher amounts of support covary with lower levels of quality of life. This would seem to be caused by the fact that both level of social support and quality of life have a common cause: The stressor involved which may lead both to receiving support and to distress at the same time [31]. It is recommended to measure degree of satisfaction with received support to ensure that any differences in stressors, and thus in need for support, are taken into account [31]. Future research should concentrate on the exact relation. ships between active coping, social support and quality of life with social support operationalized as the degree of satisfaction with received support (e.g. loneliness).

Active coping does not seem to have an effect on negative social interactions. Negative interactions with others, however, may have significant implications for mental health [46]. In fact, negative elements of social interaction seem to be more strongly related to mental health outcomes than positive elements [47]. Consequently it would be useful to study ways to decrease negative aspects of social ties.

Our study indicates that active coping behavior in patients with rheumatic diseases encourages others to be supportive. Based on the results of a cross-sectional community study [12], it is argued that coping behavior provides interpersonal cues regarding what is wanted or needed in a stressful situation and that the members of the social environment respond accordingly. In fact, in a role-playing experiment [48] it was found that most support was received by cancer patients who show some distress by acknowledging their problems, and also try to cope with it. Obviously, for generating social support it is important to share distress and also show coping efforts. Moreover, in a simulation experiment with eight diseaserelated stigmas (AIDS, cancer, drug abuse, heart disease, anorexia, depression, obesity, and child abuse) [49], actively coping persons, as opposed to persons who did not try to solve their problems, were more likely to receive support. This may be explained by affective reactions to coping efforts; actively coping persons were 
blamed less, were attributed a higher chance for improvement, received more pity and less anger, and were experienced as being less stressful to others [49]. Emotions play an important motivational role in helping behavior [50], and consequently emotions evoked by the patients' active coping may explain why positive social interactions with the social environment increased and loneliness in these patients decreased.

The results were probably not due to a social desirability response set, as social desirability was measured for incorporation as a possible confounder in multiple regression analyses. Moreover, the supervisors as well as the participating patients were naive to the theoretical model under study.

Patients who decided not to enter the study after randomization but before pre-intervention were not included $(n=15)$. However, this dropout does not seem to be selective as there were no significant differences in patient characteristics with the 168 patients of the final study sample. Nevertheless, support for the theoretical model has been found in a selected group of rheumatic patients. Only part of all 2792 adult patients who visited the rheumatology outpatient clinic during a three-month period filled out a questionnaire and thus provided data for the selection of patients for the study. These patients may not be representative of all patients who visit their rheumatologist regularly. In addition, because of the criteria used for selection, and also because of the voluntary participation in a time-consuming trial, the final group of patients can be seen as a selected group of patients. Selection is also evident from the differences in age, education and gender between patients who agreed to participate and patients who were selected but did not want to take part. Moreover, dropout during the study ( $n=12$ at post-intervention and $n=4$ at follow-up) was selective. The results should be interpreted accordingly, meaning that generalizability of the results is restricted.

In summary, the results provide indications for a mediational role of loneliness on the relationship between action-directed coping and quality of life in adults with chronic rheumatic diseases affecting the joints, who have had these rheumatic diseases for more than one year, who have a limited social environment and functional health status and who are highly motivated to participate in a 10-session course and do the necessary homework.

The study design does justice to the longitudinal character of the mediational model tested. In future research, however, three measurements will be necessary after a coping intervention, to test the mediational model with actual, not estimated, scores on the mediator.

It seems worthwhile to test the theoretical model that active coping increases social support and consequently improves quality of life in other chronic patients too. Many of the problems faced by patients with other chronic diseases are similar to those in rheumatic patients. Moreover, there are indications that active coping may increase social support and quality of life in these patients too $[7,13,48,49,51]$. This makes the testing of the mediational model important for future interventions and, consequently, opens new perspectives for patient care.

\section{Acknowledgements}

The authors wish to thank the rheumatologists of Atrium Medical Center (Heerlen, The Netherlands) and Maasland Hospital (Sittard, The Netherlands), and the supervisors of the coping intervention and the mutual support groups. We also thank the patients who participated in this study for their valuable contributions. 


\section{References}

[1] Buckley L, Vacek P, Cooper S. Educational and psychosocial needs of patients with chronic disease. Arthritis Care Res 1990;3:5-10.

[2] Wolfe F, Hawley DJ, Wilson K. The prevalence and meaning of fatigue in rheumatic disease.

J Rheumatol 1996;23:1407-17.

[3] Verbrugge L, Patrick D. Seven chronic conditions: Their impact on US adults' activity levels and use of medical services. Am J Public Health 1995;85:17382.

[4] Burke M, Flaherty M. Coping strategies and health status of elderly arthritic women. J Adv Nurs 1993;18:7-13.

[5] Cornwell CJ, Schmitt MH. Perceived health status, self-esteem and body image in women with rheumatoid arthritis or systemic lupus erythematosus. Res Nurs Health 1990;13:99-107.

[6] Young L. Psychological factors in rheumatoid arthritis. J Consult Clin Psychol 1992;60:619-27.

[7] Friedland J, Renwick R, McColl M. Coping and social support as determinants of quality of life in HIV/AIDS. AIDS Care 1996;8:15-31.

[8] Murray TJ. The psychosocial aspects of multiple sclerosis. Neurol Clin 1995;13:197-223.

[9] Lazarus RS, Folkman S. Stress, appraisal, and coping. New York: Springer, 1984.
[10] McColl MA, Lei H, Skinner H. Structural relationships between social support and coping. Soc Sci Med 1995;41:395-407.

[11] Manne SL, Zautra AJ. Spouse criticism and support: Their association with coping and psychological adjustment among women with rheumatoid arthritis. J Pers Soc Psychol 1989;56:608-17.

[12] Dunkel-Schetter C, Folkman S, Lazarus RS. Correlates of social support receipt. J Pers Soc Psychol 1987;53:71-80.

[13] Ros WJG. Social support in cancer patients. Utrecht: Utrecht University, 1989.

[14] Savelkoul M, Post M, de Witte LP, van den Borne HW. Social support, coping and subjective well-being in patients with rheumatic diseases. Patient Educ Couns 2000;39:205-18.

[15] Smith CA, Wallston KA. Adaptation in patients with chronic rheumatoid arthritis: Application of a general model. Health Psychol 1992;11:151-162.

[16] Parker JDA, Endler NS. Coping with coping assessment: A critical review. Eur J Pers 1992;6:321-44.

[17] de Ridder DTD, Schreurs K. Coping en sociale steun van chronisch zieken [Coping and social support in people with chronic diseases]. Zoetermeer: Nationale Commissie Chronisch Zieken, 1994. 
[18] Baron RM, Kenny DA. The moderator-mediator variable distinction in social psychological research: Conceptual, strategic and statistical considerations. J Pers Soc Psychol 1986;51:1173-82.

[19] MacKinnon DP. Analysis of mediating variables in prevention and intervention research. NIDA Res Monogr 1994;139:127-153.

[20] World Health Organization Quality of Life assessment - group. Position paper from the World Health Organization. Soc Sci Med 1995;41:1403-9.

[21] Peplau LA. Loneliness research: Basic concepts and findings. In: Sarason IG, Sarason BR, editors. Social support: Theory, research, and applications. Boston: Marinus Nijhoff, 1985: 269-86.

[22] Sugisawa H, Liang J, Liu X. Social networks, social support and mortality among older people in Japan. J Gerontol 1994;49:S3-S13.

[23] Savelkoul M, de Witte LP. Development, content and process evaluation of a coping intervention for patients with rheumatic diseases. Patient Educ Couns 2001;45:163-72.

[24] Savelkoul M, de Witte LP, Candel MJJM, van der Tempel $\mathrm{H}$, van den Borne B. Effects of a coping intervention on patients with rheumatic diseases: Results of a randomized controlled trial. Arthritis Care Res 2001;45:69-76.
[25] Janssen M, Bal RM, Komproe I, Philipsen H, Furda J. Evaluatie van de 15-item versie van de Utrechtse Coping Lijst. [Evaluation of the 15-item version of the Utrecht Coping Questionnaire] Maastricht: Maastricht University, 1997.

[26] Schreurs PJG, Tellegen B, van de Willige G. Gezondheid, stress en coping: De ontwikkeling van de Utrechtse Copinglijst. [Health, stress and coping: The development of the Utrecht Coping Questionnaire] Tijdschr Psychol 1984;12:101-17.

[27] Schreurs PJG, van de Willige G, Tellegen B, Brosschot JF. De Utrechtse Coping Lijst: UCL-handleiding. [The Utrecht Coping Questionnaire: Manual] Lisse: Swets en Zeitlinger, 1988.

[28] van Sonderen E. Het meten van sociale steun met de Sociale Steun Lijst - Interacties (SSL-I) en de Sociale Steun Lijst - Discrepanties (SSL-D): Een handleiding [Measuring social support with the Social Support List - Interactions (SSL-I) and the Social Support List - Discrepancies (SSL-D): Manual]. Groningen: Noordelijk Centrum voor Gezondheidsvraagstukken, 1993.

[29] van Sonderen E. Measuring social support. Groningen: University of Groningen, 1991. 
6 Social support as a mediator between active coping and quality of life in patients with rheumatic diseases:

Results of a longitudinal study

[30] van Sonderen E, Ormel J. Het meten van aspecten van sociale steun en hun relatie met welbevinden: Een onderzoek naar de bruikbaarheid van de SSL-1 en de SSL-D [Measuring aspects of social support and their relation with well-being: A study into the feasibility of the Social Support List - Interactions (SSL-I) and the Social Support List -Discrepancies SSL-D]. Gedrag en Gezondheid 1997;25:190-200.

[31] van Sonderen E, Sanderman R. Social support. In: Vingerhoets AJJM, editor. Advances in behavioral medicine assessment. In press.

[32] de Jong-Gierveld J, Kamphuis F. The development of a Rasch-type Loneliness Scale. Appl Psych Meas 1985;9:289-99.

[33] Fugl-Meyer AR, Bränholm IB, Fugl-Meyer KS. Happiness and domain specific life satisfaction in adult Northern Swedes. Clin Rehabil 1991;5:25-33.

[34] Post MWM, van Dijk AJ, van Asbeck FWA, Schrijvers AJP. Life satisfaction of persons with spinal cord injury compared to a population group. Scand J Rehab Med 1998;30:23-30.

[35] Bränholm IB. On life satisfaction, occupational roles and activity preferences: Occupational therapy aspects. Umeá: University of Umeà, 1992.

[36] Bränholm IB, Erhardsson M. On life satisfaction and activity preferences in subjects with multiple sclerosis: A comparative study. Scand J Occup Ther $1994 ; 1: 17-23$
[37] Fugl-Meyer AR, Eklund M, Fugl-Meyer KS. Vocational rehabilitation in Northern Sweden III. Scand J Rehab Med 1991;23:83-7.

[38] Viitanen M, Fugl-Meyer KS, Bernspång B, FuglMeyer AR. Life satisfaction in long-term survivors after stroke. Scand J Rehab Med 1988;20:17-24.

[39] Post M. Living with spinal cord injury: A study of health status and life satisfaction of independently living people with a spinal cord injury. Utrecht: Utrecht University, 1997

[40] de Bruin AF, de Witte LP, Diederiks JPM. The sickness impact profile: SIP68, a short generic version. First evaluation of the reliability and reproducibility. J Clin Epidemiol 1994;47:863-71.

[41] de Bruin AF, Diederiks JPM, de Witte LP, Stevens FCJ, Philipsen $\mathrm{H}$. The development of a short generic version of the sickness impact profile. J Clin Epidemiol 1994;47:407-18.

[42] de Bruin AF, Diederiks JPM, de Witte LP, Stevens FC, Philipsen H. Assessing the responsiveness of a functional status measure: The Sickness Impact Profile versus the SIP68. J Clin Epidemiol 1997; 50:529-40.

[43] Visser AP, Breemhaar B, Kleijnen JGVM. Social desirability and program evaluation in health care. Impact Assessment Bulletin 1989;7:99-113.

[44] Crowne DP, Marlowe D. The approval motive: Studies in evaluative dependence. New York: Wiley, 1964. 
6 Social support as a mediator between active coping and quality of life in patients with rheumatic diseases: Results of a longitudinal study

[45] Sobel ME. Asymptotic confidence intervals for indirect effects in structural equation models. In: Leinhardt S, editor. Sociological Methodology. San Francisco: Jossey-Bass, 1982: 290-312.

[46] Hirsch B, Rapkin B. Social networks and adult social identities: Profiles and correlates of support and rejection. Am J Community Psychol 1986;14:395-412.

[47] Rook K. The negative side of social interaction: Impact on well-being. J Soc Psychol 1984;46:10971108.

[48] Silver RC, Wortman CB, Crofton C. The role of coping in support provision: The self-presentational dilemma of victims of life crises. In: Sarason BR, Sarason IG, Pierce GR, editors. Social support: An interactional view. New York: John Wiley, 1990: 397-426.

[49] Schwarzer R, Weiner B. Stigma controllability and coping as predictors of emotions and social support. Journal of Social and Personal Relationships 1991;8:133-140.

[50] Carlson M, Miller N. Explanation of the relation between negative mood and helping. Psychol Bull $1987 ; 102: 72-90$.

[51] Schwartz CE. Teaching coping skills enhances quality of life more than peer support: Results of a randomized trial with multiple sclerosis patients. Health Psychol 1999;18:211-20. 

Discussion 


\begin{abstract}
The study described in this thesis had a practical as well as a theoretical objective. First, it investigated the effects on coping, social support and quality of life of teaching people with rheumatic diseases to cope actively. Second and more theoretically, the study aimed to gain an insight into the relationship between coping and social support in influencing quality of life. As part of this theoretical objective, it tested the hypothesis that active coping increases social support which, in turn, improves quality of life of people with rheumatic diseases.

This last chapter of the thesis closes with the main findings, methodological considerations, recommendations for future research and practice implications.
\end{abstract}

\section{Main findings}

Two questions were to be answered: (1) What effects does stimulating active coping in people with rheumatic diseases have on coping, social support and quality of life? and (2) Is there support for a hypothesized sequence between active coping, social support, and quality of life?

Regarding the first research question, 14 controlled group-intervention studies aimed at stimulating active coping were systematically reviewed (chapter 2 ). Results showed that effects on quality of life (life satisfaction, functional health status) were measured in 13 studies, of which 6 found positive effects (all on functional health status); effects on social support were measured in 4 studies, of which 1 found positive effects; and effects on coping were measured in 3 studies, of which 1 found significant positive effects on active coping. No study found negative effects of an active coping intervention on coping, social support or quality of life. All studies included in the systematic review tested the effects of self-management interventions (some taught in an atmosphere of emotional support) and cognitive-behavioral therapy (aimed at improving the way of dealing with pain and stress). No intervention could be found that was described as being specifically aimed at teaching patients a general method to cope actively with problems they may encounter. Chapter 5 describes the evaluation of such a coping intervention, explicitly aimed at stimulating patients to use a method for systematic problem solving and seek social support in dealing with daily problems. Results showed that this intervention leads to increased action-directed coping and quality of life (functional health status in general and the mobility range in specific). These effects, however, did not persist up to six-months follow-up. In patients who attended at least half of the 10 sessions, the coping intervention also decreased loneliness at post-intervention and increased positive interactions with the social environment at the six-month follow-up. In these patients too, an additional improvement in quality of life indicated by a higher level of life satisfaction was found at the six-month follow-up. A process evaluation of the coping intervention revealed that the coping intervention was implemented according to plan and positively evaluated by the participating patients (chapter 4). In sum, it can be concluded that stimulating active coping in patients with rheumatic diseases may have positive effects on active coping, social support and quality of life. No negative effects of stimulating active coping have been found.

As far as the second research question is concerned ("Is there support for a hypothesized sequence between active coping, social support, and quality of life?"), a cross-sectional study in 628 adult outpatients showed that coping by awaiting / avoidance influences social support negatively which, in turn, decreases the patients' subjective well-being (chapter 3 ). The results indicated 
no direct support for the hypothesized sequence between active coping (i.e. action-directed coping and coping by seeking social support), social support and subjective well-being. As we found a significant correlation between coping by awaiting / avoidance and action-directed coping $(r=-13, p<.01)$, the results provide some indirect support for the hypothesis as far as action-directed coping is concerned. The nonsignificant correlation that we found between avoidant coping and coping by seeking social support, however, suggests that these are distinct constructs. Because causal inferences could not be made in this cross-sectional study, mediation by social support on the relationship between active coping and quality of life was tested using data from a longitudinal coping-intervention study (chapter 6 ). Results showed that action-directed coping increased social support, indicated by decreased loneliness, which, in turn, improved the patients' quality of life (indicated by improvements in life satisfaction as well as in functional health status). These results imply that active coping may increase social support which, in turn, improves quality of life of people with rheumatic diseases. However, the fact that estimations for the indicators of social support were used in the analyses, (i.e. the average of measurements at post-intervention and follow-up), has to be taken into account. Moreover, both the other variables that were used as indicators for social support besides loneliness (i.e. positive social interactions and negative social interactions) did not show any mediating effect on a relationship between active coping and quality of life. As far as positive social interactions are concerned, this variable indeed was positively influenced by active coping (action-directed coping as well as coping by seeking social support), but it decreased functional health status as an indicator of quality of life, in turn. An explanation may be the fact that both level of social support and quality of life have a common cause, i.e. the stressor involved; the occurrence of a stressor may lead both to receiving support and to distress at the same time [1]. Negative social interactions like criticism, reproach, or overprotection, were not influenced by active coping and, consequently, did not have a mediating effect on the relationship between active coping and quality of life. Moreover, none of the indicators of social support was a mediator for a positive relationship between coping by seeking social support and quality of life. The general conclusion regarding the second research question is that there are indications that action-directed coping decreases loneliness and that this effect mediates the positive relationship between action-directed coping and quality of life. The hypothesis, however, does not hold for coping by seeking social support as another indicator of active coping and for social interactions as operationalizations of social support.

On the whole, the study described in this thesis suggests not only that loneliness as an indicator of social support may increase the quality of life in people with rheumatic diseases, but also that the patients' own coping behavior (i.e. action-directed coping) may have a positive effect on this sequence. Besides, we found that it is possible to influence active coping behavior and thereby start the chain reaction with a coping intervention. Moreover, apart from the exact relationships between the concepts, people with rheumatic diseases seem to benefit from active coping in terms of improvements in support from their social environment and the quality of their lives. Our data also indicate that the participants' attendance as well as maintenance sessions are very important aspects of an intervention in order to obtain and sustain the positive effects. 


\section{Methodological considerations}

In investigating coping, social support and quality of life in people with rheumatic diseases, problems did arise with the measurement of the concepts (validity and reliability of the measurement instruments), missing values, sample size, and dropout. In addition, some more specific methodological considerations are relevant for the study described in this thesis.

\section{Measuring coping, social support and quality of life} For coping several classifications exist [2]. Attempts have been made in this thesis to classify coping strategies and behaviors in two basic dimensions: emotion-focused versus problem-focused and approach versus avoidance (figure 2 in chapter 3 ). Besides, as is the case with social support and quality of life, in coping different approaches to conceptualization and, consequently, measurement exist. One way of conceptualizing coping is as a personality trait; although coping is often not consistent across situations, it is suggested that persons tend to develop a personal style of adaptation to severe stress [3-5]. Trait measures are based on the assumption that people are cognitively, attitudinally, and behaviorally consistent across situations. Another approach to coping is situation-oriented [6]. In this approach coping is conceptualized in terms of the special demands of specific kinds of situations. Measurement focuses on how people actually cope in specific stressful encounters. Coping is seen as a shifting process in which a person must, at certain times, rely more on one form of coping (e.g. defensive strategies), and at other times on another form (e.g. problemsolving strategies), as the situation changes. The measures of coping that have evolved from treating coping as a situation-specific variable as well as from coping as a dispositional or trait variable are unsatisfactory [7-9]. The underlying assumption in the short version of the Utrecht
Coping Questionnaire which we used in our study is that coping can be seen as a general trait; the Utrecht Coping Questionnaire measures any given stressful situation as the target of coping and the time frame for the coping ratings is not specified in the questionnaire (coping is measured "in general"). The internal consistency of the subscale on palliative coping of the short version of this questionnaire was low. This is confirmed in other studies [7]. The results of these studies also indicate that women reported seeking social support more as a coping strategy and men indicated more action-directed coping, indicating construct validity of the questionnaire. Correlations with locus of control, autonomy at work and health as experienced by the respondent, however, were not significant or low for all subscales [7]. Psychometric weaknesses such as low internal consistencies, no test-retest data, and lack of information on construct validity in general coping instruments, often used for assessment of coping of chronically ill patients, have been raised by several researchers $[2,8]$. However, the subscales used for measuring coping in our study are reliable (palliative coping has been deleted from analyses). With regard to validity, there are indications that asking people how they generally cope with problems is unsuccessful in eliciting valid responses as a measure of how individuals actually cope with ongoing situations [9]. Assessments of actual coping activities across a variety of situations and an aggregation of these assessments are recommended [9]. For practical reasons, however, we had to rely on self-report assessments of retrospective coping. Besides, situation-specific questionnaires were only available for patients with specific rheumatic diseases (e.g. rheumatoid arthritis) and consequently were not useful in our study population.

From the literature it can be concluded that the concept "social support" has also led to a lot of confusion on both the theoretical and empirical level. Obviously, it is a vari- 
able about which no consensus exists $[10,11]$. Social support, as described in the literature, covers a range of related concepts [12], from social network, to supportive interactions [13], and the feeling of being supported [14]. Having a social network is necessary to experience social support [15]. Support is then received by means of supportive interactions between a network member and the person concerned, leading in turn to perceptions of being supported. Consequently, social network size is merely an indicator of the potential of support. To measure the actual exchange of support between social network members, it is operationalized in our study as the number of interactions between the respondent and his or her network members (social interactions) as well as the perceived adequacy of this support. The perceived adequacy of social interactions in our study is operationalized as the respondent's satisfaction with the supportive interactions (chapter 3 ) and the respondents' sense of loneliness (chapters 5 and 6). As loneliness is the unpleasant experience that occurs when a person's network of social relationships is deficient in some important way, either quantitatively or qualitatively [16], and can be seen as a cognitive assessment of the adequacy of one's social network and support [17], we considered it to be an adequate indicator of the respondent's feeling of being supported, i.e. social support.

As in case of social support, there is not one single definition of what should be considered as "quality of life". In the study described in this thesis, quality of life is operationalized with a health-related [18], as well as a more subjective indicator. The health-related quality of life is represented by functional health status (chapters 5 and 6). Subjective quality of life is indicated by the patients' evaluations of happiness in life and satisfaction with life [19] on two visual analog scales (chapter 3), and by measuring life satisfaction on a broader scale (satisfaction with life in general and with eight specific life domains; chapters 5 and 6). Social support in some studies is defined as part of the social aspect of quality of life $[20,21]$, which makes the distinction between these concepts very difficult. In fact, some items of the questionnaire we used to measure life satisfaction pertain to social relations. This means that quality of life measured in this way would not be conceptually distinct from social support. In our study, items measuring satisfaction with social relations were deleted from the analyses in order to obtain conceptually distinct variables (chapter 6).

\section{Missing values, sample size, and dropout}

Apart from being a consequence of conceptual problems, measuring social support and coping was also problematic because of many missing values on the scales we used. In the study described in chapter 3 , the original group of 1307 respondents was decreased to 628 , mainly because of many missing values on the questionnaires measuring coping and social support. Between 224 and 266 respondents did not fill out enough questions on the subscales of the short version of the Utrecht Coping Questionnaire and 480 respondents did not fill out enough questions on the Social Support List - Discrepancies.

Problems also arose in obtaining an adequate sample size for evaluating the coping intervention (chapter 5). Data were obtained from as large a sample as was practically feasible and financially possible. The power to detect effects in this study, however, was less than $60 \%$. This means that some effects of the coping intervention may not have been detected and the conclusions on the effects may not be totally exhaustive.

Because of the nature of chronic diseases, the willingness and possibilities for patients to participate in studies and complete all assessments can be limited. In these studies 
dropout tends to be high and, moreover, often causes selection bias. It can be assumed that selection bias in favor of motivated and willing patients with relatively good functioning takes place. This may especially be expected when testing an intervention consisting of several intensive sessions. In fact, in the randomized controlled trial described in the present thesis (chapter 5), patients who agreed to participate were significantly older and higher educated and the proportion of women was higher in this group too. All conclusions should be interpreted accordingly; they cannot be generalized to all people having rheumatic diseases. In addition, dropout during the randomized controlled trial of which data have been used for testing the subsequent relationship between coping, social support, and quality of life ( $n=16$; chapter 6 ) was selective, meaning that generalizability of the results is restricted. This obviously decreases the external validity of the study.

\section{Specific methodological considerations}

One of the more specific methodological weaknesses in our study is that outcome assessment was not blinded. Persons who constructed the datafiles and who were involved in choosing what analyses to perform and interpreting the results were aware of the hypotheses to be tested (chapters 3 and 6) or knew what data were related to what condition (chapter 5). Although there is no reason to assume that this has led to misrepresentations, it is impossible to prove that outcome assessment was ignorant. Also, follow-up measurements were lacking in frequency to form a base for solid conclusions in testing the subsequent relationship between coping, social support and quality of life. To test the subsequent relationship between the three concepts, three measurements after manipulating coping would have been necessary with enough time between the measurements for the vari- ables to change. In the study described in chapter 6 , scores on social support were estimated by taking the average of the measurements at post-intervention and follow-up. The assumption for taking this score was that it would be the best proximal estimation for the actual score halfway between post-intervention and follow-up. As social support in reality may have had another score at that point in time, the study design in this respect may decrease the internal validity, as is indicated in the first part of this chapter (main findings).

Patients with different diagnoses were incorporated in the study and this increases the external validity of the study results. At the same time the inclusion of patients with different diagnoses does not threaten the internal validity because the study population is homogeneous with respect to selected diagnoses (comparable in being chronic, unpredictable, and affecting the joints).

\section{Recommendations for future research}

- First and foremost, researchers should strive for agreement on the definitions and operationalizations of the concepts social support and quality of life to increase correspondence in measurements and consequently to provide an opportunity to combine study results. Until now, there is no agreement on what domains exactly comprise quality of life: psychological functioning, physical health status and social functioning [21], as well as happiness and satisfaction with life (this thesis). There also is no consensus on whether social support is an element of quality of life $[20,21]$ and what types of social support can be distinguished. Another important condition for combining study results is consensus on the operationalization of coping (situation specific or personality trait?) as well as on the classification of coping strategies and behaviors described in the literature (figure 2 in chapter 3 ). As far as coping is 
concerned, efforts should also be aimed at developing reliable and valid measurement instruments. Moreover, considering the condition of respondents in studies on chronic diseases, these instruments should be easy to apply.

- Health care providers should be involved in studies on coping, social support and quality of life in chronic patients. Their expert advice can be very useful in the conceptualization of the concepts (see also the first recommendation described above), in the development of interventions in chronic diseases (see also chapter 4 of this thesis), as well as in designing or choosing from available instruments to measure coping, social support and quality of life.

- In systematically reviewing the literature on coping interventions for people with rheumatic diseases (chapter 2), we found that although indications of quality of life were outcome variables in almost all selected studies, coping and social support as outcome variables were mostly neglected. Moreover, no study explicitly examined the subsequent relationship between coping, social support, and quality of life. Studies with one of the variables coping, social support, and quality of life as an outcome variable, should also focus, if possible, on the combined effects of coping and social support on quality of life. Besides, research questions in these studies should be based on the present state of knowledge on the relationship between the concepts, like the finding that the relation between amount of received support (i.e. social interactions) and quality of life is often not significant and sometimes even negative [1], and that different types of social support (daily emotional support, problem-oriented emotional support, social companionship) each may have a different influence on quality of life [21].

- To increase the diffusion of information that can ulti- mately be used for improving the quality of life in chronic patients, it is further recommended that results of studies on coping, social support and quality of life in chronic patients be exchanged also if the results are nonsignificant, "not interesting" or negative. In addition, information on studies that are relatively unknown should be made more accessible. The advice is not restricted to informing researchers; much attention should also be paid to formulating practice implications. As useful information may ultimately not be published, the dissemination of study results should be stimulated during congresses and other expert meetings.

- Most studies on coping, social support and quality of life in people with rheumatic diseases include patients with rheumatoid arthritis or osteoarthritis (chapter 2). It is important, however, to incorporate patients with other rheumatic diseases too. Moreover, the inclusion of people with other chronic diseases besides rheumatic diseases is recommended in studies on coping, social support and quality of life. Including patients with different chronic diseases can increase the generalizability of the results of studies, thus serving an important goal in improving the life circumstances of people facing similar problems.

- The systematic review described in chapter 2 shows that, in many cases, information for methodologically assessing the studies was not sufficient. This information, however, is important to evaluate the results of the studies. Therefore, it is recommended that all information necessary for methodological assessments (including the exact procedure used for randomization, whether outcome assessment has been blinded to group assignment, whether patients as well as providers of an intervention were blind to the expected outcomes, withdrawal from treatment, compliance, 
and co-interventions), is provided in future publications. Checklists for criteria important for methodological assessment of a study have been described in the literature (chapter 2) and can be used for this purpose.

To increase participation and decrease the number of missing values and dropouts in intervention studies, much attention must be paid to providing patients with information on the study procedure. This is best done by people the patients know, like their physicians or other health care providers (home care nurses), who can answer all questions they may have. In addition. the researchers should provide study participants with assistance in filling out questionnaires and stress anonymity in measurements. As part of the dropout is unavoidable in studies concerning people with chronic diseases, it is important to investigate and report whether and in what respect the dropout is selective.

In studies investigating the hypothesis that active coping increases social support, it is recommended to manipulate coping in an experimental design. This not only provides information on the impact of coping on social support, but it also may give indications on ways to influence coping (by changing cognitions, skills, or both). It is recommended to provide information in publications and other presentations on how coping is manipulated, and to check whether manipulations were done as intended.

\section{Practice implications}

- Difficulties like fatigue, pain, restrictions in daily functioning, and adjustment are common in people with rheumatic as well as other chronic diseases (e.g. AIDS, cancer, diabetes mellitus, multiple sclerosis) [22-24]. As the impact of stress caused by chronic diseases on well-being is influenced by social support and coping [6], these variables are also important in people with other chronic illnesses besides rheumatic diseases. Many interventions in health education have been developed with aim of increasing the well-being of people with rheumatic as well as other chronic diseases. The findings of many studies suggest that social support has a positive effect on well-being $[25,26]$. No social support strategies, however, are reported with coping as a key component for increasing social support (chapter 2 and [27]). Informed decision-making should increasingly dominate health education practice; as we found indications that active coping may actually decrease loneliness and consequently improve quality of life, coping behavior seems to be a key component in patients with chronic diseases who may become socially isolated and experience a decrease in the quality of their lives as has been suggested in other studies [19,28-33]. Families and other support providers are not resources from which the chronically ill person may draw social support on demand. The reciprocal and complex interactions in daily life generate supportive as well as nonsupportive interactions. It would be useful to influence in a relatively stable way the patient's coping, inasmuch as it is a variable apt to positively influence the behavior of the social environment and thereby increase the patient's well-being.

- One of the conclusions of systematically reviewing interventions aimed at stimulating active coping in people with rheumatic diseases, was that no intervention was described as being specifically aimed at teaching patients a general method to cope actively with problems they may encounter. The programs were mostly focused on teaching specific solutions to specific problems instead. Little attention was paid to problem-solving techniques and, moreover, this was done in only a few interventions. This is also indicated in a 
review of psychosocial theories and their application to patient education ("Unfortunately, most patient education programs teach specific solutions to problems rather than the problem-solving process itself") and compared with feeding the starving man a fish instead of teaching him how to fish [34]. Teaching problem-solving skills as a method of coping should be utilized more in chronic diseases. The problems of patients with chronic diseases can be predicted to change a number of times over the course of a lifetime. Consequently, skills in determining what the problems are and how to go about solving these might have more lasting impact than specific skills imparted in a discrete program. Besides, the study described in this thesis (chapter 5) adds to the evidence of possible positive effects of such an intervention on the patient. Moreover, in a study on their needs and expectations [35], people with rheumatic diseases stress the importance of being able to solve everyday problems.

- Because of the focus on behavior in teaching skills in problem solving and support seeking, it is recommended that such an intervention takes place in groups of patients (modeling). In addition, these groups should be supervised by a therapist experienced in behavioral therapy. An assistant who is experienced in the chronic disease(s) of the participating patients may be very useful as a cofacilitator (chapter 4 ).

- An important aspect in group interventions in problem solving and support seeking skills is the composition of the different groups of patients participating in the intervention [36,37]. First of all, the sizes of these groups should be about 10 patients. Smaller groups restrict mutual exchange of information and support and larger groups decrease the attention for every individual group member. Furthermore, groups of patients participating in a problem-solving and support-seeking intervention should be homogeneous in age so that patients can identify with each other. A project manager should be assigned for composing the groups, inviting the patients and for making logistic arrangements (location, et cetera).

- The selection of patients is another important aspect of organizing a group intervention aimed at teaching problem-solving and support-seeking skills (chapter 4). Selection should be restricted to patients with a disease duration of more than one year because the first year of having a chronic disease can be turbulent. In addition, it is recommended to select patients who experience a relatively high impact of the chronic disease on their daily functioning and have a relatively high feeling of social isolation. As these patients experience problems in daily life, they will probably gain most from problem-solving and support-seeking skills. Selection on disease duration, impact of the disease, and the patient's social situation, can be performed by the patients' physicians.

- In addition, it is important to select motivated patients for participation in a coping intervention as described in chapter 4. Although chances of new problems are high in every stage of a chronic disease, there is a possibility that patients at some time feel they have solved most of their problems and reached satisfying levels of social support. The coping intervention described in this thesis (chapter 4) allows these patients to participate in helping others to apply the steps in problem solving and consequently learn a systematic approach to solving problems that they can apply whenever they experience a problem personally because of new life circumstances. Nevertheless, there will always be patients who are not interested and consequently selection of motivated patients is recommended to decrease dropout. After a first selection by the patients' 
physicians based on disease duration and daily functioning, further information on the intervention should be provided by the intervention's supervisors. After explaining the aim, content, duration and structure of the intervention and after informing the patient on the time required for participation, supervisors can decide together with the patient if the patient's motivation is high enough for participation. Special attention should be paid to motivating unmotivated patients because exactly these patients may be socially isolated. People these patients know well, like their general practitioners, district nurses or acquaintances from patients' associations, can provide them with clear information on the positive consequences of participation in the coping intervention for them personally. Unmotivated patients may be happy without support, they may assume that their social environment is not willing to provide them with support, or they may be unhappy with their social situation and at the same time unaware of their possibilities in gaining social support. In patients who are happy without support, motivation can be increased by emphasizing that the intervention may be helpful in checking whether this is true for all kinds of support available and in learning how to defend against undesired social interactions. In patients who feel their social environment is not willing to provide them with support, motivation may be increased by explaining to them that the problem-solving and support-seeking skills can be used as a tool to check if their assumption is really true and as an instrument for finding new social contacts. The third group of unmotivated patients, patients who are unaware of their abilities in gaining support they would like to receive more, can be motivated by explaining to them that the coping intervention may help them in increasing their self-efficacy in seeking social support.
- Despite the positive effects of teaching a systematic way to solve problems and compliance with the needs of the patients, extensive process evaluations of such an intervention when implemented are recommended. Process evaluations will be necessary to foster the insight into the patients' perceptions of the intervention and provide suggestions for future implementation. Process evaluations can be performed by the supervisors of the intervention. They can evaluate the intervention during group discussions with participants after every meeting, halfway and at the end of the intervention. Another, more neutral possibility for process evaluation, besides this, are questionnaires filled out by the patients.

- For patient education to justify its place as a routine part of patient care, it requires proof of its cost-effectiveness. For the study described in this thesis it is difficult to quantify the financial balance; the costs of providing the coping intervention described in chapter 4 are easily quantifiable but the effects on the patients are not. Moreover, the effects will probably not all be cost-saving in the short term as patients are stimulated to seek support from health professionals too. In the long term, however, costs may be saved as patients gain more control over problems caused by their disease. In sum, the costs of providing a coping intervention as described in chapter 4 must be viewed as additional expenditure but when placed in the context of other medical expenses, even minor positive effects on the patient's well-being make it cost-effective. 


\section{References}

[1] van Sonderen E, Sanderman R. Social support. In: Vingerhoets AJJM, editor. Advances in behavioral medicine assessment. In press.

[2] Parker JDA, Endler NS. Coping with coping assessment: A critical review. Eur J Pers 1992;6:321-44.

[3] Vaillant GE. Health consequences of adaptation to life. Am J Med 1979;67:732-4.

[4] Schreurs PJG., Tellegen B, van de Willige G. Gezondheid, stress en coping: De ontwikkeling van de Utrechtse Copinglijst. [Health, stress and coping: The development of the Utrecht Coping Questionnaire] Tijdschr Psychol 1984;12:101-17.

[5] Schreurs PJG, van de Willige G, Tellegen B, Brosschot JF. De Utrechtse Coping Lijst: UCL-handleiding. [The Utrecht Coping Questionnaire: Manual] Lisse: Swets-Zeitlinger, 1988.

[6] Lazarus RS, Folkman S. Stress, appraisal, and coping. New York: Springer, 1984.

[7] Janssen M, Bal RM, Komproe I, Philipsen H, Furda J. Evaluatie van de 15-item versie van de Utrechtse Coping Lijst. [Evaluation of the 15-item version of the Utrecht Coping Questionnaire] Maastricht: Maastricht University, 1997.
[8] Stone AA, Kennedy-Moore E, Newman MG, Greenberg M, Neale JM. Conceptual and methodological issues in current coping assessments. In: Carpenter BN, editor. Personal coping: Theory, research, and application. Westport: Praeger / Greenwood, 1992: 15-29.

[9] Schwartz JE, Neale J, Marco C, Shiffman SS, Stone AA. Does trait coping exist? A momentary assessment approach to the evaluation of traits. J Pers Soc Psychol 1999;77:360-9.

[10] Thoits PA. Conceptual, methodological, and theoretical problems in studying social support as a buffer against life stress. J Health Soc Behav 1982;23:145-59.

[11] Sarason BR, Sarason IG, Pierce GR. Traditional views of social support and their impact on assessment. In: Sarason BR, Sarason IG, Pierce GR, editors. Social support: An interactional view. New York: John Wiley \& Sons, 1990: 9-25.

[12] Vaux A. Social support: Theory, research, and intervention. New York: Praeger, 1988.

[13] House JS. Work stress and social support. Reading: Addison-Wesley, 1981.

[14] Thoits PA. Social support and psychological well-being: Theoretical possibilities. In: Sarason IG, Sarason BR, editors. Social support: Theory, research and applications. Dordrecht: Martinus Nijhoff, 1984: 51-72. 
[15] van Sonderen E. Measurement of social network and social support: Empirical results in relation to the Euridiss instruments. International Journal of Health Sciences 1990;1:203-16.

[16] Peplau LA. Loneliness research: Basic concepts and findings. In: Sarason IG, Sarason BR, editors. Social support: Theory, research, and applications.

Boston: Martinus Nijhoff, 1985: 269-86.

[17] Sugisawa H, Liang J, Liu X. Social networks, social support and mortality among older people in Japan. J Gerontol 1994;49:S3-S13.

[18] World Health Organization Quality of Life assessment - group (WHOQOL). Position paper from the World Health Organization. Soc Sci Med 1995;41:1403-9.

[19] Cornelissen PGJ, Rasker JJ, Valkenburg HA. The arthritis sufferer and the community: A comparison of arthritis sufferers in rural and urban areas. Ann Rheum Dis 1988;47:150-6.

[20] Krol B, Sanderman R, Suurmeijer, TPBM. Social support, rheumatoid arthritis and quality of life: Concepts, measurement and research. Patient Educ Couns 1993;20:101-20.

[21] Doeglas DM. Functional ability, social support and quality of life: A longitudinal study in patients with early rheumatoid arthritis. Groningen: Rijksuniversiteit Groningen, 2000.
[22] Friedland J, Renwick R, McColl M. Coping and social support as determinants of quality of life in HIVIAIDS. AIDS Care 1996;8:15-31.

[23] Murray TJ. The psychosocial aspects of multiple sclerosis. Neurol Clin 1995;13:197-223.

[24] Verbrugge L, Patrick D. Seven chronic conditions: Their impact on US adults' activity levels and use of medical services. Am J Public Health 1995;85:173-82.

[25] Wallston BS, Alagna SW, DeVellis BM, DeVellis RF. Social support and health. Health Psychol 1983;2:367-91.

[26] Wortman CB, Conway TL. The role of social support in adaptation and recovery from physical illness. In: Cohen S, Syme LS, editors. Social support and health. Orlando: Academic Press, 1983.

[27] Froland C, Pancoast DL, Chapman JJ, Kimboko RJ. Helping networks and human services.

Beverly Hills: Sage, 1981.

[28] Anderson KO, Bradley LA, Young LD, McDaniel LK, Wise CM. Rheumatoid arthritis: Review of psychological factors related to etiology, effects, and treatment. Psychol Bull 1985;98:358-87.

[29] Liang MH, Rogers M, Larson M, Eaton HM, Murawski BJ, Taylor JE, Swafford J, Schur PH. The psychosocial impact of systemic lupus erythematosus and rheumatoid arthritis. Arthritis Rheum $1984 ; 27: 13-9$ 
[30] Fitzpatrick R, Newman S, Lamb R, Shipley M. Social relationships and psychological well-being in rheumatoid arthritis. Soc Sci Med 1988;27:399-403.

[31] Smith CA, Wallston KA. Adaptation in patients with chronic rheumatoid arthritis: Application of a general model. Health Psychol 1992;11:151-62.

[32] Kutner NG. Social ties, social support, and perceived health status among chronically disabled people. Soc Sci Med 1987;25:29-34.

[33] Jacobs JWG, van der Heide A, Rasker JJ, Bijlsma JWJ. Measurement of functional ability and health status in the arthritic patient. Patient Educ Couns 1993;20:121-32.

[34] Gonzalez VM, Goeppinger J, Lorig K. Four psychosocial theories and their application to patient education and clinical practice. Arthritis Care Res $1990 ; 3: 132-43$.

[35] Samuelsson A, Ahlmén M, Sullivan M. The rheumatic patient's early needs and expectations. Patient Educ Couns 1993;20:77-91.

[36] Savelkoul M. Sociale steun bij reuma: Probleem oplossen en sociale steun zoeken door mensen met reuma. Handleiding voor cursusleiders. [Social support in rheumatic diseases: Problem solving and seeking social support by patients with rheumatic diseases. Manual for course leaders]. Hoensbroek: Coördinatiecentrum Chronisch Zieken - Limburg. 2000
[37] Ritzen W, Souren P, Savelkoul M. Steun zoeken als eerste stap. [Seeking social support as a first step] Maatwerk 2001;3:4-9. 


\section{Summary}

Because of emotional, behavioral, and social consequences of rheumatic diseases, they may negatively influence the quality of the lives of those people who are affected. Until now, there is no cure for rheumatic diseases and in many patients treatment cannot prevent a decrease in quality of life. Consequently, it is important to find ways to improve the quality of life of people with rheumatic diseases. Although little is known about the exact relationships, in several studies indications have been found that social support may increase quality of life and that this social support, in turn, may be increased by active coping. This thesis reports on the impact of coping on social support and quality of life of patients with chronic rheumatic diseases affecting the joints. The core questions are whether stimulating active coping affects the rheumatic patient's coping behavior, social support, and quality of life and if the hypothesis that active coping increases social support which, in turn, improves quality of life, can be supported.
Chapter 1 provides a general introduction to this thesis. The importance of improving the rheumatic patient's quality of life is stressed and the relevance of social sup. port and coping in this respect are outlined. The first chapter more specifically consists of paragraphs on rheumatic diseases, the prevalence of rheumatic diseases, the impact of rheumatic diseases on quality of life, the concepts quality of life, social support and coping, the research questions and an outline of the study that is the subject of this thesis.

Chapter $\mathbf{2}$ addresses the state of affairs regarding active coping interventions for people with rheumatic diseases by providing a systematic review of controlled studies investigating the effects of these interventions. More specifically, the impact of active coping interventions on coping, social support and quality of life are reviewed as is the subsequent relationship between these concepts. Very few of the 14 selected studies included coping and social support as outcome measures. Effects on social support (improved contacts with relatives and friends) have been found in 1 of 4 studies investigating this variable. Coping has been measured in 3 studies with positive effects found on active coping in 1 study. Almost all studies, i.e. 13 studies, measured effects on quality of life and 6 studies found positive effects (all on functional health status). Whether active coping increases social support which, in turn, improves quality of life could not be determined from the selected studies. The reason for this is that only two trials measured all three concepts coping, social support and quality of life and none of these studies investigated the interrelationships between the variables. Based on the results it is recommended that trials on the effects of coping interventions should include the measurement of all three variables coping, social support and quality of life and also pay attention to testing a sequen- 
tial relationship between these variables. As information for methodological quality assessment was lacking for many trials, more information on methodology should be provided.

Chapter 3 presents the results of a cross-sectional study that was conducted among rheumatic outpatients. In this study three hypotheses describing the relationships between coping behavior, social support and quality of life were investigated using path analyses. The first hypothesis is that social support is a coping resource and coping as a consequence of support or criticism from the social environment has an impact on subjective well-being. The second hypothesis states that coping behavior influences social support received which, in turn, influences the patients' quality of life. In the third hypothesis coping and social support have a reciprocal relationship and both influence well-being. Results showed that the second hypothesis may be a useful framework for investigating coping behavior, social support and quality of life in patients with rheumatic diseases; the results of the study show that avoidant coping behavior decreases social support which, in turn, negatively influences the rheumatic patient's subjective well-being. The study also showed that this hypothesis cannot be confirmed for action-directed coping and seeking social support. It is stressed, however, that causal inferences are not possible because cross-sectional data are used. An experimental study in which coping is manipulated is recommended for testing the hypothesis for which indications have been found in this cross-sectional study.

Chapter 4 reports on the development of a coping intervention for people with rheumatic diseases by describing results of an expert meeting and a literature study, a draft version of the intervention and expert advice on this con- cept of a reference group, and finally a pilot test. Also, the resulting content of the coping intervention is outlined as well as the methods and results of a process evaluation of this intervention. The final intervention is aimed at teaching active coping (i.e. action-directed coping and coping by seeking social support) by providing participants with skills in systematic problem solving and in seeking social support. The supervisors of the coping intervention groups, as well as the participating patients took part in the process evaluation. Data were provided by the patients during group evaluations and by means of questionnaires; supervisors were asked specific questions during telephone interviews, group sessions and in the instruction book describing the protocol for the intervention. Results show that the content of the coping intervention is evaluated positively. Besides, enthusiastic and empathic supervisors and mutual support between participating patients were important aspects of the coping intervention. The process evaluation also showed that several patients were reluctant to apply the method in solving the problems through which the problem solving and support seeking skills were taught. This may have been caused by the fact that the intervention did not include problem orientation. The chapter is concluded with the following guidelines for implementation of the coping intervention: Problem orientation may be added as an introduction to the method of systematic problem solving comprising the present intervention and intake conversations with participants should be conducted to reduce drop-out during the intervention.

Chapter $\mathbf{5}$ presents a randomized controlled trial that was undertaken to provide insight in the effects on coping. social support (social interactions and loneliness) and quality of life (functional health status and life satisfaction) of the active coping intervention described in chap- 
ter 4 . The conclusion of the study in chapter 5 was that when people with rheumatic diseases were taught to cope actively, they showed an increase in action-directed coping as well as in functional health status and mobility in specific. No effects of the coping intervention could be found at six-months follow-up. Another finding was that attending at least half of all 10 sessions of the intervention in which active coping was taught, additionally leads to less loneliness right after the intervention and to an increase in life satisfaction and a decrease in negative social interactions at six-months follow-up. Based on the results of this study, the coping intervention is recommended as part of regular care but maintenance sessions should be added.

Chapter 6 addresses the mediating role of social support on the relationship between active coping and quality of life using data from the randomized controlled trial described in chapter 5 . The study was based upon the hypothesis that by stimulating people with rheumatic diseases to cope actively with their problems, such an intervention would lead to more support from the social environment and, consequently, to a higher quality of life in these patients. It is argued that investigating this hypothesis is important because it may lead to ways for increasing social support and quality of life by teaching active coping and at the same time gives information on the exact relationship between the concepts which is useful for other interventions in the future. The results showed that decreased loneliness serves as a mediator for a positive relationship between action-directed coping (as an indicator of active coping) and both life satisfaction and functional health status (representing quality of life). The hypothesis, however, does not hold for coping by seeking social support as another indicator of active coping. In addition, no significant effects have been found of active coping on quality of life via positive and negative social interactions, which were both used as indicators of social support.

Chapter 7 encompasses a general discussion of the whole study. First, it discusses the major findings in relation to the research questions leading to the general conclusion that stimulating active coping behavior (i.e. action-directed coping and coping by seeking social support) can have increasing effects on action-directed coping, social support and quality of life and decreased loneliness may act as a mediator on the relationship between action-directed coping and quality of life. Although results showed that it is possible to increase active coping during a group intervention, attendance of participants is indicated as an important aspect of such an intervention and maintenance sessions are recommended. The last chapter further elaborates on methodological problems in measuring coping, social support and quality of life, gaining and keeping an adequate sample size, and some more specific methodological considerations like outcome assessment, follow-up measurements and external validity. The chapter ends with recommendations for future research (e.g. agreement on definitions and operationalizations of coping, social support and quality of life) and practice implications (e.g. elaborate the coping intervention described in this thesis to patients with other chronic diseases). 


\section{Samenvatting}

Reumatische aandoeningen kunnen de kwaliteit van leven van patiēnten negatief beïnvloeden door emotionele, gedragsmatige en sociale gevolgen. Tot op heden kunnen reumatische aandoeningen niet genezen worden. Ook kan in veel gevallen de voorhanden zijnde behandeling niet voorkomen dat de kwaliteit van leven van de patiënt afneemt. Daarom is het van belang te zoeken naar manieren om de kwaliteit van leven van mensen met een reumatische aandoening te verbeteren. Hoewel er nog weinig bekend is over de exacte samenhang, zijn er aanwijzingen uit onderzoek dat sociale steun de kwaliteit van leven kan bevorderen en dat sociale steun kan worden verhoogd door actieve coping.

In dit proefschrift wordt de invloed van coping op sociale steun en de kwaliteit van leven van mensen met een chronische reumatische gewrichtsaandoening beschreven. De eerste onderzoeksvraag is of het bevorderen van actieve coping van in. vloed is op het copinggedrag, de ontvangen sociale steun en de kwaliteit van leven van mensen met reuma. De tweede vraag binnen het onderzoek is of er bewijs kan worden gevonden voor de hypothese dat actieve coping sociale steun bevordert en dat deze toename in steun vanuit de sociale omgeving de kwaliteit van leven verhoogt.
In hoofdstuk 1 staat een algemene inleiding. Het belang van het verhogen van de kwaliteit van leven bij reuma wordt benadrukt en de relevantie van sociale steun en coping hierbij wordt toegelicht. Achtereenvolgens wordt ingegaan op de meest voorkomende reumatische aandoeningen, de prevalentie van reumatische aandoeningen, de invloed op de kwaliteit van leven, de concepten kwaliteit van leven, sociale steun en coping, de onderzoeksvragen en de studie die onderwerp is van het proefschrift.

Hoofdstuk 2 is een systematische review die inzicht biedt in de stand van zaken met betrekking tot interventies die gericht zijn op bevordering van actieve coping bij mensen met reuma. In dit hoofdstuk staat een systematische screening van gecontroleerde studies naar effecten van deze coping-interventies centraal. Aandachtspunten hierbij zijn de invloed van de interventies op coping, sociale steun en kwaliteit van leven en de achtereenvolgende relatie tussen deze variabelen. In slechts enkele van de 14 geselecteerde trials zijn coping en sociale steun onderdeel van de variabelen die gemeten zijn. Effecten op sociale steun (verbeterde contacten met vrienden en familie) zijn gevonden in 1 van de 4 onderzoeken waarin deze variabele een uitkomstmaat is. Coping is gemeten in 3 studies waarbij in 1 van deze een positief effect op actieve coping is geconstateerd. Kwaliteit van leven wordt gemeten in bijna alle (13 van de 14) geselecteerde onderzoeken en in 6 van deze worden positieve effecten op kwaliteit van leven gevonden. Deze effecten betreffen allemaal een toename in de functionele gezondheidstoestand. Of actieve coping sociale steun bevordert en dientengevolge de kwaliteit van leven verhoogt, kan niet worden vastgesteld op basis van de systematische review. De reden hiervoor is dat slechts in twee trials zowel coping, sociale steun als kwaliteit van leven gemeten zijn en in 
geen van beide de aandacht uitgaat naar de onderlinge relatie tussen deze variabelen. Aanbevolen wordt om in toekomstige trials die gericht zijn op het meten van effecten van coping-interventies, zowel coping, sociale steun als kwaliteit van leven te meten en de analyses vervolgens te richten op het testen van een mogelijke causale keten tussen deze variabelen. Ook wordt het belang van het geven van volledige methodologische informatie over de trials benadrukt, omdat door de systematische review duidelijk werd dat deze informatie vaak ontbreekt.

In hoofdstuk 3 wordt een cross-sectioneel onderzoek bij patiënten die poliklinisch in behandeling zijn bij een reumatoloog beschreven. Met behulp van padanalyses zijn drie hypothesen over de relatie tussen coping, sociale steun en kwaliteit van leven getoetst. In de eerste hypothese is sociale steun van invloed op coping waarbij coping vervolgens de kwaliteit van leven beïnvloedt. De tweede hypothese stelt dat coping sociale steun beïnvloedt en dat sociale steun vervolgens een effect heeft op de kwaliteit van leven. In de derde hypothese beïnvloeden coping en sociale steun elkaar wederzijds en oefenen beide variabelen invloed uit op de kwaliteit van leven. De resultaten ondersteunen de tweede hypothese als raamwerk voor onderzoek naar de relatie tussen coping, sociale steun en kwaliteit van leven; ze tonen dat vermijden als copinggedrag sociale steun vermindert en dat deze afname in steun vervolgens tot een lager subjectief welbevinden bij de patiënten leidt. Voor de actieve copinggedragingen "probleem oplossen" en "sociale steun zoeken" kan de tweede hypothese evenwel niet bevestigd worden. Benadrukt wordt dat causaliteit binnen deze cross-sectionele studie niet kan worden aangetoond. Om de hypothese waarvoor aanwijzingen zijn gevonden op basis van de cross-sectionele data verder te toetsen, wordt een experimenteel onderzoek aanbevolen waarin coping wordt beïnvloed.

In hoofdstuk 4 wordt de ontwikkeling van een coping-interventie voor mensen met reuma beschreven. Achtereenvolgens komen de resultaten van een workshop en een literatuurstudie, een concept-versie van de interventie met commentaar hierop van een referentiegroep en een pretest van de interventie aan de orde. De inhoud van de resulterende groepsinterventie wordt vervolgens uiteengezet alsmede de methode en de resultaten van een proces-evaluatie van deze interventie. De interventie is gericht op het aanleren van actieve coping (probleem oplossen en sociale steun zoeken), door deelnemers vaardigheden in systematisch probleem oplossen en sociale steun zoeken te leren. Aan de proces-evaluatie namen zowel begeleiders van de interventie als patiënten die de interventie volgden deel. Gegevens van deelnemende patiënten werden verzameld met behulp van groepsinterviews en vragenlijsten. Vragen aan de begeleiders werden gesteld tijdens telefonische interviews, groepsbijeenkomsten en in de handleiding waarin het protocol voor de interventie stond. Uit de resultaten blijkt dat de inhoud van de interventie positief wordt beoordeeld. Belangrijke aspecten van de coping-interventie blijken de begeleiders (enthousiasme en empathie) en het lotgenotencontact te zijn. Verder komt naar voren dat sommige patiënten weerstand hebben tegen het toepassen van de methode voor probleem oplossen aan de hand waarvan de vaardigheden in systematisch probleem oplossen en sociale steun zoeken geleerd worden. Dit kan een gevolg zijn van het ontbreken van probleemoriëntatie als eerste onderdeel van de interventie. Het hoofdstuk wordt afgesloten met de volgende richtlijnen voor implementatie: probleemoriëntatie toevoegen aan de interventie als inleiding op de methode voor het sys- 
tematisch oplossen van problemen en intake gesprekken voeren met deelnemers om uitval gedurende de interventie zoveel mogelijk te beperken.

Hoofdstuk $\mathbf{5}$ gaat over een gerandomiseerde trial die is uitgevoerd om de effecten van de coping-interventie (zoals beschreven in hoofdstuk 4) op coping, sociale steun (sociale interacties en eenzaamheid) en kwaliteit van leven (functionele gezondheidstoestand en tevredenheid met het leven) te meten. De conclusie luidt dat als mensen met reuma een actieve manier van coping leren, zij meer probleem oplossen als actief copinggedrag vertonen en dat hun functionele gezondheidstoestand in het algemeen en hun mobiliteit in het bijzonder toenemen. Een half jaar na afloop van de interventie werden geen effecten meer gevonden. Bij patiënten die aan minstens de helft van de 10 interventiebijeenkomsten deelnamen, was naast de eerder genoemde effecten tevens eenzaamheid direct na afloop van de interventie gedaald. Ook werd bij deze mensen een half jaar later meer tevredenheid met het leven en een afname in negatieve sociale interacties geconstateerd. Gebaseerd op deze resultaten wordt de coping-interventie aanbevolen als regulier onderdeel van de zorg voor mensen met reuma waarbij herhalingsbijeenkomsten aan de interventie dienen te worden toegevoegd.

Hoofdstuk 6 gaat over de mediërende rol van sociale steun in de relatie tussen actieve coping en kwaliteit van leven. Voor de in dit hoofdstuk beschreven studie zijn de onderzoeksgegevens van de in hoofdstuk 5 beschreven gerandomiseerde trial gebruikt. De studie in hoofdstuk 6 is gebaseerd op de hypothese dat bevordering van actieve coping bij mensen met reuma leidt tot meer steun uit de sociale omgeving, hetgeen een toename in de kwaliteit van leven veroorzaakt. Het testen van de hypothese is van belang omdat dit kan leiden tot manieren om sociale steun en kwaliteit van leven te verhogen door het aanleren van actieve coping en omdat het tegelijkertijd duidelijkheid geeft over de exacte relatie tussen de concepten, hetgeen nuttig is voor toekomstige interventies. Uit de resultaten blijkt dat een afname in eenzaamheid (als indicator van sociale steun) kan optreden als bemiddelende factor ("mediator") in een positieve relatie tussen probleem oplossen als vorm van actieve coping en kwaliteit van leven (functionele gezondheidstoestand en tevredenheid met het leven). De hypothese geldt echter niet voor sociale steun zoeken als andere vorm van actieve coping. Verder blijkt uit de resultaten dat er geen significante effecten van actieve coping op kwaliteit van leven zijn via negatieve en positieve sociale interacties die beide als indicatoren van sociale steun in de studie waren opgenomen.

In de algemene discussie in hoofdstuk 7 worden de belangrijkste bevindingen gerelateerd aan de onderzoeksvragen. Dit leidt tot de conclusie dat stimulering van actieve coping, meer specifiek van probleem oplossen en sociale steun zoeken, bij mensen met reuma kan leiden tot een toename van probleem oplossen als copinggedrag, meer sociale steun en een hogere kwaliteit van leven en dat er aanwijzingen zijn dat een afname in eenzaamheid een mediërende rol speelt in een positieve relatie tussen actieve coping en kwaliteit van leven. Verder wordt benadrukt dat hoewel is gebleken dat actieve coping kan worden bevorderd door middel van een groepsinterventie, voldoende aanwezigheid van de deelnemers een belangrijk aspect van deze interventie is en dat de toevoeging van herhalingsbijeenkomsten wordt aanbevolen. Vervolgens komen aan de orde: methodologische problemen bij het meten van coping, sociale steun en kwaliteit van leven, de moeilijkheid om een steekproef 
van adequate omvang te verkrijgen en behouden en enkele meer specifieke methodologische overwegingen (vaststellen van de resultaten, follow-up metingen en externe validiteit). Het hoofdstuk wordt afgesloten met aanbevelingen voor toekomstig onderzoek (onder andere de noodzaak om te komen tot eenduidige definiëring en operationalisering van coping, sociale steun en kwaliteit van leven) en voor de praktijk (zoals het voorstel om de copinginterventie zoals in dit proefschrift beschreven, uit te breiden naar mensen met andere chronische aandoeningen). 


\section{About the author}

May 12, 1967

1979-1986

1986-1993

1994

1995-2001

2001 -
Date of birth

High school

Health Sciences, Maastricht University, The Netherlands

- Health Education

- Health Policy and Administration

Research consultant in a community project

at the municipality of Maastricht, The Netherlands

PhD student, Department of Health Education and Promotion,

Maastricht University, The Netherlands

Research and development consultant at the Section of Care,

Netherlands Institute for Care and Welfare (NIZW),

Utrecht, The Netherlands 

苂: 